University of Redlands

\title{
Implementing Web GIS for Monitoring Carbon Sequestration in Sustainable Agroforestry Projects
}

\author{
A Major Individual Project submitted in partial satisfaction of the requirements \\ for the degree of Master of Science in Geographic Information Systems \\ by \\ Johnson Kosgei \\ Maxwell Baber, Ph.D., Committee Chair \\ Mark Stewart, MS.
}

August 2009 
Implementing Web GIS for Monitoring Carbon Sequestration in Sustainable Agroforestry Projects

Copyright (C) 2009

by

Johnson Kosgei 
The report of Johnson Kosgei is approved.

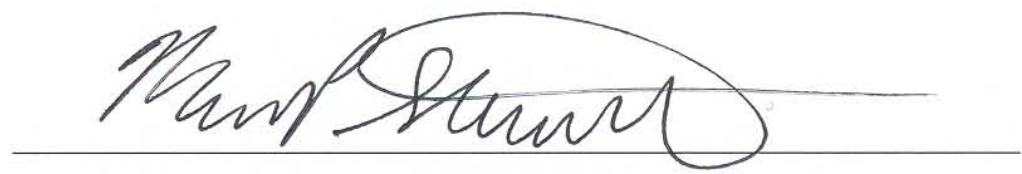

Mark Stewart, M.S.

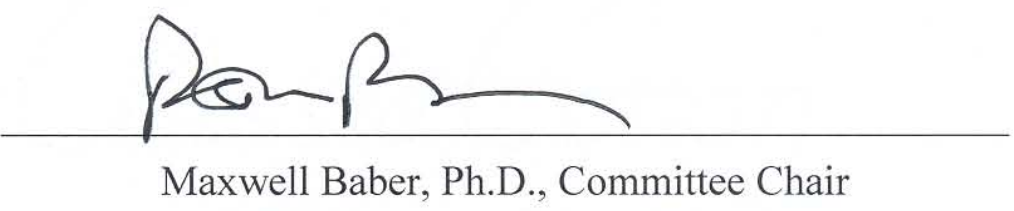

August 2009 



\section{Acknowledgements}

This project could not have been without the support of many individuals whose invaluable support I would like to acknowledge. Completing this project has been an experience of knowing that a person is made of people. Thank you Max Baber for providing the guidance to tackle my project with the same confidence you have always had in me. Thank you for your continuous encouragement and for your recognition of my potential in situations when I thought I had none. I also want to express my thanks to you Mark Stewart for your time and the interest you took in my project. By allowing me to tap into your immense experience and skills, I have overcome challenges that I did not think I could.

I take this opportunity to acknowledge the gratitude of Mrs. June Morison and the Morrison Family Foundation for having awarded me a fellowship that saw me through the MS GIS Program. Getting this opportunity was a dream come true. May God continue to bless and reward you abundantly. It is also with deep gratitude that I appreciate the continued support from my Cohort 14 colleagues, the MS GIS faculty, and staff. Your encouragement and confidence in me always gave me the desire to move in the right direction. I thank my parents and family for their love and support I always received from them despite distance and space between us. Talking to you was a great source of inspiration and a constant reminder to persevere in pursuit of excellence.

Above all, I thank God for His everlasting love, care, and protection through this program and throughout my life. It is by His grace that I am here writing this paper, having completed a Masters' project at the University of Redlands. 



\begin{abstract}
Implementing Web GIS for Monitoring Carbon Sequestration in Sustainable Agroforestry Practices

by

Johnson Kosgei
\end{abstract}

This project implemented an internet-based GIS to support effective monitoring and evaluation of agroforestry systems on carbon sequestration on small scale farms in East Africa. Small scale agriculture is one of the main economic activities practiced by farmers in East Africa. The demand for more farm produce out of the diminishing land exerts pressure on existing farms, resulting in land degradation and consequently environmental degeneration in the region. Striking a balance between conservation goals and agricultural needs is not easy. There is a need to utilize technological advancements like GIS to establish appropriate farming practices that ensure improved and sustained farm productivity, as well as to conserve the environment. Quantifying and monitoring sequestered carbon not only provides revenue through certified carbon credits, but also a means of evaluating the impact of agroforestry methods on the environment. This project was undertaken to support the Vi Agroforestry Programme's implementation of agroforestry projects, and to assess the amount of carbon sequestered. An internet-based GIS system was designed to share spatial data and information to project stakeholders and other audiences. The system primarily supports decision making in adopting sustained farming practices, and provides a reliable means of keeping track of agroforestry techniques and quantifying the amount of sequestered carbon at each project. 



\section{Table of Contents}

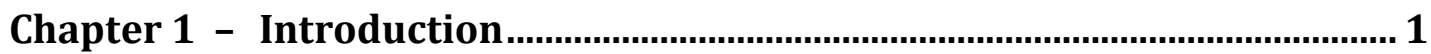

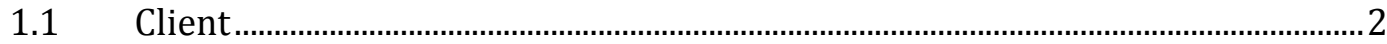

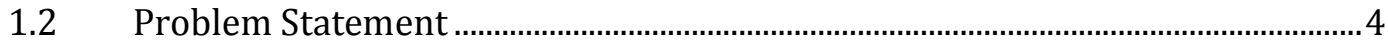

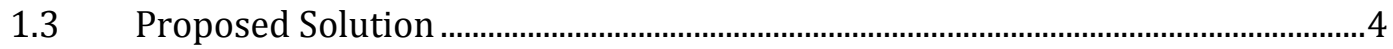

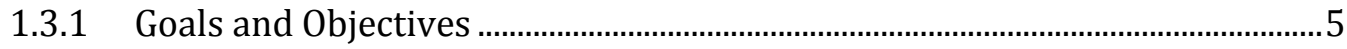

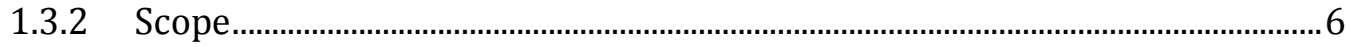

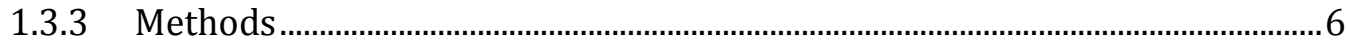

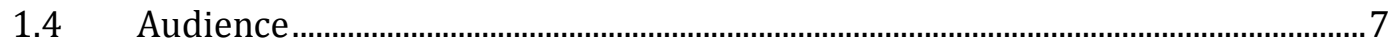

1.5 Overview of the rest of this report..............................................................................

Chapter 2 - Background and Literature Review …….................................. 9

$2.1 \quad$ Carbon sequestration in agroforestry....................................................................9

2.2 Role of GIS in sustainable management of natural resources.............................10

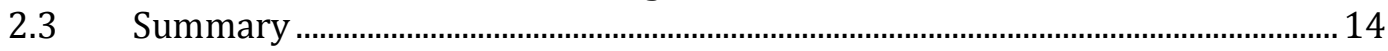

Chapter 3 - Systems Analysis and Design ...................................................15

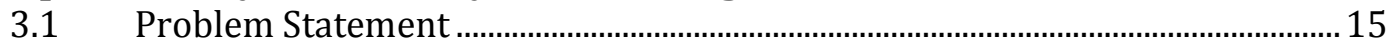

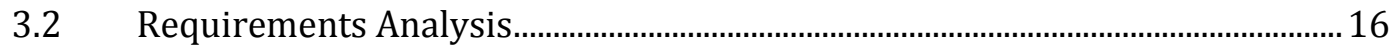

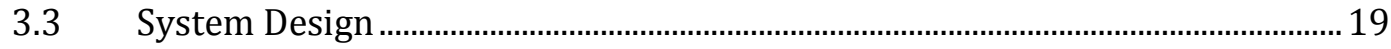

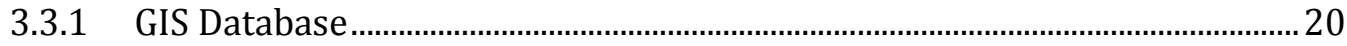

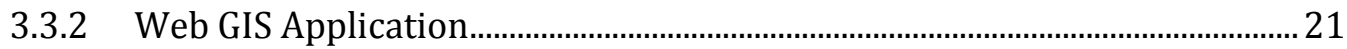

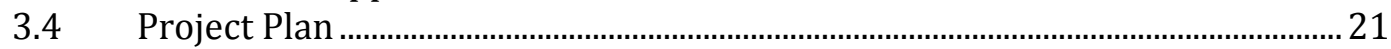

3.4.1 Database Design Phase............................................................................................ 22

3.4.2 Prototype Database Implementation Phase...……………………………………...22

3.4.3 Web GIS Application Development Phase................................................................23

3.4.4 Project Implementation Approach and Schedule ...............................................23

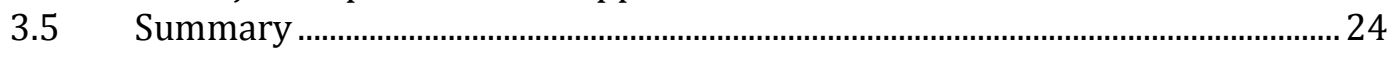

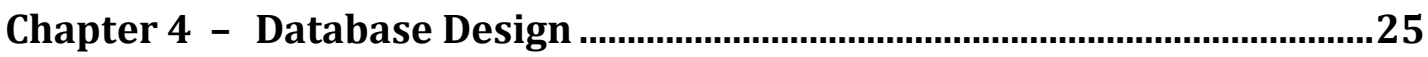

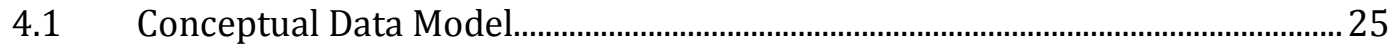

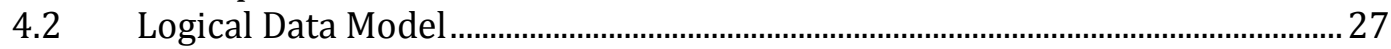

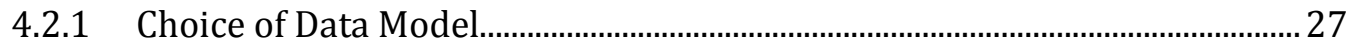

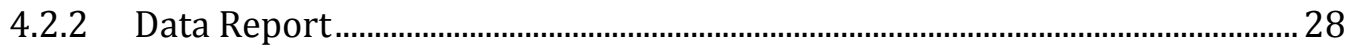

4.2.3 Data Characteristics ..................................................................................................29

4.3 Elements of a Logical Data Model ...........................................................................30

4.3.1 Agro-Ecological Zones................................................................................................33

4.3.2 Project Sites and Sampling Reference Points .......................................................... 34

4.3.3 Permanent Sampling Plots ………………………………………………………....... 35

4.3.4 Households.................................................................................................................. 36

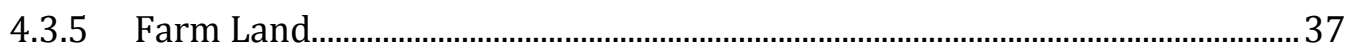

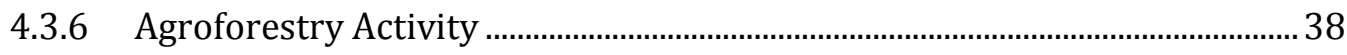

4.3.7 Crop Production and On-Farm Trees....................................................................4 40

4.3.8 Farm Head and Financial Condition ......................................................................... 41

4.3.9 Living Conditions................................................................................................. 43

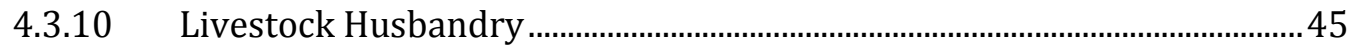

4.3.11 Administrative Boundaries........................................................................... 46

4.3.12 Administrative and Market Places ...................................................................4

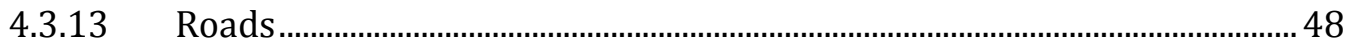




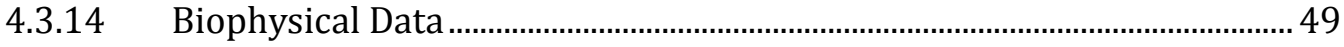

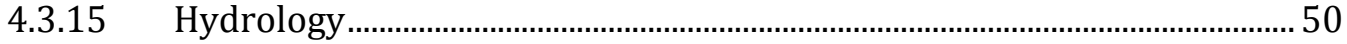

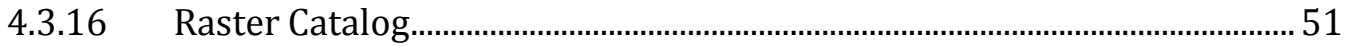

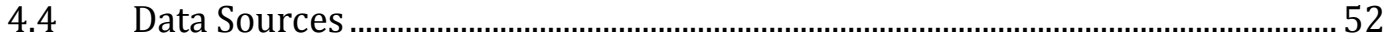

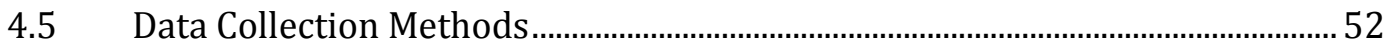

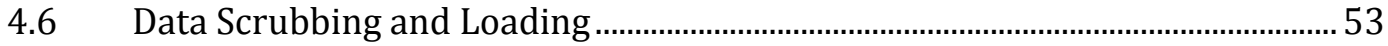

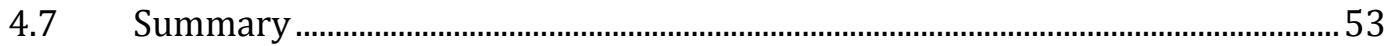

Chapter 5 - Database Implementation ........................................................... 55

$5.1 \quad$ Requirements Analysis..................................................................................... 55

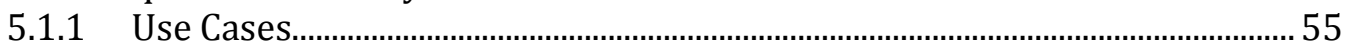

5.1.2 Information Product Descriptions (IPD's) ..........................................................56

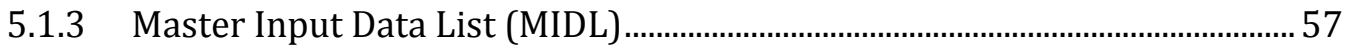

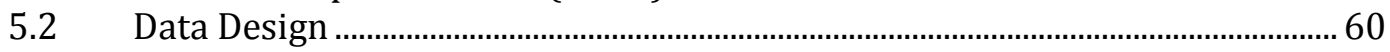

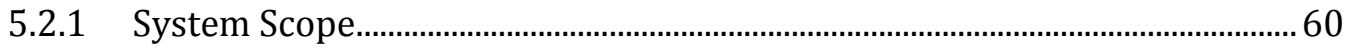

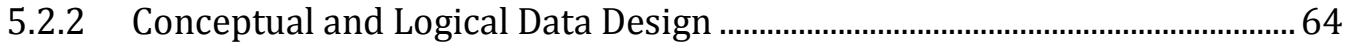

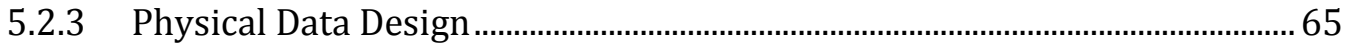

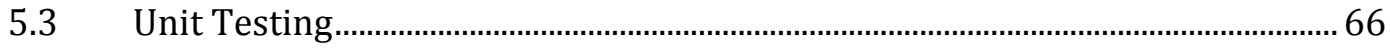

Chapter 6 - Web Mapping Application Implementation ............................68

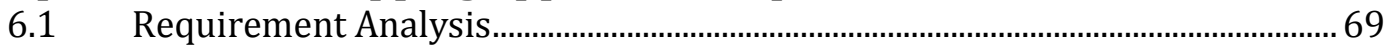

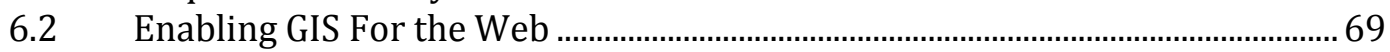

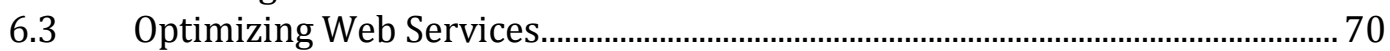

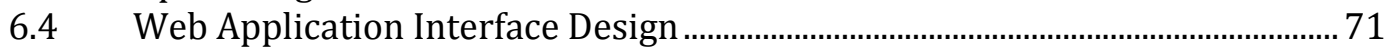

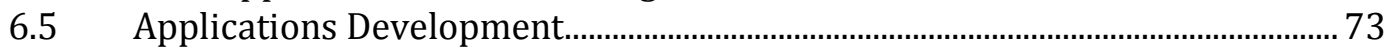

6.6 Web Application Test and Deployment............................................................... 75

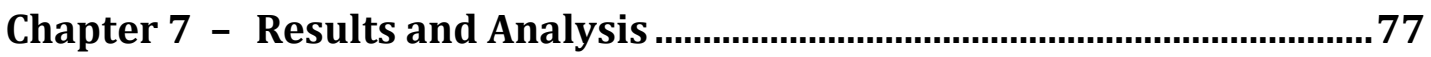

7.1 Carbon Sequestration Monitoring Database ……………........................................ 77

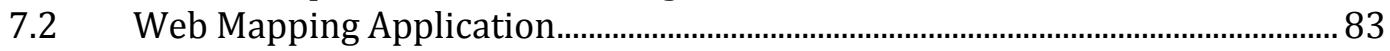

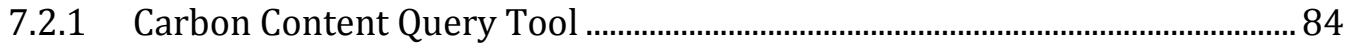

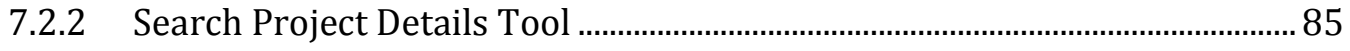

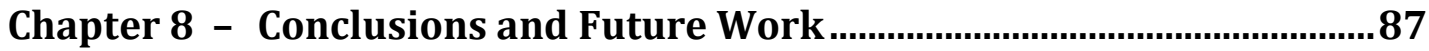

8.1 Future Work on the Database ................................................................................ 88

8.2 Future Work on the Web Mapping Applications .................................................... 88

8.3 Effective Monitoring of Carbon Sequestration Projects ........................................ 89

Works Cited............................................................................................................. 91

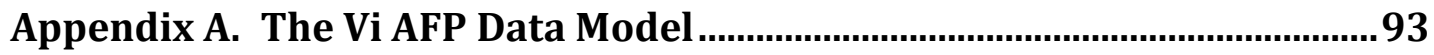

Appendix B. GIS User Needs Analysis Questionnaire .................................94

Appendix C. Project Use Cases ............................................................................ 98

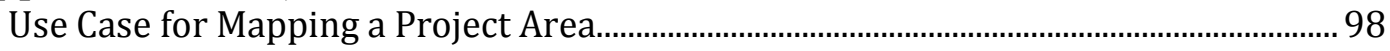

Use Case for Carrying Out a Baseline Biomass Assessment ............................................. 99

Use Case for Monitoring Carbon at a Project Site ........................................................... 100

Use Case for Writing Donor Reports of Project Status..................................................... 101

Appendix D. Information Products Descriptions ...................................... 102

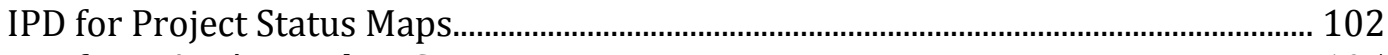

IPD for VIAFP's Baseline Survey Preparation Maps.............................................................. 105 
Appendix E. Web Mapping Application Programming Code ...................... 108

Appendix F. Web Mapping Application Help Page........................................ 122 


\section{Table of Figures}

Figure 1.1: Vi Agroforestry Programme project areas in Kenya ............................... 3

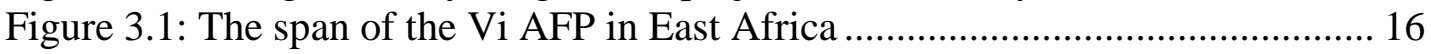

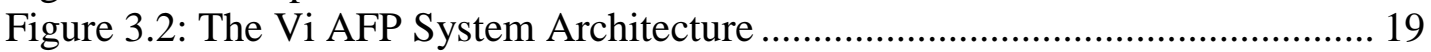

Figure 3.3: A workflow diagram of project implementation .................................. 22

Figure 4.1 Domain UML Model of Agroforestry Activities................................... 26

Figure 4.2: Geodatabase Structure of the Vi AFP .................................................. 31

Figure 4.3: A section or the Vi AFP data model showing logical relationships ....... 32

Figure 4.4: An instance diagram of AgroecologicalZones feature class................... 33

Figure 4.5: Instance diagrams of the relationship between project sites and sampling

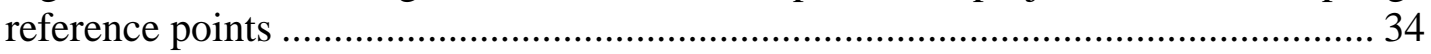

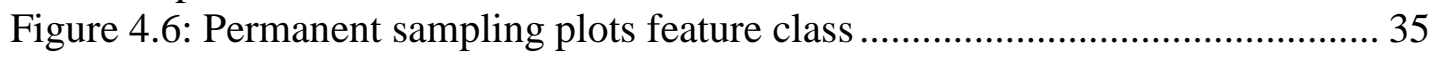

Figure 4.7: Household feature class and its domain tables ................................... 36

Figure 4.8: FarmLand class and related features ................................................. 38

Figure 4.9: AgroforestryActivity table, domains, and it's relation to farm land ........ 39

Figure 4.10: Crop production and on-farm trees database tables and their relation to

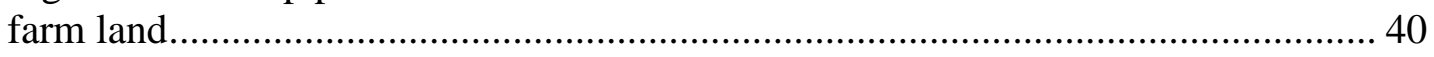

Figure 4.11: Domains of crops, tree species, and production season........................ 41

Figure 4.12: Instance of FarmHead data base table and its relationships with

Households and FinancialCondition tables ....................................................... 42

Figure 4.13: Domain tables associated to FarmHead and FinancialCondition

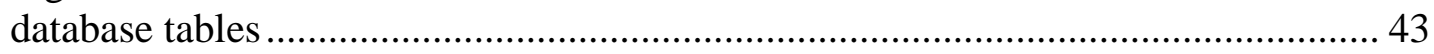

Figure 4.14: Instance of LivingConditions table and its relationship with the

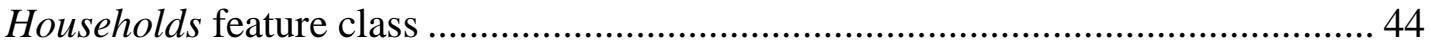

Figure 4.15: Domains associated with LivingConditions database table ................. 45

Figure 4.16: LivestockHusbandry table and related class and domains .................... 46

Figure 4.17: Feature classes of administrative boundaries................................... 47

Figure 4.18: Administrative and market places..................................................... 48

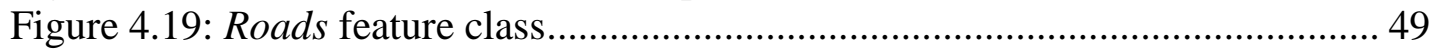

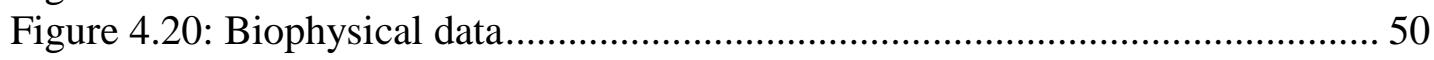

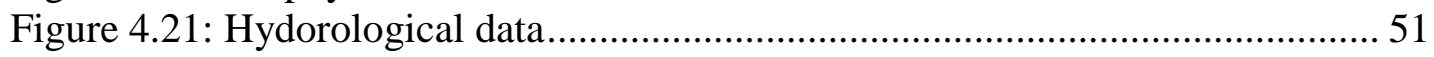

Figure 5.1: Building the Vi AFP Database. Adapted from "Designing

Geodatabases,” by D. Arctur \& M. Zeiler, 2004, p. 377. Copyright 2004 by ESRI

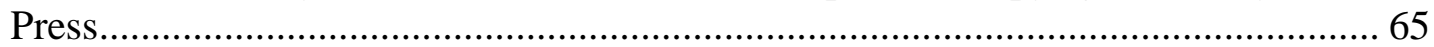

Figure 5.2: Testing geodatabase elements for draw and fetch times........................ 67

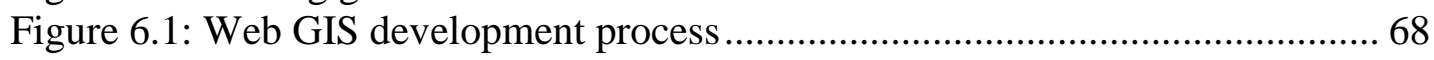

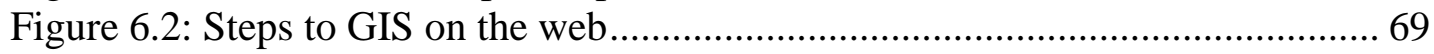

Figure 6.3: Optimizing web services in ArcMap ................................................ 71

Figure 6.4: Layout comparison of Vi AFP's main web page and the designed web

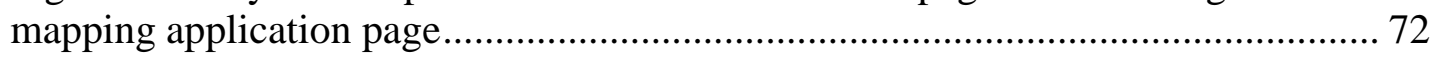

Figure 6.5: The Vi AFP web mapping application page ....................................... 72

Figure 6.6: The Vi AFP web application map services........................................ 73

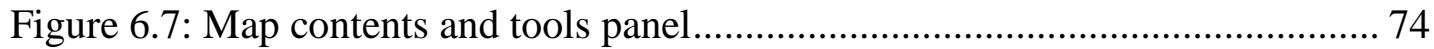

Figure 6.8: Application test statistics of the Vi AFP web mapping application ....... 75 
Figure 7.1: Monitoring framework supported by the designed database.................. 78

Figure 7.2: Standard project region map............................................................ 79

Figure 7.3: Potential sustainable land management (SLM) map of project sites ......80

Figure 7.4: Reference sample points used for project monitoring ...........................81

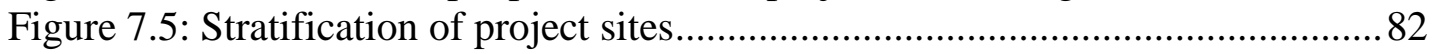

Figure 7.6: Potential SLM adoption map of stratified project sites .......................... 83

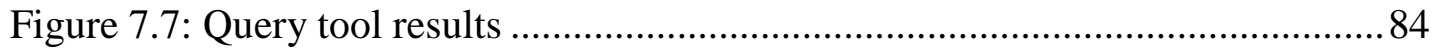

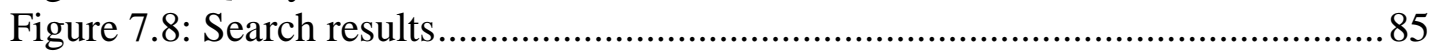





\section{List of Tables}

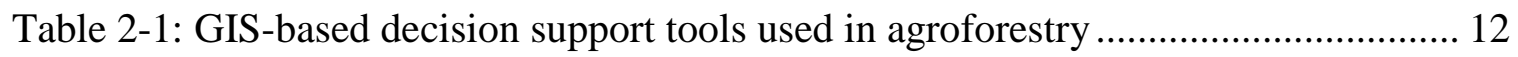

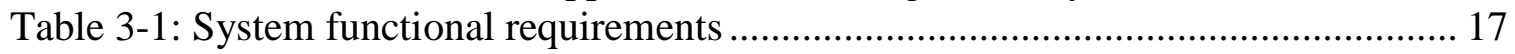

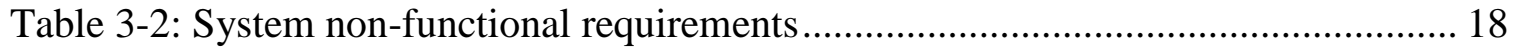

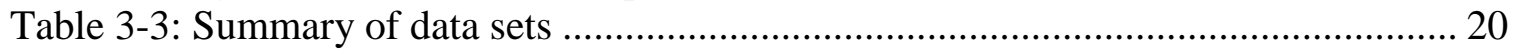

Table 3-4: Projected time allocation versus actual time spent....................................... 24

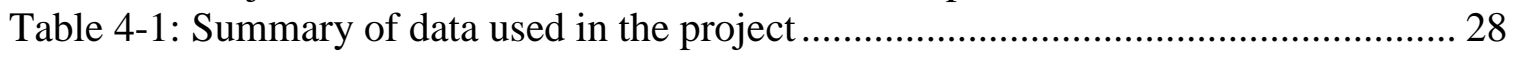

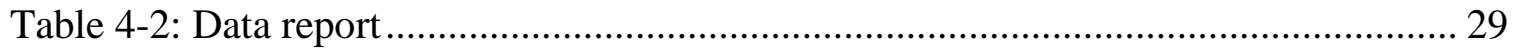

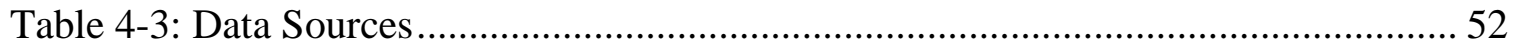

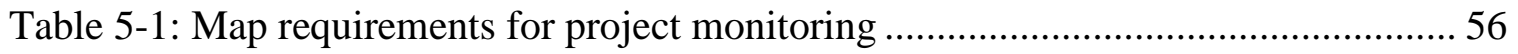

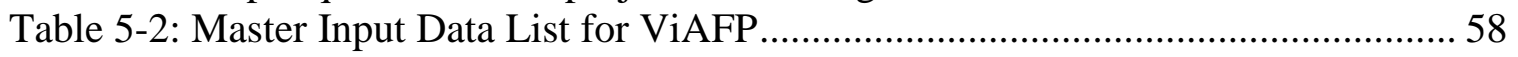

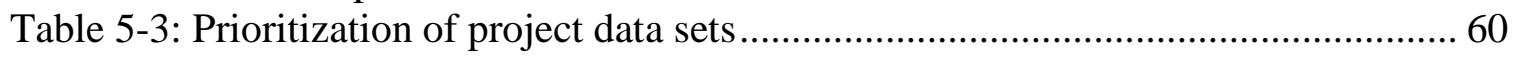

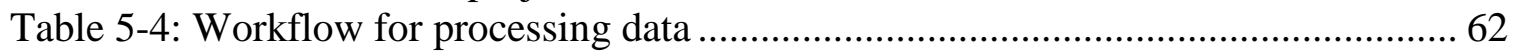

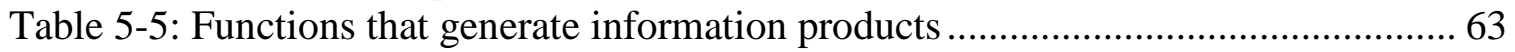

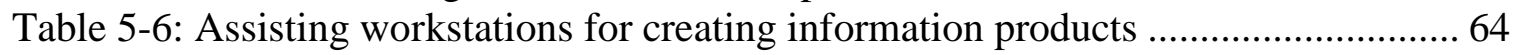

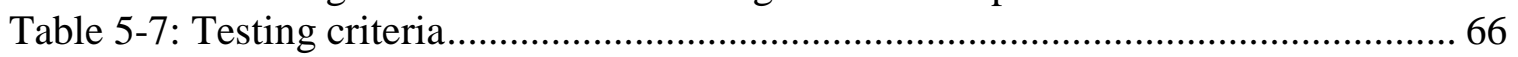





\section{List of Acronyms and Definitions}

$\begin{array}{ll}\text { API } & \text { Application Programming Interface } \\ \text { DBMS } & \text { Database Management System } \\ \text { EER } & \text { Enhanced-Entity Relationship } \\ \text { ESRI } & \text { Environmental Systems Research Institute } \\ \text { GIS } & \text { Geographic Information System } \\ \text { HTML } & \text { Hypertext Markup Language } \\ \text { IIS } & \text { Internet Information Services } \\ \text { IPD } & \text { Information Product Document } \\ \text { MIDL } & \text { Master Input Data List } \\ \text { SCC } & \text { Swedish Cooperative Center } \\ \text { SOC } & \text { Server Object Container } \\ \text { SOM } & \text { Server Object Manager } \\ \text { SQL } & \text { Structured Query Language } \\ \text { UML } & \text { Unified Modeling Language } \\ \text { VI AFP } & \text { Vi Agroforestry Programme }\end{array}$





\section{Chapter 1 - Introduction}

According to the United Nations Population Division, approximately 80 percent of the population of Eastern Africa lives in rural areas. The majority of this population is poor and depends on subsistence agriculture for their livelihoods. Despite the fact that agriculture is the backbone of these economies and crucial to sustainable economic growth, the full potential of the sector is far from being realized. Failure to attain full potential has been contributed to by many factors, including inadequate governance; high levels of population growth in the region coupled with inadequate farming technologies which has resulted in soil degradation; clearing of forests to create new land for agriculture; and the exposure of land to water and wind erosion, as well as negative effects on wildlife habitat. These underlying issues need to be addressed to avert a general socio-economic crisis in the region.

In order to counteract this trend, a delicate balance of increasing land productivity to meet the food demands of the growing population is needed, while also engaging in environmentally sustainable practices. Environmental degradation, climate change, limited land for agriculture and declining soil fertility require more efficient use of available land. The Swedish Cooperative Center Vi Agroforestry Programme (SCC Vi AFP) is a grass roots non-governmental organization that promotes agroforestry practices that restore soil fertility, increase land productivity, and protect the environment. This is carried out through agroforestry systems where appropriate trees and bushes are integrated with crops and/or animals, improving the environment in various ways while simultaneously strengthening the livelihoods of smallholder famers through increased diversified production. These practices improve the soil structure and result in storage of atmospheric carbon dioxide, hence the reduction of green house gas (GHG) emission. This carbon emission reduction practice is based on the premise that reforestation adds to the planet's carbon storage and helps moderate global warming by slowing the buildup of carbon emissions in the atmosphere. One way of evaluating the impact of these practices is through measurements of net sequestered carbon resulting from the adoption of sustainable project activities as compared to the amount that would have occurred without implementing such a project. In a carbon market, a ton of carbon sequestered is called a carbon credit. Quantifying the amount of carbon credits sequestered is not only an assessment of impacts of the Vi Agroforestry Programme’s (Vi AFP) interventions, but also an opportunity for its farmers to trade in the carbon market and generate additional revenue to farmers.

The Vi AFP has the opportunity to participate in the two major carbon markets, both the Clean Development Mechanism (CDM) under the Kyoto Protocol, and the fast growing voluntary carbon market. Its capacity for trading on carbon credits will depend largely on the credibility of systems the organization employs to monitor and evaluate the amounts of sequestered carbon. The application of conventional monitoring systems to carbon sequestration projects has been marred with uncertainties and inaccuracies, time delays, and intensive labors. A more effective and reliable systems builds market credibility and allow the Vi AFP to attract a larger market share, increase its funding sources, and thus increase positive impacts of such projects in the region. 
An effective monitoring system is required to account for GHG emissions, while meeting the high carbon market standards. A geographic information system (GIS) was used in this project to demonstrate a credible system with a sound scientific background for effective monitoring and evaluation of carbon sequestration projects. A web mapping application was used to share spatial data and information about the project's status and progress to a broader audience that includes carbon buyers, potential project donors, and interested general public.

\subsection{Client}

The client for this project is the Swedish Cooperative Center Vi Agroforestry Programme (SCC Vi AFP); a grass root based non-governmental organization (NGO) that work with small scale farmers in East Africa to promote sustainable agroforestry practices in the region. SCC Vi AFP has an integrated regional organization with the Swedish Cooperative Centre, a Swedish NGO with its head office in Stockholm. It runs several projects around Lake Victoria basin, one in Rwanda, two in Kenya, one in Uganda and three in Tanzania. This project focused on improving the monitoring and evaluations system used in the Agricultural Carbon Finance Project in Kenya. The central management of these projects in the region is based in the Kenya office.

The organization is implementing its first carbon sequestration project in the western region of Kenya (Figure 1.1). This area of interest forms part of Lake Victoria basin. The basin is of an important ecological balance for the biodiversity and communities living in the five countries surrounding the lake. The Vi AFP's projects in the Lake Victoria contribute to a long-term development effort initiated by governments sharing the lake and its catchments, and other development partners. Efforts to restore and conserve the lake require reforestation and sustained land uses at the catchment areas. Carbon sequestration projects of the Vi AFP therefore focuses on reforesting and preserving these catchment areas through implementation of sustainable agroforestry practices. 


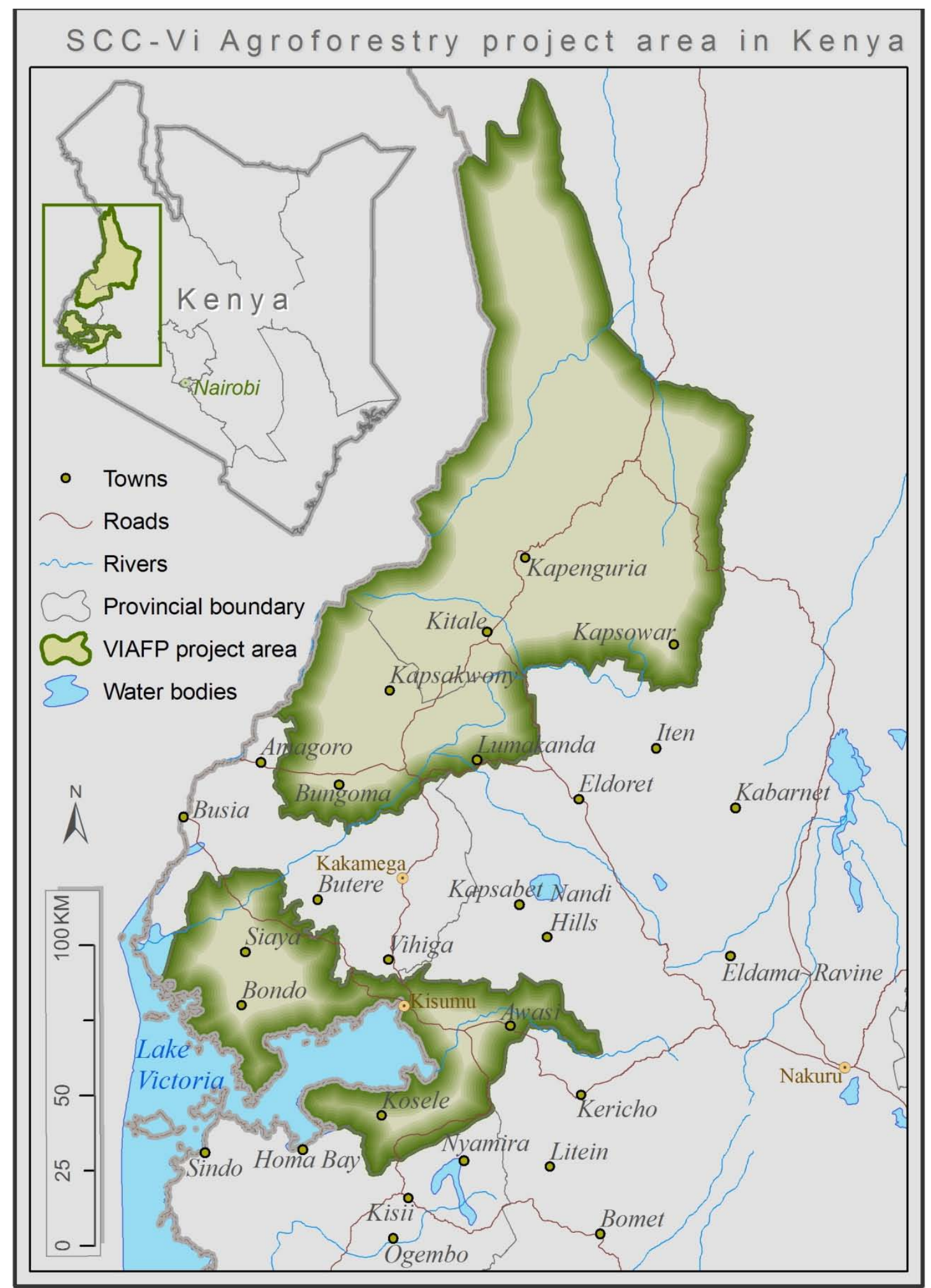

Figure 1.1: Vi Agroforestry Programme project areas in Kenya 
The Vi AFP is carrying out the Agricultural Carbon Finance Project in collaboration with the World Bank Biocarbon Fund. Agricultural Carbon Finance Projects adopt sustainable land management practices for climate change mitigation and adaptation, and transact verified emission reductions. Projects are verified against specific set standards on how to account and report green house gas (GHG) emission reductions. Monitoring and evaluation procedures of the Vi AFP projects must be approved by the Voluntary Carbon Standard body to allow the organization to trade in the carbon market. In order for a monitoring system to meet the high standard of credibility, it is essential to demonstrate the carbon changes within a project area on which sustainable land management practices are being carried out.

\subsection{Problem Statement}

The span of the Vi AFP projects is wide and complex. There are seven projects in four countries that need to be managed in terms of planning, monitoring, and evaluation. In addition, different agroforestry systems that have varying results are being practiced. This raises the need to keep track and evaluate these varying systems and their impacts against project goals. Carbon emission reduction through sustainable agroforestry is a process that requires accurate quantification and verification of carbon changes in order to be traded at carbon markets. An effective and accurate means of verification is therefore required to ensure the participation of the Vi AFP in this market.

The Vi AFP has been collecting large volumes of tabular, location-based, and satellite imagery over the 25 years of its operation. However, despite these large volumes of data, there is a lack of reliable access to spatial data that can be used in decision making to guide project implementation. A system is required to store and manage this data to allow for easy access, retrieval and manipulation into useful information.

Over the 25 years that that Vi AFP has worked in the East African region, many accomplishments and experiences have been accumulated. In order to advance this, the organization needs an advocacy tool to effectively communicate its history, successes, and progress to a wider target audience. The Vi AFP being a donor-funded organization also requires a system of advocacy to reach out to its supporters, collaborators, and potential donors. A tool is needed to share credible information on the status and progress of projects to donors and interested parties. Sharing spatial information and maps online is also required to raise transparency and credibility of the organization to trade in the carbon market and thus attract a larger demand. The organization does not currently have the capacity or the resources to leverage from this technology.

\subsection{Proposed Solution}

The nature of the problem of evaluating sustainable farming practices on farms is spatial. It is a factor of both the extent over which these systems are being implemented, as well as their location, and the inherent biophysical characteristics. The spatial capabilities of a GIS system make it the most suitable tool to model and monitor these inter-related characteristics of farming systems. On the other hand, the internet provides a convenient way of passing information to a wider audience. In this project, a Web GIS solution was proposed. 
This project report discusses the implementation of a Web GIS to meet the needs of monitoring and evaluating carbon sequestration projects of the Vi Agroforestry programme. A GIS database was designed to host both spatial and non-spatial data that the organization has over the past stored in either excel spread sheets or access tables. A comprehensive analysis of the project workflow was made to ensure that all carbon project performance indicators were captured in the database. An object-relational spatial database was used to model the relationships of monitoring indicators and complementary data. The database was designed and normalized to provide fast and efficient retrieval of data while maintaining logical linkages between related elements. The spatial database was also designed to aid in field data collection workflows. A schema of the database is used during field data collection to generate structured data collection forms that enforce accuracy and integrity. This also greatly speeds up the process of data pre-processing that is required before data can be consumed.

An interactive web mapping application was also created to host and serve spatial information and data about carbon projects to project stakeholders and interested partners. A GIS web page was designed using ArcGIS server technology, JavaScript API, and HTML. A major design consideration in using these technologies was to retain the look and feel of the Vi AFP main web site. The GIS web application allows users to search, locate, and view maps and related information about the organization's biocarbon projects. It also gives the number of households participating in each carbon sequestration project. Specific queries regarding amounts of biomass contents that is sequestered at a given project site can also be answered by the application. The target audience for this web-based GIS includes collaborating partners of the project, potential carbon credit buyers, the Vi AFP staff, participating members, and project donors.

\subsubsection{Goals and Objectives}

The goal of this project was to design and implement a decision support Web GIS solution for monitoring and evaluating impacts of the Vi AFP agroforestry projects on carbon sequestration. The GIS system created stored and provided spatial information needed in decision-making to aid in allocation and distribution of resources during project planning implementation, and monitoring. It facilitated the execution, monitoring, and evaluation of carbon sequestration projects through accurate quantification and data documentation of sequestered carbon variations over time. The web mapping application implemented in this project forms an outreach and advocacy tool that will improve access to spatial data that is necessary for not only creating general public awareness on such projects but also for donors' appraisal of projects they fund.

Strategically at a local level, the objective of this project is to support the implementation of the Vi AFP projects in adopting the most appropriate farming techniques in project areas. This will guide the adoption of well-evaluated farming techniques that translate into environmentally sound practices, improve carbon sequestration, and contribute to increasing the productivity of available farmland. It will make farming activity a worthwhile venture for most farmers who rely entirely on subsistence farming for their livelihoods. Farmers will be able to get more benefits from equivalent sizes of lands and thus improve their living conditions.

At a regional level, the goal of this project is to increase the capacity of the organization to implement and accurately monitor and evaluate carbon sequestration 
projects. Consequently, more farmers in the region will get an opportunity to participate in carbon trading through the Vi AFP. The success of the project will improve the credibility of the Vi AFP's projects in East Africa as being a credible market to trade in certified carbon. This will attract more buyers from the developing world and also raise the value price of unit sequestered carbon credit, leading to better compensation to the farmers. Web GIS for monitoring carbon projects in this context will be the first of its kind in the region; implementation of similar projects at full scale in other regions of Africa would be influenced by the success of this project.

\subsubsection{Scope}

To meet the client's needs, two GIS components were developed: a GIS database and a prototype Web GIS application. A GIS database was designed and implemented to collate and store spatial data and information on the Vi AFP carbon projects. A prototype Web GIS application was developed to serve project data and information products to online audience via the web.

In this project the user needs assessment was carried out in the department of project monitoring and evaluation within the organization. Questionnaires followed up with telephone conversations were used in the process of collecting user's requirements. The process entailed determining what data are available, evaluating the quality of the available data, identifying the location of the data, and establishing what new data are required and what data handling functions are necessary to turn the data into the required information products. Information Products Descriptions (IPDs) and a Master Input Data List (MIDL) were created in the process.

The project also identified system functions required to implement a sound GIS for the organization based on required information products and data requirements. A collection of functions and system capabilities necessary to generate the required information products from raw data was made. Use cases that model the monitoring procedures were also developed in this project. The project reviewed the existing information systems and communication infrastructure in order to make recommendations of adequate system configuration required to support a Web GIS system.

This project also developed a GIS web page that interlinks with the main Vi AFP web page. The client's needs analysis was conducted to determine what information the organization can authorize to a public audience. The project developed GIS web applications to meet the requirements of the client. Two web applications were developed for this system: a find task that locates the project areas, and a query task that identifies project sites with specific amounts of sequestered carbon.

\subsubsection{Methods}

This project accomplished several major tasks, including database design, database implementation, and Web GIS design and implementation. Varying techniques were used in developing each resulting component at every stage.

Database design involved conducting a user requirement analysis and defining the system scope. A user needs assessment was carried out with the use of questionnaires. A team of project managers, personnel involved in the monitoring and evaluation, and field 
extension officers of the Vi AFP was selected with the help of the client. Caution was taken to have effective vertical and horizontal organizational representation of those involved at all stages of biocarbon project implementation. Questionnaire forms were designed and sent out to the selected team of personnel. The questionnaire contained two sections, the first section being introductory with a description and definition of GIS, its functions, potential uses, and applications. The second section required the respondent to state his/her responsibilities, how individuals make their decisions, what they need to know to perform their tasks, and what information products are appropriate for their tasks. Follow-up phone conversations with each respondent were held after receiving feedback. Through this process information product documents (IPDs) were created. Functional, technical, operational, and transitional requirements were evaluated and documented.

Database design involved creating a conceptual data design, choosing a logical model, and building the physical database. During conceptual data design, data characteristics including data sources, scale of the data set, resolution, map projections, and error tolerances were considered in creating the conceptual design. The logical data model was chosen based on two main factors: a data model that represented the real world procedures of project monitoring and evaluation, and limitations of the model to perform some of the required functions - data type handling, scalability, complexity, and execution speed. A semi object-relational data model was chosen because it allowed data to be stored and manipulated most effectively for creating the required information products. It versatility can best describe the complexity of real world projects in a database. The physical design of the database was developed using the ArcGIS Diagrammer application. The resulting schema was then converted into Environmental Systems Research Institute (ESRI) file Geodatabase.

The project implemented a Web GIS using JavaScript API and ArcGIS server technology. A user needs analysis was carried out to determine information content to be shared online, as well as appropriate applications to be developed to suit the target audience and meet a specific purpose. A GIS website was built using HTML to suit the look and feel of the Vi Agroforestry Programme main web site. GIS applications were built using JavaScript API while utilizing the Dojo toolkit widgets tools to improve the appearance and usability of applications.

\subsection{Audience}

This describes how GIS was used to accomplish an effective and efficient monitoring and evaluation system to quantify the amounts of carbon sequestered by agroforestry projects. It is intended for an audience of professionals interested in using GIS as a tool in their diverse disciplines. The target audience thus includes GIS and non-GIS practitioners and professionals in the field of natural resource management. The report can also be used by project participants involved in agroforestry carbon sequestration, and potential and current project donors interested in carbon sequestration agroforestry projects. It is meant to enforce confidence in a project monitoring process with a basis of scientific principles of measurements and reporting. Experiences and discussions of issues in this project may be particularly useful to GIS practitioners who may want to establish Web GIS applications in the realm of conservation. 


\subsection{Overview of the rest of this report}

This report is divided into three major sections: introduction and literature review; system analysis, design and implementation; and results, analyses, and conclusions.

The first section consists of chapters 1 and 2 and gives background on what this project is all about. It describes who the client for this project is and what the client's problem is. The introduction also gives a statement of the problem this project sought to answer and the proposed solution to that problem. The sub-section of proposed solution discusses the goals and objectives of this project, the scope of the project, techniques used to implement the solution, and the audience for whom this report is intended. A review of pertinent literature and similar projects is reported in the background section with a summary of findings and how this project tackled the problem.

The second major section of this report consists of chapters 3 through 6 and outlines system analysis, design, and implementation. It documents the problem statement and the understanding of client's requirements. This section also describes the major components of the system and how they relate with each other. An analysis of the project plan that was initially proposed during the planning of this project versus reality of what transpired is outlined in this section. This is followed by the choice and method of how the project database was designed. This section also contains the conceptual model of the client's problem domain that describes entities of interest and their relationships, and a logical data model describing feature classes and tables in the project database. Also outlined in this section are sources and methods of collecting data, and the scrubbing and loading procedures for data used in this project. It is followed by what the project accomplished at the implementation stage.

The third section is comprised of chapters 7 and 8 and gives a reflection of the implications of the project results for the client. It also contains the conclusive summary of what the project set to accomplish, how it was accomplished, the accomplishments and how the client's requirements were met. A description of potential research areas and extensions to this project is given in the last chapter. The appendix contains the data schema, user needs assessment questionnaire, data model, and other important extraneous information that is pertinent to this project. 


\section{Chapter 2 - Background and Literature Review}

Implementation approaches of monitoring and evaluation systems for environmental resource management are cross-disciplinary. In most cases, technological advancements of available tools drive improvements on monitoring and evaluation systems. Of note, are the limited technological applications in agroforestry compared with its counterparts in agriculture and forestry. However, the use of computer-based tools in agroforestry will change with the growing recognition of their productive roles in farming practices (Ellis, Bentrup, \& Schoeneberger, 2004). This section is a review of carbon sequestration in agroforestry and the role of GIS in sustainable management of natural resources. In this context, carbon sequestration is the process through which carbon dioxide $\left(\mathrm{CO}_{2}\right)$ from the atmosphere is absorbed by and stored as carbon in biomass (tree trunks, branches, foliage and roots) and soils.

Ikerd (1993), perceives sustainable agriculture as a model of development which considers production units as organisms that consist of many complex interrelated suborganisms, all of which have distinct physical, biological, and social limits. He argues that diversification, integration, and synthesis are among the fundamental strategies for sustainable development. This integration can be accomplished through a system. In agroforestry, different farming techniques are the components that can be spatially modeled into unique systems, which can in turn be monitored and evaluated (Ikerd, 1993).

\subsection{Carbon sequestration in agroforestry}

Technologies associated with carbon capture and storage have been engineered and implemented over the past recent years to deliberately capture and store $\mathrm{CO}_{2}$ from the atmosphere. Several carbon storage options exist, including geological $\mathrm{CO}_{2}$ storage, terrestrial carbon sequestration, mineral carbonation, and oceanic carbon storage. Terrestrial carbon sequestration refers to the storage of carbon in the biosphere, relying on the photosynthetic process of capturing and converting atmospheric $\mathrm{CO}_{2}$ into organic carbon (Stephens, 2006). Stephens notes that among these technologies, terrestrial carbon sequestration through biomass enhancement requires the least amount of engineering and has attractive co-benefits of conserving the environment. This literature review considers soil carbon sequestration through sustainable agroforestry. The processes of terrestrial carbon sequestration are being advocated for by both governments and non-governmental stakeholders as well as public and private institutions. The World Bank and the International Emissions Trading Association (IETA) are collaborating to raise funds to provide finances for reducing greenhouse gas emissions. This fund targets small-scale projects in developing countries and rural areas of developing countries.

Agroforestry is one of the main economic activities practiced in East Africa and is a source of livelihood for the majority of the population. Over time, the constant growth in population exerts increased demand for additional output from farms resulting in of unsustainable practices and overexploitation of available land. The United Nations report on Environment and Development of 1992 recognizes this as one of the development challenges in developing countries. The report recommends the use of appropriate technologies in agricultural production to ensure sustained development. This is 
necessary in order to satisfy the increasing demands for food and other agricultural commodities while avoiding further encroachment on land that is only marginally suitable for cultivation (United Nations, 1992).

Agricultural Soil carbon sequestration is another means of reducing carbon emissions and can be enhanced through changes in land use and judicial management of agroforestry systems. In their study, (Antle, Capalbo, Mooney, Elliot, \& Paustin, 2001) showed that economic efficiency of soil carbon sequestration depends on opportunity costs of changing production practices to increase sequestration rates. It focused on the process of implementing sustainable agroforestry practices, as opposed to that of forest plantations as a viable economic venture. Compared against different agroforestry methods, under varying policy conditions, agroforestry proved to be a viable activity for sustained carbon sequestration (Antle, Capalbo, Mooney, Elliot, \& Paustin, 2001).

There is a growing recognition of the significance of agroforestry in carbon sequestration and carbon dioxide mitigation. Smith \& Marco (2007) notes that "many agricultural practices can potentially mitigate greenhouse gas (GHG) emissions, the most prominent of which are improved cropland and grazing land management and restoration of degraded lands and cultivated organic soils” (Smith P. \& Marco B., 2007 p. 9). "The amount of carbon being sequestered depends on the agroforestry system put in place, the structure and function of which are, to a great extent, determined by environmental and socio-economic factors. ...others factors include tree species and system management” (Alain \& Serigne, 2003, p. 4). They discuss the various agroforestry systems and the relative significance each has in sequestering carbon. Carbon can be sequestered either in plant biomass or through the soil (soil carbon). According to this study, not all agroforestry systems have the potential to sequester carbon. There are typical variations in agroforestry systems that need to be quantified and shown.

This literature review indicates that agroforestry is an important means of sequestering carbon. It is also an opportunity for farmers in Kenya to improve productivity and generate revenue while protecting the environment. An effective monitoring system supported by GIS has the potential to achieve and ensure such projects are successful.

\subsection{Role of GIS in sustainable management of natural resources}

Computer-based technologies play an integral role for information management and decision making in all disciplines related to natural resource management. Natural resource management science is characterized by high diversity and complex interactions that must be managed for multiple objectives, alternatives, and social interests over varied landscapes (Ellis, Bentrup, \& Schoeneberger, 2004). GIS offers a sound technical approach for documenting, monitoring, and evaluating the impact of agricultural farming activities. "Successful design of agroforestry practices hinges on the ability to pull together very diverse and sometimes large sets of information (i.e., biophysical, economic, and social factors), and then implementing the synthesis of this information across several spatial scales from site to landscape” (Ellis, Bentrup, \& Schoeneberger, 2004, p. 401). Campagna (2006) draws attention to the fact that economic, social and environmental processes are inherently spatial due to their occurrence in space and their temporal changes. She argues that GIS is an essential tool that can be used to offer effective support for spatial planning and decision making while 
addressing these issues (Campagna, 2006). According to Nair (1991), because agroforestry systems are diverse and complex, they need to be categorized in order to evaluate them. He proposes a classification criteria based on composition and arrangement of components, functions, socio-economic scale or management, and ecological spread. Nair (1991) classified agroforestry systems into three sub-systems, namely: agricilviculture (crops and trees), silvopastoral (pasture, animals, and trees), and agricilvopastoral (crops, pasture, animals, and trees). Later, Ellis, Nair, and Jeswani, (2005) evaluated agroforestry sytems as categorized into five major types by the Association for Temperate Agroforestry (1997). The catogories they considered are:

i. Alley cropping

ii. Silvopasture

iii. Windbreaks

iv. Riparian buffers

v. Forest farming

Catogorization of agroforestry systems allows information systems to handle complex spatial scenarios. In the case of this project, the amount of carbon variations over time is a function of acreage as well as location and time attributes, so are the land management practices being considered. According to Tomlinson (2007), there is an abundance of reliable technologies and spatial data that significantly widens the scope of potential GIS applications. "Geographic information systems integrate seemingly disparate information quickly and visually, which facilitates communication, collaboration, and decision making” (Tomlinson, 2007, p. XV).

The World Bank recognizes the need for more suitable technologies than conventional agroforestry management practices. It encourages use of spatial technologies for more effective resource management and economic gains (World Bank, 2007). In order to promote organizational cooperation, emphasis should be placed on fostering innovation and the transfer of geographic data and technology through partnerships and international collaboration involving developed and African countries (National Research Council of the National Academies, 2002). The United Nations Agenda 21 expresses the need for modern informational frameworks. It urges developing countries to seek to achieve sustainable consumption patterns in their development process, guaranteeing the provision of basic needs for the poor, while avoiding unsustainable practices. This requires enhanced technological and other assistance from industrialized countries (United Nations, 1992). It is a call for integrating current technological advancements in information systems in effective management of natural resources.

Ellis, Bentrup, and Schoeneberger (2004) in discusses the development of decission support tools (DSTs) including GIS in agroforestry (Table 2-1). 
Table 2-1: GIS-based decision support tools used in agroforestry

\begin{tabular}{|c|c|c|}
\hline Decision support tool & Description & Reference \\
\hline $\begin{array}{l}\text { Agroforestry System } \\
\text { Suitability in Africa }\end{array}$ & $\begin{array}{l}\text { Spatial analysis using climate, soil land use } \\
\text { and other spatial data alongside plant species } \\
\text { data to determine species and agroforestry } \\
\text { suitability }\end{array}$ & $\begin{array}{l}\text { Booth et al. 1989; } \\
\text { Booth et al. 1990; } \\
\text { Unruh and } \\
\text { Lefebvre } 1995\end{array}$ \\
\hline $\begin{array}{l}\text { Agroforestry System } \\
\text { Suitability in Ecuador }\end{array}$ & $\begin{array}{l}\text { GIS Spatial analysis to determine suitable } \\
\text { areas of Annona cherimola agroforestry } \\
\text { systems in Southern Ecuador. }\end{array}$ & $\begin{array}{l}\text { Bydekerke et al. } \\
1998\end{array}$ \\
\hline $\begin{array}{l}\text { Agroforestry System } \\
\text { Assessment in Nebraska }\end{array}$ & $\begin{array}{l}\text { Spatial suitability assessment for willow and } \\
\text { forest farming agroforestry systems in a } \\
\text { Nebraska watershed }\end{array}$ & $\begin{array}{l}\text { Bentrup and } \\
\text { Leininger } 2002\end{array}$ \\
\hline $\begin{array}{l}\text { Agroforestry Parklands in } \\
\text { Burkina Faso }\end{array}$ & $\begin{array}{l}\text { Spatial analysis of dynamics of agroforestry } \\
\text { parklands and species distribution due to } \\
\text { human impacts }\end{array}$ & $\begin{array}{l}\text { Bernard and } \\
\text { Depommier } 1997\end{array}$ \\
\hline $\begin{array}{l}\text { Agroforestry Planning } \\
\text { Tool in China }\end{array}$ & $\begin{array}{l}\text { Hybrid DST integrating GIS data, regression } \\
\text { models plus expert knowledge to assess } \\
\text { biophysical, social and economic suitability of } \\
\text { Paulownia intercropping agroforestry systems }\end{array}$ & Liu et al. 1999 \\
\hline $\begin{array}{l}\text { PLANTGRO (Plantation } \\
\text { and Agroforestry Species } \\
\text { Selection Tool) Hybrid }\end{array}$ & $\begin{array}{l}\text { Plantation and agroforestry species selection } \\
\text { tool integrates GIS and expert system on plant } \\
\text { growth }\end{array}$ & $\begin{array}{l}\text { Booth 1996; } \\
\text { Hackett and } \\
\text { Vanclay } 2003\end{array}$ \\
\hline $\begin{array}{l}\text { SEADSS (Southeastern } \\
\text { Agroforestry } \\
\text { Decision Support System) }\end{array}$ & $\begin{array}{l}\text { Landscape and site-scale agroforestry } \\
\text { planning and species selection DST for } \\
\text { landowners and extension agents of Southeast } \\
\text { US that integrates GIS, tree and shrub } \\
\text { database and expert knowledge }\end{array}$ & Ellis et al. 2003 \\
\hline $\begin{array}{l}\text { Conservation Buffer } \\
\text { Planning Tools for } \\
\text { Western Cornbelt Region, } \\
\text { USA }\end{array}$ & $\begin{array}{l}\text { Suite of GIS, economic models and } \\
\text { visualization tool for landowners and resource } \\
\text { managers to evaluate agroforestry strategies in } \\
\text { Midwest Cornbelt region of the USA }\end{array}$ & $\begin{array}{l}\text { Bentrup et al. } \\
2003\end{array}$ \\
\hline
\end{tabular}

GIS has been applied to the management of agroforestry practices in various parts of the world in a wide range of agro-ecological regions from tropical to temperate. The use of information systems in agroforestry began with development of databases to aid in guiding plant selection. With the changing needs, improved technologies, and data proliferation, their application has evolved to monitoring, precision farming, and 
modeling different systems and predicting outcomes of different scenarios (Ellis, Bentrup, \& Schoeneberger, 2004). Among the first agroforestry systems to be deployed was the prototype of an Agroforestry Expert System by the United Nations University. This system addressed land use factors including rainfall amount and distribution, elevation, slope, soil texture, soil fertility, and soil reaction (Warkentin, Nair, Ruth, \& Sparague, 1990). This system was however focused only on alley cropping and it was customized to meet limited regional needs. It could however be improved adding parameters such as climatic and socio-economic, and dynamic biophysical factors like soil erosion, seasonal variations, and climate change. These parameters would increase the systems usability in more diverse geographical and ecological conditions and to address other agroforestry techniques (Warkentin, Nair, Ruth, \& Sparague, 1990).

In the United Sates, a GIS-based database management application for agroforestry planning and tree selection has been developed to aid in the implementation of agroforestry projects. The Florida Agroforestry Decision Support System (FADSS) was designed to disseminate important information to farmers. A prototype application was developed to guide land owners in selecting tree species for agroforestry in specific situations (Ellis, Nair, Linehan, Beck, \& Blanche, 2000). Databases of soils, climate, and plants were used to implement this system. Its main objective was to explore existing spatial data to inform and support decision making in site selection, and to incorporate ecological, economic, and management criteria in tree species selection. Nebraska, Bentrup and Leininger (2002) researched on the application of GIS suitability assessment to agroforestry. Using GIS, they selected a suitable location for the production of decorative willow flowers. Suitability assessment factors used in this project were soil types, frequency of flooding, water tables, slope, and land uses (Bentrup \& Leininger, 2002). The system integrated complex and diverse variables to support informed decision-making while selecting planting sites.

The perpetual advancements in technology and availability of more information about agroforestry systems have seen not only the rise of internet-based GIS, but also better functionalities to meet the needs of diverse audiences. These applications range from simple demonstrations and references to GIS use, to complex geoprocessing tools used to solve spatial problems and support decision making. The internet is affecting GIS in three major areas of GIS data access, spatial information dissemination, and GIS processing and analysis. It enhances accessibility and reusability of GIS analysis tools, and enables users to work on GIS data using web browsers without installing GIS software on their local machines (Peng \& Tsou, 2003). Web-based GIS has great potential in many fields by allowing a wider involvement in environmental decision making and through increased accessibility to analysis tools necessary for decision making (Kingston, Carver, Evans, \& Turton, 2000). The utility of a decision-support system in agroforestry must be driven by current technological limitations, economic, social, and biophysical diversity that must be incorporated into planning and design process, and most importantly, the end-users of the system (Ellis, Bentrup, \& Schoeneberger, 2004).

Despite the advantage of sensitization and wider accessibility of Web GIS data, Kingston, Carver, Evans, \& Turton (2000), concludes that the usability of web-based GIS depends largely on the design of the interface, data accuracy, and GIS skills of the target audience. 
Developments of agroforestry systems have also evolved into internet-based systems. In the Southeast United States, the Southeastern Agroforestry Decision Support System (SEADSS) was developed to provide on-line access to county-level spatial information used to evaluate agroforestry sites and suitable species. It links regional GIS with subtropical tree and shrub database (Ellis, Nair, \& Jeswani, 2005). The Agroforestry Tree Database, developed by the World Agroforestry Center, is also available on the internet and as a CD-ROM. It has over 500 trees and related information and was developed for decision support in agroforestry tree selection at a global scale (Ellis, Nair, \& Jeswani, 2005). The SEADSS system provides users with online GIS capabilities to identify and evaluate sites and select suitable trees for different sites using ArcIMS.

The project discussed by this paper sought to utilize GIS technology to not only support decision making during project implementation but also as a tool to monitor and evaluate sequestered carbon in projects. This was realized by establishing a baseline and creating provisions in the system that keeps track of project progress at all monitoring stages.

\subsection{Summary}

A sound technical approach is required for the effective management of natural resources. It can be seen that "technological developments and their application in farming and agriculture can remarkably increase per-capita food availability despite a consistent decline in per-capita agricultural land area” (Bettinger \& Michael, 2004, p. 87)The two main improvements that a decision support system should consider are: factoring in the uniqueness of East African ecological and climatic conditions, and including more variables that determine effectiveness of agroforestry systems being adopted. This would ensure better leverage of GIS to monitor agroforestry projects over time.

The integration of GIS in agroforestry and carbon sequestrations is still at an early stage. It is mostly utilized in the United States, specifically the South East, that major research, development and application is evident. Most developed systems are designed to meet specific requirements within a particular geographic extent and cannot be directly applied to other regions. The development of these systems is to a great extent pegged on availability of new pertinent information and technological advancements (Ellis, Bentrup, \& Schoeneberger, 2004). A majority of the systems reviewed focused on either agroforestry tree species selection or site suitability assessment and selection. The development of online-GIS for monitoring agroforestry projects, as in this project is yet to be fully exploited.

Based on the reviewed literature, it is evident that technological advancements and use of GIS in agroforestry systems helps to improve productivity and enhance protection of the environment. Sound monitoring and evaluation based on GIS adds to the overall credibility and reliability based on scientifically grounded principles. 


\section{Chapter 3 - Systems Analysis and Design}

A system analysis of this project was conducted to determine the most suitable design to meet the client's needs. Defining the client's problem guided requirement analysis in determining the functional and non-functional requirements of the system. This chapter discusses issues considered during system design; it outlines the choice of the system and the approach used in design it. This chapter also discusses the project planning efforts that were applied to this project. It discusses the evolution of the project plan as initially anticipated through execution.

\subsection{Problem Statement}

The Swedish Cooperative Center Vi Agroforestry Programme (SCC Vi AFP) has seven projects spanning five countries in Eastern Africa (Figure 3.1). With such a wide scope of operations, the monitoring and evaluation system is often characterized by a lack of access to information required for decision making. For over 25 years of project implementation, the organization has spent enormous resources in collecting spatial data and other information pertinent to these projects. With the ever growing volumes of data and information, there is a need for a spatial management system that can store and readily provide access and retrieval of information required for decision making. Agroforestry carbon emission reduction projects also demand a system that has the capacity to keep track of carbon changes over time and across regions. An effective and efficient system is required by the Vi AFP to support the decision making process during planning, implementation, monitoring, and evaluation of these agroforestry projects.

The Vi AFP is also a donor-funded organization that relies mainly on external and international funding sources to advance its projects. Advocacy is a key undertaking for the organization, thus the need to reach out to wider audiences. An internet based GIS system was needed to share information about project location and progress of activities with donors, partners, and the general public, both at local and international levels. 


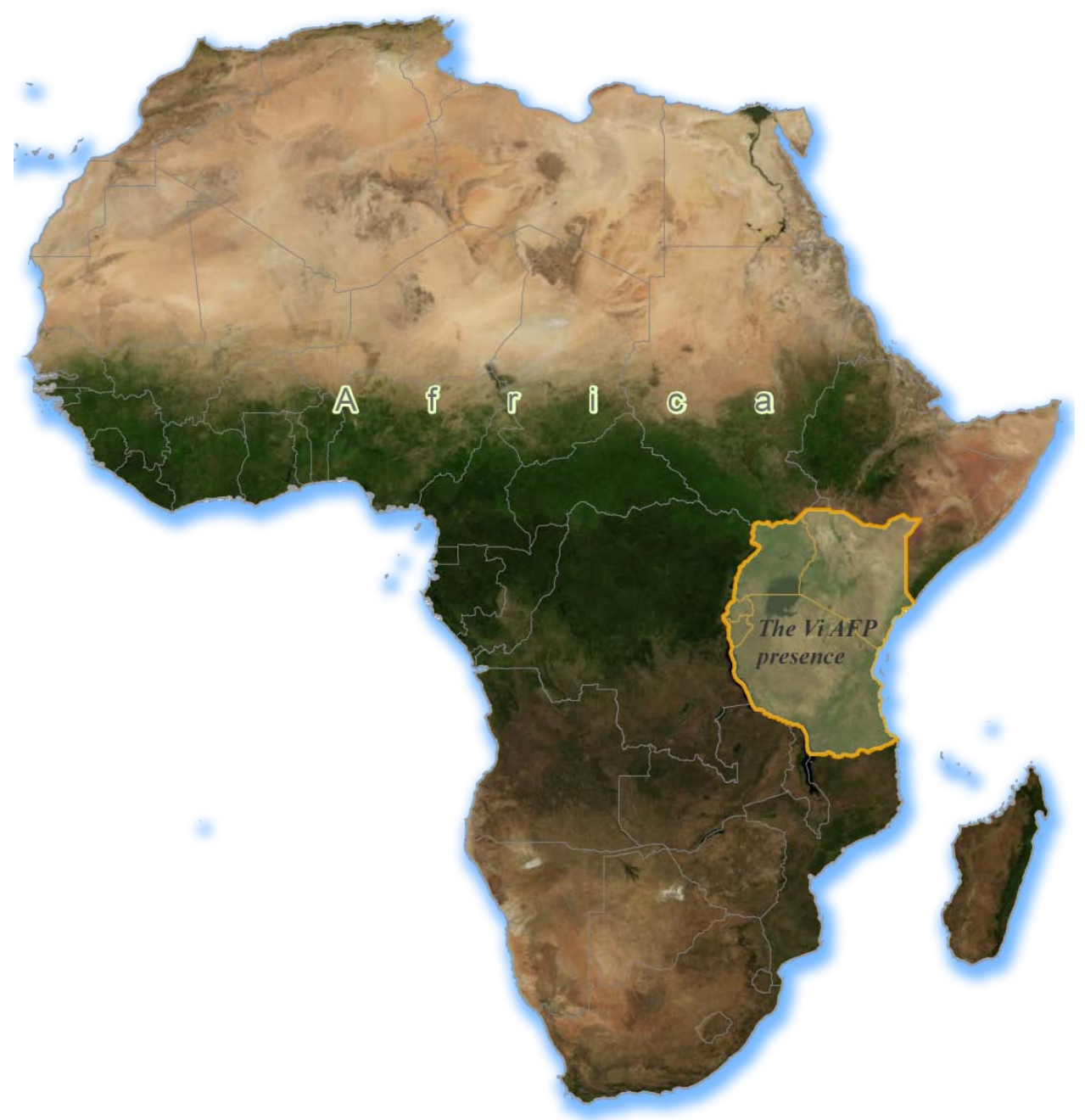

Figure 3.1: The span of the Vi AFP in East Africa

\subsection{Requirements Analysis}

A requirement analysis was carried out to assess and determine functional and nonfunctional requirements of the system. This was done through a user needs assessment process that led to development of use cases that defined system functional requirements. Requirements were categorized based on need; either mandatory or desired. Tables 3-1 and 3-2 give a summary of the functional and non-functional requirements the system met. 
Table 3-1: System functional requirements

\begin{tabular}{|c|c|c|}
\hline \multicolumn{3}{|c|}{ Functional requirements of the Vi AFP Web GIS system } \\
\hline 1.0 & Overall system requirements & Remarks \\
\hline 1.1 & $\begin{array}{l}\text { Enforce an effective and efficient project monitoring system for the } \\
\text { organization. }\end{array}$ & Mandatory \\
\hline 1.2 & $\begin{array}{l}\text { Support decision making during resource allocation, management, } \\
\text { and project implementation. }\end{array}$ & Mandatory \\
\hline 2.0 & Database & \\
\hline 2.1 & $\begin{array}{l}\text { The system should accommodate all spatial and non-spatial } \\
\text { performance indicators that are required for monitoring and } \\
\text { evaluation of agroforestry projects. }\end{array}$ & Mandatory \\
\hline 2.2 & $\begin{array}{l}\text { The system should allow for storage, updating, and retrieval of both } \\
\text { spatial and non-spatial data pertinent to the project. }\end{array}$ & Mandatory \\
\hline 2.3 & $\begin{array}{l}\text { The system should convert, manage, and store all the various data } \\
\text { formats derived from different sources. }\end{array}$ & Mandatory \\
\hline 2.4 & $\begin{array}{l}\text { Consistent logical relationships between data and system elements } \\
\text { should be maintained by the system. }\end{array}$ & Mandatory \\
\hline 2.5 & $\begin{array}{l}\text { The database should allow for data check in/out for remote editing } \\
\text { during the field data collection process. }\end{array}$ & Desired \\
\hline 2.6 & $\begin{array}{l}\text { The database should provide all the necessary information required } \\
\text { to prepare needed information products for reporting and } \\
\text { documentation of projects. }\end{array}$ & Desired \\
\hline 2.7 & $\begin{array}{l}\text { Incorporate carbon monitoring parameters including satellite } \\
\text { imageries and photos, into the database. }\end{array}$ & Mandatory \\
\hline 3.0 & Web GIS application & \\
\hline 3.1 & $\begin{array}{l}\text { Applications should display a base map showing the geographic } \\
\text { location of project areas. }\end{array}$ & Mandatory \\
\hline 3.2 & $\begin{array}{l}\text { The system should allow for querying and display of project sites } \\
\text { with certain amounts of sequestered carbon at a given time. }\end{array}$ & Mandatory \\
\hline 3.3 & $\begin{array}{l}\text { The application should give the number of households involved for } \\
\text { a given project, when queried. }\end{array}$ & Mandatory \\
\hline
\end{tabular}




\section{Functional requirements of the Vi AFP Web GIS system}

\begin{tabular}{|l|l|l|}
\hline 3.4 & $\begin{array}{l}\text { The application should provide navigation tools, e.g. overview map } \\
\text { and zoom in/out functionalities for navigating through the web } \\
\text { map. }\end{array}$ & Mandatory \\
\hline
\end{tabular}

Table 3-2: System non-functional requirements

\begin{tabular}{|c|c|c|}
\hline \multicolumn{3}{|c|}{ Non-functional requirements of the Vi AFP Web GIS system } \\
\hline 1.0 & Overall system requirements & Remarks \\
\hline 1.1 & $\begin{array}{l}\text { System accuracy, completeness, and structured procedures will } \\
\text { increase confidence in the monitoring and evaluation of projects. }\end{array}$ & Mandatory \\
\hline 1.2 & $\begin{array}{l}\text { Should increase credibility of amounts of the carbon reduction } \\
\text { emissions reported by the organization. }\end{array}$ & Desired \\
\hline 1.3 & $\begin{array}{l}\text { The system should be scalable and replicable in other similar } \\
\text { projects within the region. }\end{array}$ & Desired \\
\hline 2.0 & Database & \\
\hline 2.1 & $\begin{array}{l}\text { Should maintain consistent logical relations among stored data } \\
\text { sets without introducing redundancy in the database. }\end{array}$ & Mandatory \\
\hline 2.2 & $\begin{array}{l}\text { Should be sufficiently normalized to reduce storage space and } \\
\text { ensure quick access to information. }\end{array}$ & Mandatory \\
\hline 2.3 & $\begin{array}{l}\text { Searchable fields should be indexed to improve search and query } \\
\text { responses. }\end{array}$ & Mandatory \\
\hline 2.4 & $\begin{array}{l}\text { The system design should model as accurately as possible the } \\
\text { real world operations of agroforestry activities. }\end{array}$ & Desired \\
\hline 3.0 & Web mapping application & \\
\hline 3.1 & $\begin{array}{l}\text { Applications should be light weight and functional under low } \\
\text { internet bandwidths. }\end{array}$ & Mandatory \\
\hline 3.2 & $\begin{array}{l}\text { The system should take the minimum acceptable response time } \\
\text { to retrieve and display information when queried. }\end{array}$ & Desired \\
\hline 3.3 & $\begin{array}{l}\text { The system should be reliable and operational year-round, with } \\
\text { scheduled downtime for system maintenance. }\end{array}$ & Desired \\
\hline
\end{tabular}




\begin{tabular}{|l|l|l|}
\hline \multicolumn{2}{|l|}{ Non-functional requirements of the Vi AFP Web GIS system } \\
\hline 3.4 & $\begin{array}{l}\text { The interface should have the look and feel of the main } \\
\text { organization's web site, and integrate with the organization's } \\
\text { main site without significant difference in visual appearance. }\end{array}$ & Mandatory \\
\hline 3.5 & $\begin{array}{l}\text { The application should comfortably handle an anticipated } \\
\text { number of hits as determined by web site capacity analysis, at } \\
\text { any particular time. }\end{array}$ & Desired \\
\hline
\end{tabular}

The primary function of this system was to create a structured data repository of project performance indicators to support decision making during implementation, monitoring, and evaluating projects. This enabled the system to meet the required need for preparing the required information products. It also needed to be able to share spatial information over the internet. The system at best needed to be an accurate abstraction of real-world operations and project activities, and thus had to incorporate all data formats and workflow requirements. It ensured that complete and accurate sets of project parameters captured sufficient information for project monitoring analysis.

The system delivered also met all mandatory functional and non-functional requirements. Other desired non-functional requirements depended upon the capacity of the organization's infrastructure to support the system. With an allocation of additional resources for this project, other desired functionalities could be realized.

\subsection{System Design}

Several system components were designed and implemented to meet the requirements of the client. This project developed an object-relational spatial database system to store and manage the organization's project data. The project also built a GIS web page that contained GIS application tools that provide access to project information over the internet (Figure 3.1).

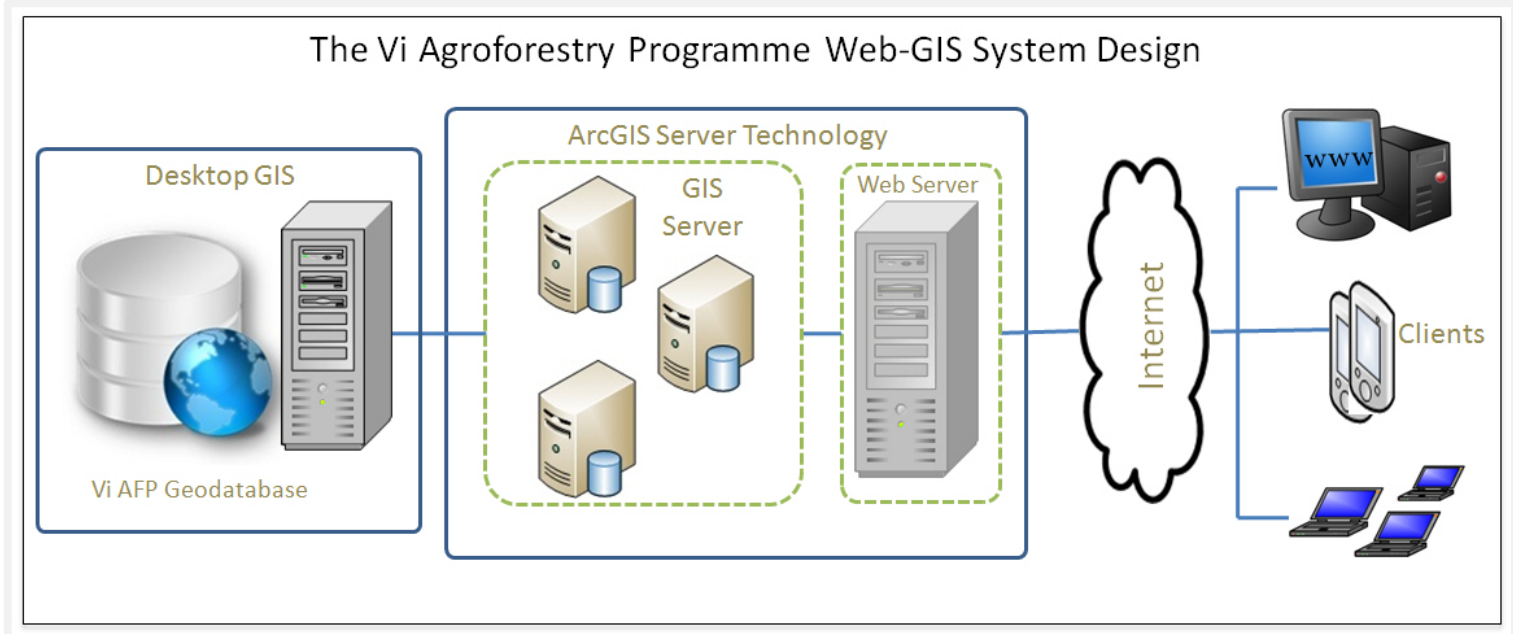

Figure 3.2: The Vi AFP System Architecture 
The project's desktop GIS consisted of a semi object-relational database, desktop GIS software application, and a hardware platform. An ArcGIS ${ }^{\circledR}$ server system component consists of a GIS server, a web server, and internet connectivity. The GIS server for this project had both server object container (SOC) and server object manager (SOM) hosted on one server workstation. An internet information services (IIS) server was used to publish the developed web site. The IIS supports, among other protocols, hypertext transport protocol (HTTP) that was used in the project to exchange data over the internet. HTTP is a set of rules for exchanging information between the web browser and the web/HTTP server (Peng \& Tsou, 2003).

\subsubsection{GIS Database}

Based on the requirements analysis, a spatial database was implemented to meet the data requirements of the Vi Agroforestry Programme (Vi AFP). Database systems control the organization, storage, management, and retrieval of data in a database. A spatial database was designed to model the real-world project data and operations. In order to model the complex reality of activities involved in agroforestry projects, a semi object-relational GIS database was implemented for this project.

It was decided to implement a semi object-relational data model due to its flexibility in data structures, thus the ability to more closely describe the real world. A semi objectrelational data model is a hybrid of both the relational and object-oriented data models, and is capable of handling complex data by using an abstract data type. An abstract data type is a rich type of data structure that allows the addition of specialized behavior to the relational model. This flexibility in data structure enables semi object-relational database models to more closely describe the real world (Tomlinson, 2007). Semi object-relational data models allow integration with other enterprise business systems through their ability to support extended forms of Structured Query Language (SQL) and to access relational database management systems. Semi object relational data models also have the advantage of speed to provide fast access to information.

Data structure in the spatial database for this project was organized into different categories, as shown in Table 3-3.

Table 3-3: Summary of data sets

\begin{tabular}{|l|l|}
\hline Dataset Category & Dataset Names \\
\hline Agroforestry projects & $\begin{array}{l}\text { Activity project sites, Sustainable land management } \\
\text { techniques, Agroforestry crops, Participating } \\
\text { households, Sampling reference clusters, Biomass } \\
\text { assessment sample plots, Livestock husbandry }\end{array}$ \\
\hline $\begin{array}{l}\text { Project performance } \\
\text { indicators }\end{array}$ & $\begin{array}{l}\text { Household living conditions, Household financial } \\
\text { conditions, Tree cover, Farm head }\end{array}$ \\
\hline Hydrography & $\begin{array}{l}\text { Rivers, wetlands, River basins, Rainfall distribution, } \\
\text { Water-points }\end{array}$ \\
\hline Biophysical features & $\begin{array}{l}\text { Land use/land cover, soils data, vegetation cover, agro- } \\
\text { ecological zones }\end{array}$ \\
\hline Base data & $\begin{array}{l}\text { Administrative boundaries, Administrative places, } \\
\text { Market centers, Roads, Satellite images }\end{array}$ \\
\hline
\end{tabular}




\subsubsection{Web GIS Application}

A Web GIS was designed to meet the requirements of the organization. An interactive internet-based GIS was implemented by developing a website and building GIS web applications within the web page. Based on requirement analysis, GIS web services were authored and published using a combination of online data resources and data residing on the organization's database. The web applications allow users to locate and view maps of project sites; users can also query more information about each project site. The target audiences for the Web GIS from Vi AFP staff, interested partners, general public, to project supporting projects.

The web page was built using Hyper Text Markup Language (HTML), Cascaded Style Sheets (CSS), and Java application development tools. A JavaScript Application Programming Interface (API) tools was used in developing the applications. The JavaScript approach as it is requires less browser resources and can run effectively on low connectivity networks. The website was published using an IIS web server.

\subsection{Project Plan}

A project plan was prepared to provide guidelines on how to successfully execute project tasks and create deliverables that met the client's needs in a timely manner. The plan divided the project into three phases, namely: database design, database implementation, and Web GIS deployment (Figure 3.2). The project plan outlined major milestones for each project phase and appropriate action based on the client's feedback. Approximately 750 hours were devoted to the implementation of this project, spread over a 40 week period. Figure 3.2 shows the implementation phases and the major tasks that were carried out in each project phase in detail. 


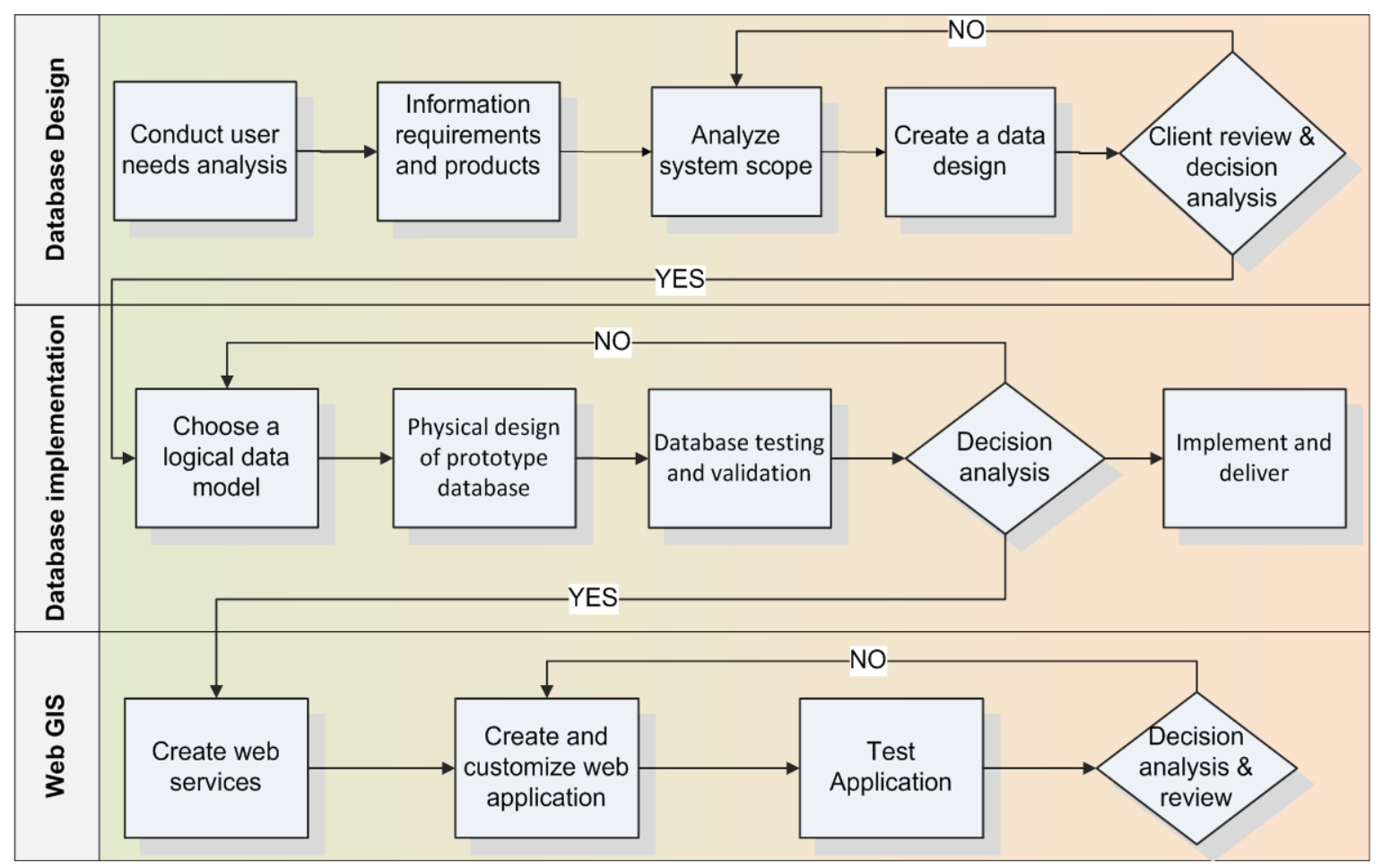

Figure 3.3: A workflow diagram of project implementation

\subsubsection{Database Design Phase}

This phase involved inception, conceptualizing, and creating a conceptual database design. A needs assessment provided the goals, objectives, and mandates of the organization and how GIS will fit into the overall organization's strategy. Interviews were conducted with potential GIS users to determine GIS requirements of the organization. The requirement analysis process produced an inventory of available data, a list of information products, information product description documents (IPDs), and a master input data list (MIDL). These phase deliverables determined the scope of the system and subsequently the database schema.

The requirement analysis process involved active participation of the client organization: the management staff, the GIS users in the monitoring and evaluation department, and field extension officers. Completion of the analysis led to creation of a database schema that was shared with the client for review. Getting feedback from the client affirming whether the organization's GIS expectations were met was the final step in this phase. With the client's approval, the project proceeded to the next implementation phase.

\subsubsection{Prototype Database Implementation Phase}

This phase required an informed choice of a logical data model was made. It involved reviewing of existing major approaches of relational, object-oriented, and semi objectrelational database design models. This was followed by development of a logical database design using the semi object-relational database design approach. This phase 
also entailed scrubbing and loading data into the database for testing and validation of the database. Tests for functional capabilities, logical relationships, feature behaviors, and design accuracies were conducted. Database logical design model and the physical database were the two main deliverables of this phase; they were reviewed and a decision reached before proceeding to the next phase. At the end of prototype database implementation phase, a prototype database was delivered to the client.

\subsubsection{Web GIS Application Development Phase}

Development and deployment of web mapping applications characterized this phase. The project determined the requirements of the client for internet-based access to spatial information. A review of available options for developing web applications determined the best approach. Web page design considerations ensured the development of an audience oriented easy-to-use application. This phase built interactive custom applications that allowed the client to create, share, and access data and information products over the web. The kinds of data and information products to be published online were carefully selected and were reviewed by the client. The review process was driven by restrictions on data use and the various data sources.

Testing of the Web GIS application subjected it to different browser conditions and bandwidth connectivity environments. The client played a key role in ensuring that the application met the requirements of the organization, and in providing the expectations of the target audience. These expectations drove the design and implementation of phase deliverables.

\subsubsection{Project Implementation Approach and Schedule}

This project adopted an agile life cycle framework for the implementation. Agile (or spiral) design of system implementation is an iterative system development approach where requirements and deliverables evolve through collaboration with the client. It is most appropriate when high risks exist in a project, as was in the case with this project. Project risks included limited time for carrying out the project, minimum web programming skills at project onset, and communication lag due to the remoteness of the client. The client's limited knowledge of the potential of GIS meant that project deliverables and objectives evolved as prototype versions and their potentials were demonstrated to him. This resulted in a rough start to get the first phase completed. With an agile approach, additional functionalities were added upon the client's reviews and as more project details were revealed. At least two prototypes were developed before creating the final operational prototype delivered to the client.

Due to constraints of available resources, project planning was an essential component in implementing this project. A project plan laid down at the planning stages before the initiation of the project helped to provide general guidance on allocating time and resources to produce project deliverables. The project was segmented into three main phases marked by major deliverables at the end. Time was the main resource for the project, thus the project plan revolved around it. This section discusses time variations between planned and actual time spent on projects as a result of unforeseen challenges and project implementation dynamics. 
The bulk of time resource was allocated to user needs analysis, design and implementation of the database, and documentation. This proportion of time allocation to individual tasks remained relatively constant through project execution; however, there were significant variations in times allocated to individual tasks. Table 3-4 gives a summary of anticipated and actual time allocations to various project tasks.

\section{Table 3-4: Projected time allocation versus actual time spent}

\begin{tabular}{|l|l|l|}
\hline Main project task & Projected time & Actual time \\
\hline $\begin{array}{l}\text { 1. User needs analysis and creation of } \\
\text { information requirements }\end{array}$ & $20 \%$ & $30 \%$ \\
\hline 2. Database design and implementation & $30 \%$ & $25 \%$ \\
\hline 3. Web mapping applications development & $10 \%$ & $15 \%$ \\
\hline 4. System testing and validation & $10 \%$ & $5 \%$ \\
\hline 5. Documentation and reporting & $20 \%$ & $15 \%$ \\
\hline 6. Satisfying academic requirements & $10 \%$ & $15 \%$ \\
\hline
\end{tabular}

In the course of implementing the project, the project plan was revised. This was done at the end of every phase of project implementation. Changes introduced to the plan were meant to accommodate unforeseen challenges, adjustments in project scope, and pace of execution as new skills were being acquired.

\subsection{Summary}

User needs analysis and creation of information requirements took the most time while implementing this project. This was partly due to GIS being a new technology to the organization, coupled with the remote location of the client. As a result, time spent on analysis of the user's requirements also increased as communication was often delayed. The client's requirements were first defined by carrying out a user needs analysis.

These requirements informed the process of determining the appropriate data model to be used to model the reality of carbon monitoring operations. System analysis and design process was a crucial stage in defining the overall outlook of the project to ensure that the system met the user's requirements.

Appropriate project management skills were vital in handling unforeseen risks and to deal with them accordingly. As the project progressed, with increasing understanding of project problems and revelations from user needs assessments, adjustments to scope were deemed necessary. Likewise, as project risks identified at project onset were being abated and with increasing experience over time, times spent on tasks were subject to variations. These changes were also a result of the agile project design approach that was used. The changes during project implementation necessitated continuous revision of the project plan. 


\section{Chapter 4 - Database Design}

An understanding of database design requirements was critical in deployment of the Web GIS project. This chapter describes in detail how the system was designed and implemented. It elaborates reasons for choosing the approach that was used in this project and illustrates how this approach best met the requirements of the client. The goals of database design for a GIS system were to:

- Meet the information content requirements of the client

- Provide a natural and easy-to-understand structuring of spatial and nonspatial information

- Support processing requirements and performance objectives that includes fast retrieval of data and effective utilization of storage space

The database design process was carried out through a series of steps:

- Requirements stage

- Conceptual database design stage

- Logical database design

- Physical database design

- Implementation and testing stage

At the requirement stage of the database design, user requirements analysis was carried out to quantify user's needs. The fundamental objective of this stage was to understand and identify information required from a GIS, as well as to identify GIS application and data requirements. The conceptual and logical database design stages involved building and testing a selected environment. This was based on the user's requirements identified through the GIS needs assessment. System deployment and prototype testing validated functional interfaces and performance metrics by ensuring that functions work and performance targets were met (Peters, 2008). After successful testing, the prototype database system was then deployed to the client. The performance and capacity of the database was demonstrated at this stage, while validating the approach used to ensure it supported full production deployment. Finally, the implementation stage put the database into use to prepare information products and support online services.

\subsection{Conceptual Data Model}

The goal of this stage in designing the database was to produce a conceptual database schema independent of a specific database management system (DBMS). The conceptual model developed was a DBMS-independent high-level data model due to the following reasons:

- The goal of a conceptual model is a complete understanding of database structure devoid of restrictions and influence of a specific DBMS.

- The conceptual schema should be a stable description of the database that is not subject to change whenever a decision to change a DBMS is made.

- Use of high-level models is more expressive and can be effectively communicated to database users, designers, and analysts. Conceptual models rely on concepts, are more exact and straightforward, and therefore easier to understand than lower-level DBMS-specific data (Elmasri \& Navathe, 2000). 
Many high-level conceptual models have been proposed for database design. In this project Unified Modeling Language (UML) was used to design a conceptual model of ViAFP's database. UML uses class diagrams that are based on extensions of the enhanced-entity relationship (EER) model. The UML design model depicts objects with a common notation that follow effective style guidelines, thus making it easy to understand, update, and maintain during system design. In this project UML class diagrams were used to show classes of the database, their interrelationships, the operations, and attributes of the classes. These class diagrams facilitate exploration of domain concepts, conceptual analysis, and depict detail design of semi object-relational database system (Ambler, 2005).

A conceptual domain model was created to represent classes and associated classes that describe the static structure of the Vi AFP database system (Figure 4.1). In UML, a modeling class is a template from which objects are instantiated; they represent entities with common characteristics. Classes define attributes, information that is pertinent to instances, and functionality that the objects support. Association classes in a model represent associations that have methods and attributes; they represent relationships that relate two or more classes.

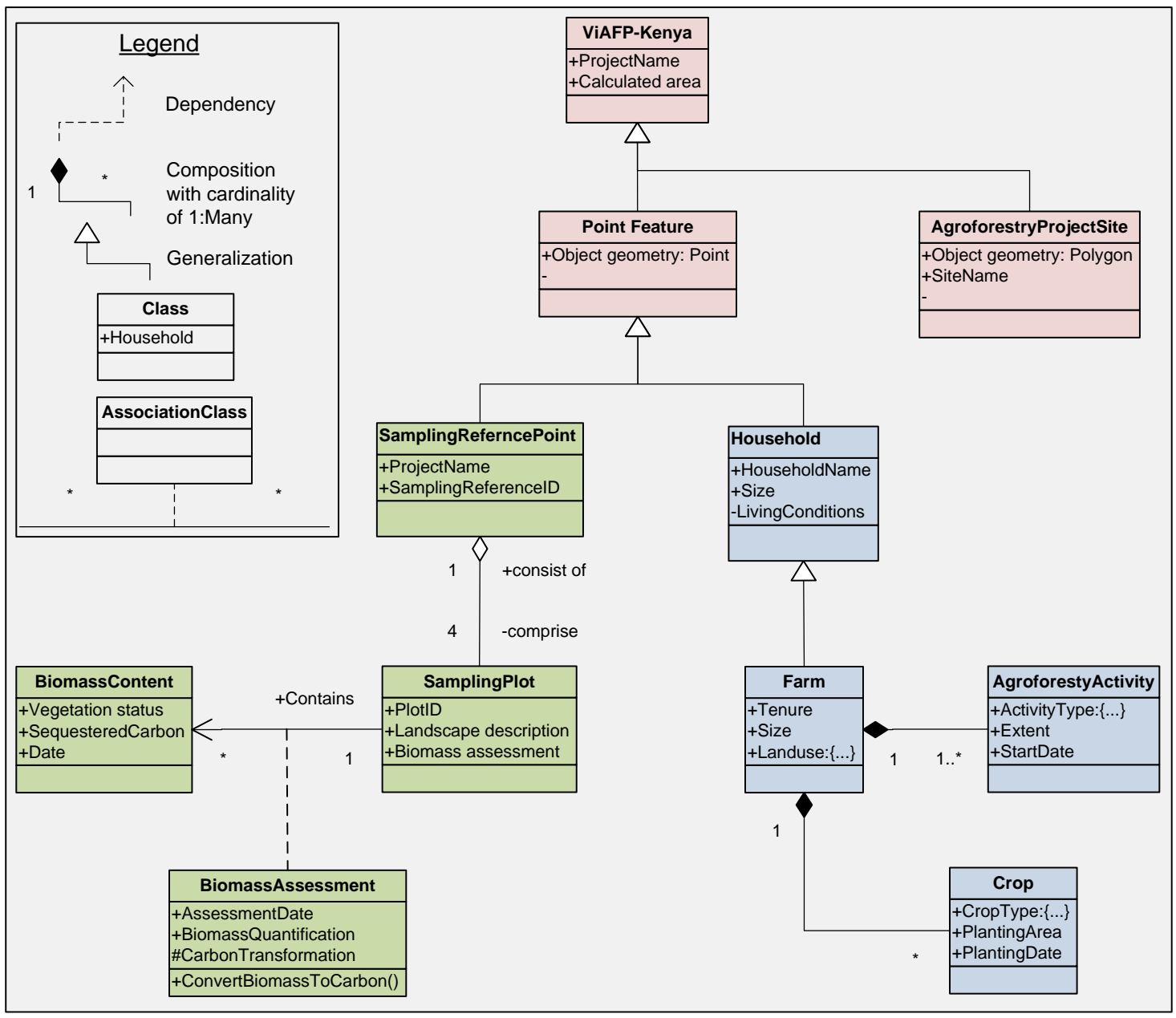

Figure 4.1 Domain UML Model of Agroforestry Activities 
Figure 4.1 shows a system of an agroforestry project implemented within a defined project site. The model is categorized into three main sections: abstract project classes (shaded in pink), agroforestry activities (shaded in blue), and carbon sequestration monitoring (shaded in green). ViAFP-Kenya is an abstract class that represents a project area. PointFeature is an abstract geometry class of point form while AgroforestryProjectSite is a geometry class of polygon form that defines the coverage of the project area. An agroforestry project area is a defined area that potentially qualifies for implementing carbon sequestration projects. Within a project area are project sites where project activities are carried out. Each project site is given a name and its extent is calculated in hectares. PointFeature defines a spatial element of point geometry type.

Household class describes the properties of a household and it inherits point geometry from PointFeature class. Household units within a project area can participate in the implementation of a project. Each household is identified by a household name and has attributes of population size, wealth status, and living conditions that are required in a monitoring system. Wealth status is defined based on indices of access to water, sources of income, and household savings. Farm object class represents farms owned by participating households which can implement agroforestry projects. The type of existing land use, ownership tenure, and size of land are attributes required by the system. At least one sustainable land management practice or agroforestry activity is practiced at every project farm. At least two or more crops can be planted on a farm as recommended by the Vi AFP. AgroforestryActivity class represents agroforestry activities, while Crop class represents recommended crops that are planted on participating farms. The composite relationships between Farm and AgroforestryActivity classes and Farm and Crop classes signify that an agroforestry activity or planted crops cannot exist without the existence of a participating farm.

The carbon sequestration monitoring section of the model has classes related to biomass/carbon monitoring. A defined project site has a set of reference cluster points established for monitoring and evaluation. SamplingReferencePoint class contains permanent sampling points of known point locations that form a monitoring framework. These points are identified by location geometry and a unique identifier. Each reference point location has four sampling plots associated with it (SamplingPlot class). These sampling plots are established at reference points. At every sampling plot, an assessment of biomass in a surrounding area of seven meter radius is also made and documented (BiomassAssessment class). Once biomass assessments have been carried out and recorded, a transformation to carbon is computed using a calibrated carbon calculation model. The conversion process gives the current status of vegetation and the amount of sequestered carbon at a given time.

\subsection{Logical Data Model}

\subsubsection{Choice of Data Model}

The objective of a logical data model is to describe a complex version of reality in a database. A logical data model of Vi AFP database systems was designed based on the conceptual data model developed earlier. Logical data models describe system elements, their design, and how they link to each other. Logical linkages are relationships required between data elements needed to produce identified information products. The project 
model was validated and approved to meet the actual reality of the client's project operations before it was developed into a physical database.

There are several ways by which to structure data according to the three major logical data models: relational, object-oriented, and object-relational. Each model affords certain desired and undesired characteristics when building a database. An evaluation of the three models was carried out in order to choose the one that would most effectively suit Vi AFP's project data requirements and the creation of information products. The choice of data model was governed by a number of factors which were broadly categorized as non-technical and technical. Non-technical issues include economic and organizational issues. Cost issues to consider are those related to acquisition/implementation, maintenance, data conversion, training, and operating costs. The technical issues that were considered in choosing the logical data model included:

- Data complexity

- Data volume

- Database integration

- Technical flexibility

\subsubsection{Data Report}

Below is a summary of the data sets that were used in the Vi AFP data model (Table 4-1). These data were identified through a user needs assessment and are required for producing information products needed. Data was categorized into thematic classes that would form datasets in a geodatabase.

Table 4-1: Summary of data used in the project

\begin{tabular}{|l|l|}
\hline Data set Category & Data set Names \\
\hline Agroforestry projects & $\begin{array}{l}\text { Agro-ecological zones, households, project sites, sample } \\
\text { plots, sampling reference points }\end{array}$ \\
\hline Hydrography & River basins, rivers, wetlands \\
\hline Biophysical data & Land use, soils data, vegetation cover \\
\hline Project indicators & $\begin{array}{l}\text { Living conditions, financial condition, agroforestry activities, } \\
\text { crop production, farm head, farm land, livestock husbandry, } \\
\text { on-farm tree cover }\end{array}$ \\
\hline Base data & Administrative boundaries, market centers, roads \\
\hline Raster data & Landsat satellite images of 1970, 1990, and 2000 \\
\hline
\end{tabular}

The Vi AFP is currently underway to collect carbon project monitoring data. A pilot project conducted produce sample data that was used for this project. A sample of 30 households was selected for the pilot process. The pilot process collected GPS locations of these households, project performance indicators, and administered a farmers self assessment questionnaires. The resulting information from this process was incorporated in this project to design the database and perform subsequent analysis. 


\subsubsection{Data Characteristics}

The following is a detailed description of data sets that were used in the Vi AFP database model. A description of type, geometry, available subtypes, the number of features per data set, the spatial extent, and a snapshot is provided in Table 4-2.

\section{Table 4-2: Data report}

\begin{tabular}{|c|c|c|c|c|c|c|}
\hline Object Class Name & Type & Geometry & Subtype & & \begin{tabular}{|l|l|} 
Total & Extent \\
\end{tabular} & Snapshot \\
\hline \multicolumn{7}{|l|}{ Agroforestry } \\
\hline AgroecologicalZones & Feature Class & Polygon & $\begin{array}{l}\text { Arid } \\
\text { Humid } \\
\text { Per arid } \\
\text { Per humid } \\
\text { Semi-arid } \\
\text { Semi-humid } \\
\text { Sub-humid } \\
\text { Transitional }\end{array}$ & \begin{tabular}{r|}
5 \\
16 \\
0 \\
1 \\
8 \\
15 \\
11 \\
16 \\
\end{tabular} & $72 \mid \begin{array}{l}611796.1951 \\
807028.1884 \\
-66536.898099 \\
168074.05859\end{array}$ & \\
\hline Households & Feature Class & Point & - & & \begin{tabular}{l|l}
0 & No Extent \\
\end{tabular} & - \\
\hline ProjectSites & Feature Class & Polygon & - & & $6 \quad \begin{array}{l}638909.7634 \\
677075.1054 \\
-44435.345695 \\
89327.839995\end{array}$ & $\begin{array}{l}8 \\
8 \\
8\end{array}$ \\
\hline SamplePlots & Feature Class & Point & - & & $1616 \mid$\begin{tabular}{l|l}
633606.5643 \\
673949.4061 \\
-42613.955806 \\
88098.81210007 \\
\end{tabular} & \\
\hline SamplingReference & Feature Class & Point & - & & $436 \mid$\begin{tabular}{l|l}
639336.0213 \\
673848.5568 \\
-42611.508093 \\
88000.623507
\end{tabular} & \\
\hline \multicolumn{7}{|l|}{ BaseData } \\
\hline AdministrativePlaces & Feature Class & Point & \begin{tabular}{|l} 
District headquarters \\
Divisional headquarters \\
Other \\
Province headquarters
\end{tabular} & \begin{tabular}{|r|}
64 \\
321 \\
5918 \\
8 \\
\end{tabular} & \begin{tabular}{|l|l|}
6311 & 605689.0532 \\
& 1488730.4009 \\
& -518394.6578 \\
585006.8798 \\
\end{tabular} & \\
\hline DistrictBoundary & Feature Class & Polygon & - & & \begin{tabular}{|l|l|}
70 & 601726.8639 \\
1493517.3946 \\
-520329.12209 \\
604915.6877 \\
\end{tabular} & \\
\hline KenyaBoundary & Feature Class & Polyline & - & & $1 \mid \begin{array}{l}601726.8635 \\
1493517.3946 \\
-520329.1219 \\
604915.6875 \\
\end{array}$ & \\
\hline MarketCenters & Feature Class & Point & - & & \begin{tabular}{l|l}
403 & 612783.0829 \\
795586.2278 \\
-62335.874705 \\
267487.5175
\end{tabular} & \\
\hline ProjectRegion & Feature Class & Polygon & - & & $1 \mid \begin{array}{l}609978.6452 \\
810612.7607 \\
-66833.016008 \\
295124.14991\end{array}$ & \\
\hline ProvinceBoundary & Feature Class & Polygon & - & & $8 \mid \begin{array}{l}601726.8639 \\
1493517.3946 \\
-520329.12209 \\
604915.6877\end{array}$ & \\
\hline
\end{tabular}




\begin{tabular}{|c|c|c|c|c|c|c|}
\hline Object Class Name & Type & Geometry & Subtype & & \begin{tabular}{|l|l|} 
Total & Extent \\
\end{tabular} & Snapshot \\
\hline Roads & Feature Class & Polyline & $\begin{array}{l}\text { Other roads } \\
\text { Road Class A } \\
\text { Road Class B } \\
\text { Road Class C } \\
\text { Road Class D } \\
\text { Road Class E } \\
\end{array}$ & \begin{tabular}{|r|}
1056 \\
89 \\
54 \\
176 \\
316 \\
701
\end{tabular} & \begin{tabular}{|l|l|}
1 & 618982.3111 \\
& 809180.1147 \\
& -65133.0961 \\
& 281345.6098 \\
\end{tabular} & \\
\hline \multicolumn{7}{|l|}{ BiophysicalData } \\
\hline LandUse & Feature Class & Polygon & - & & $754 \mid \begin{array}{l}616557.0422 \\
810612.7607 \\
-66833.016 \\
295124.1499\end{array}$ & \\
\hline Soils & Feature Class & Polygon & - & & 0|No Extent & - \\
\hline VegetationCover & Feature Class & Polygon & F & & \begin{tabular}{l|l|}
0 & No Extent \\
\end{tabular} & - \\
\hline \multicolumn{7}{|l|}{ Hydrography } \\
\hline Riverbasins & Feature Class & Polygon & - & & \begin{tabular}{l|l|}
0 & No Extent \\
\end{tabular} & - \\
\hline Rivers & Feature Class & Polyline & \begin{tabular}{|l|} 
Ditches \\
Irrigation canal \\
Permanent river \\
Seasonal river
\end{tabular} & $\begin{array}{l}0 \\
0 \\
0 \\
0\end{array}$ & 0 No Extent & - \\
\hline Wetlands & Feature Class & Polygon & - & & \begin{tabular}{l|l|}
0 & No Extent
\end{tabular} & - \\
\hline \multicolumn{7}{|c|}{ Stand Alone Object Class } \\
\hline AgroforestryActivity & Table & - & - & & \begin{tabular}{l|l} 
No Extent \\
\end{tabular} & - \\
\hline CropProduction & Table & - & - & & 0 No Extent & - \\
\hline FarmHead & Table & - & - & & \begin{tabular}{l|l|}
0 & No Extent \\
\end{tabular} & - \\
\hline FarmLand & Table & - & F & & \begin{tabular}{l|l|}
0 & No Extent \\
\end{tabular} & - \\
\hline FinancialCondition & Table & - & - & & 0 No Extent & - \\
\hline LivestockHusbandry & Table & - & - & & 0 No Extent & - \\
\hline LivingConditions & Table & - & - & & \begin{tabular}{l|l|}
0 & No Extent \\
\end{tabular} & - \\
\hline OnFarmTrees & Table & - & - & & \begin{tabular}{l|l}
0 & No Extent \\
\end{tabular} & - \\
\hline
\end{tabular}

\subsection{Elements of a Logical Data Model}

A GIS database is founded upon the geographic representation of individual entities using defined data structures e.g. points, lines, polygons, tables, and raster. This section discusses constituent elements of the project's semi object-relational data model. The data model designed for the Vi AFP represents an ordered collection of database elements and the relationships and rules that govern the behavior of data in a database. This data model comprises a logical arrangement of feature classes, feature datasets, raster datasets, tables, topologies, and relationships (Figure 4.2). These elements are managed by a SQL server relational database system and adhere to the International Organization for Standardization (ISO)/Open Geospatial Consortium (OGC) simple features specifications. 


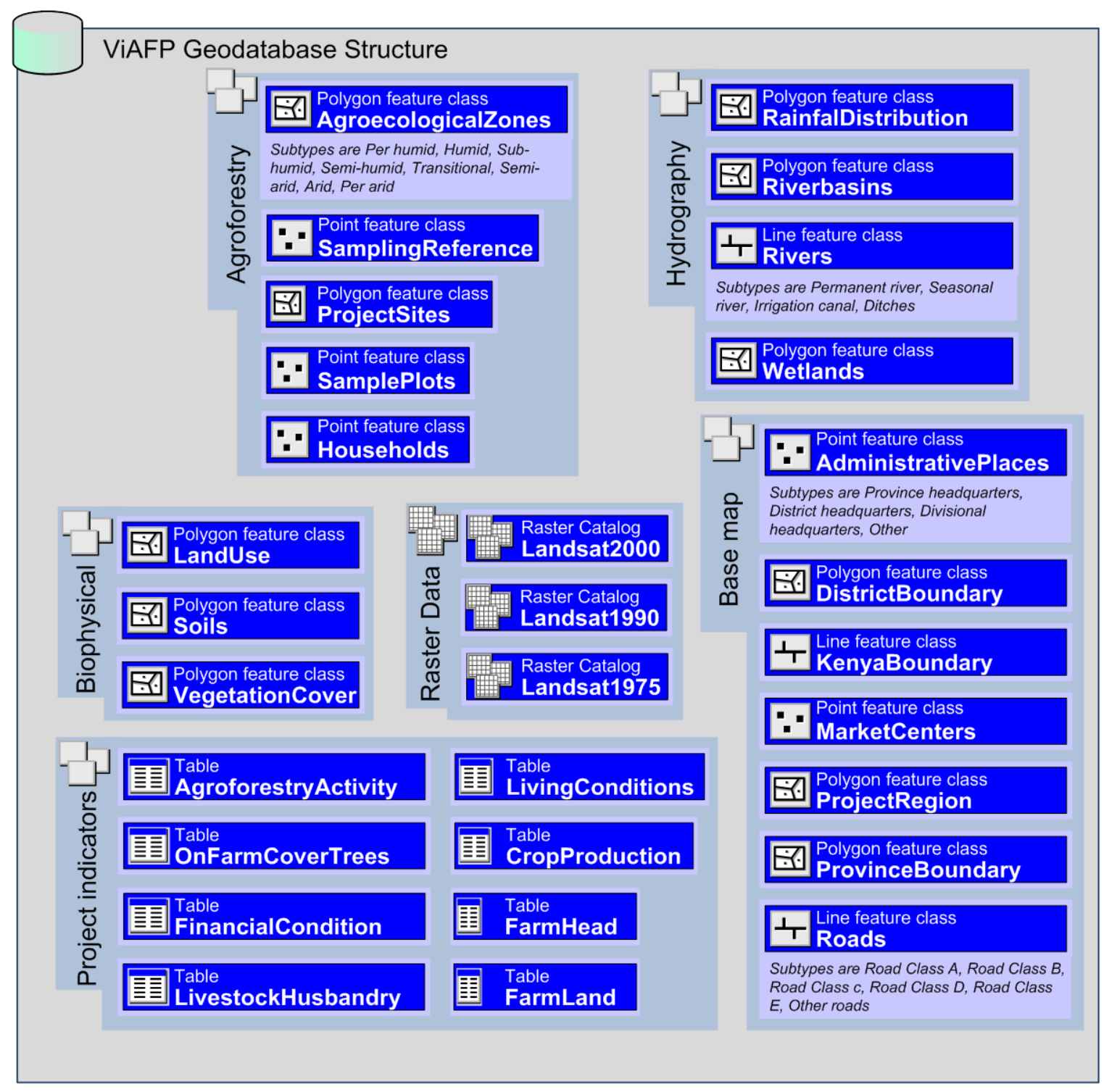

\section{Figure 4.2: Geodatabase Structure of the Vi AFP}

The fundamental elements used to build the Vi AFP database included feature classes, database tables, feature datasets, relationships, domains, and raster catalogs (Figure 4.3). A convention was adopted to use "ID" as a unique identifier attribute of the tables and feature classes. In logical relationships, this ID field also functions as either the primary key of the origin class (ID) or the foreign key of a destination class (_ID). 


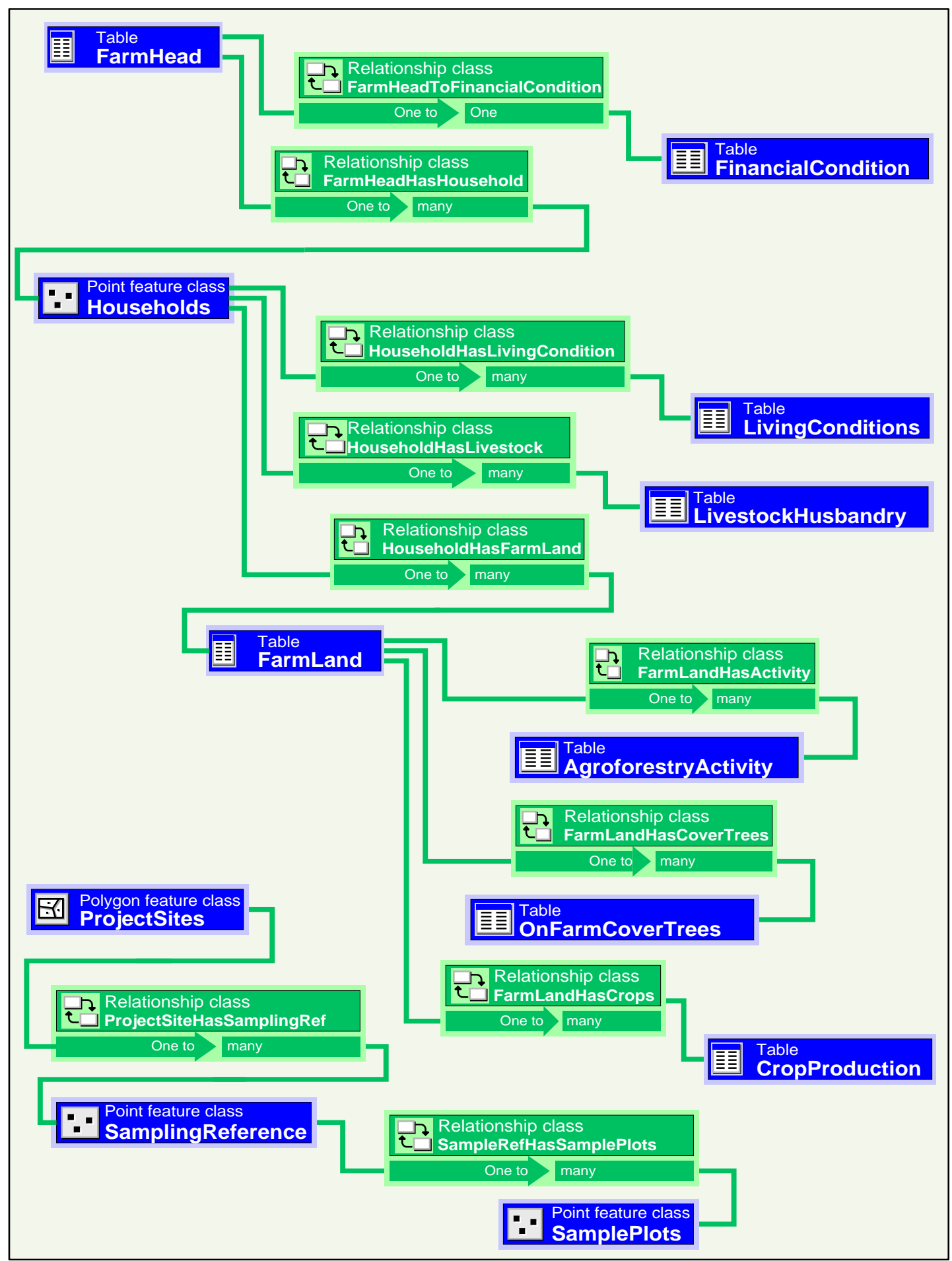

Figure 4.3: A section or the Vi AFP data model showing logical relationships

A feature class is a collection of features representing the same geographic elements that have similar spatial representation of points, lines, or polygons; and share a common set of descriptive attributes. It is represented as a table with a Shape field. Database tables are a collection of rows, each containing the same fields. Tables do not contain spatial 
attributes. Feature datasets are organized collections of related feature classes, organized for purposes of managing spatial relationships among related feature classes. Spatial relationships associate objects from a feature class or table to objects in another feature class or table. Relationships have cardinalities, rules, message directions, and other userdefined attributes. Domains are used in a database to define a set or range of valid values that a field can store. Spatial topologies define how integrated features share geometry and control their integrity through rules and editing behavior. A raster catalog is a collection of raster data sets defined in a table in which each record on the table represents an individual raster data set in the catalog. They are used to hold a time series of images which may have varying coordinate system at a time.

\subsubsection{Agro-Ecological Zones}

The AgroecologicalZones feature class (Figure 4.4) represents the agro-ecological zones into which a project area falls. These zones are derived based on temperature belts (maximum temperature limits within which the main crops of Kenya can flourish) and the main ecological zones (regions with probability of meeting the temperature and water requirements of the leading crops, i.e. the climatic yield potential). The purpose of this data set is to provide a framework for ecological land-use potential.

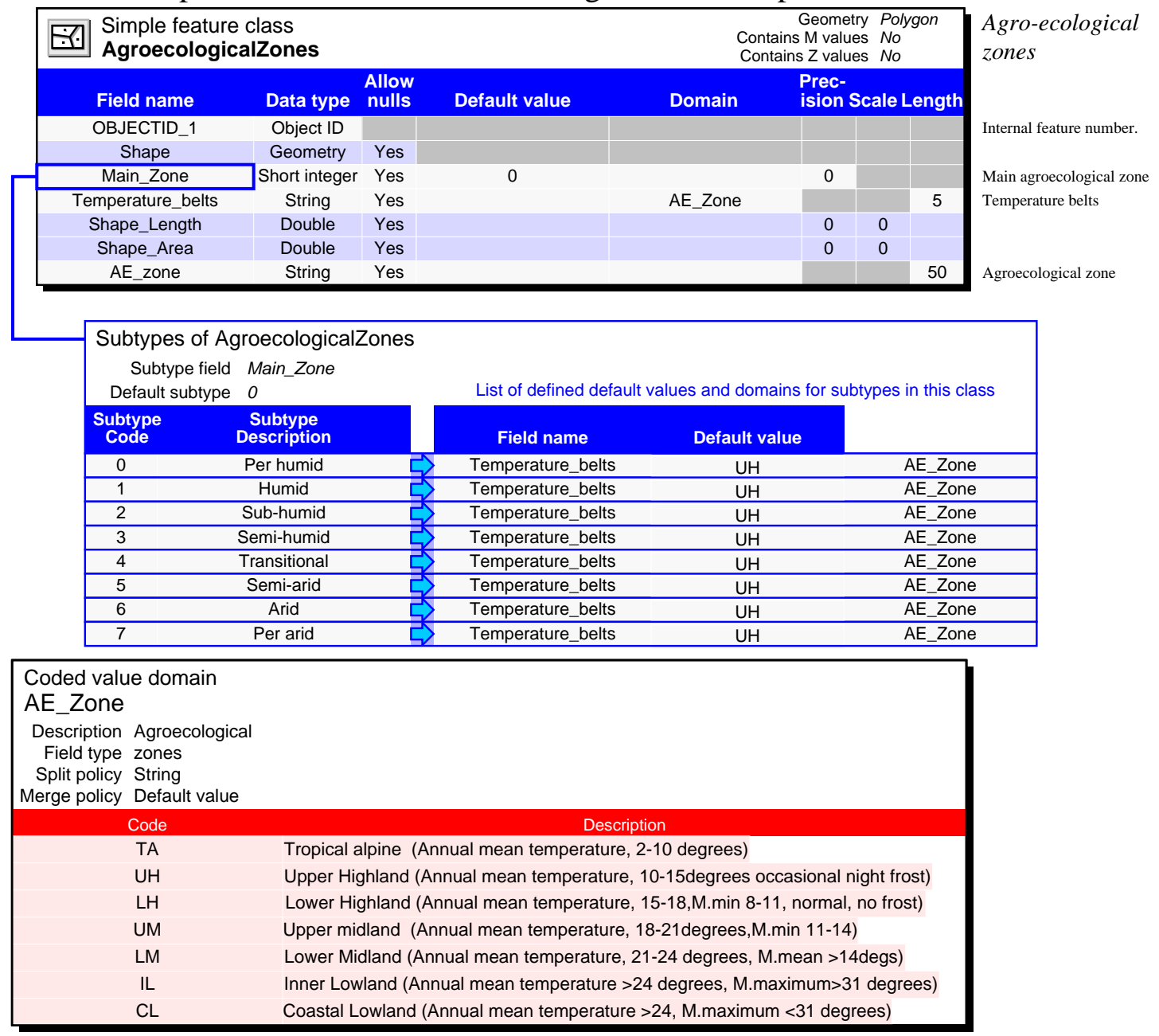

Figure 4.4: An instance diagram of AgroecologicalZones feature class 
This feature class is required to stratify potential project areas into respective agroecological zones to allow for accurate calculation of carbon pools. It is used in preparation of stratified Sustainable Land Management (SLM) Activity maps. Agroecological zones data are also useful in the calculation of baseline biomass and in modeling predicted carbon sequestration potential of a given area.

\subsubsection{Project Sites and Sampling Reference Points}

The ProjectSites feature class contains information about areas where agroforestry projects are undertaken (Figure 4.5). The Vi AFP has five project sites delineated for the purposes of administration and carbon monitoring. The boundaries are derived from administrative divisional boundaries.

\begin{tabular}{|c|c|c|c|c|c|c|c|c|c|}
\hline$\because$ & \multicolumn{4}{|c|}{$\begin{array}{l}\text { Simple feature class } \\
\text { ProjectSites }\end{array}$} & $\begin{array}{c}\text { Contains } \\
\text { Contains }\end{array}$ & $\begin{array}{l}\text { Geome } \\
\text { s M valu } \\
\text { s Z valu }\end{array}$ & \multicolumn{2}{|c|}{$\begin{array}{l}\text { Polygon } \\
\text { No } \\
\text { No }\end{array}$} & \multirow[t]{3}{*}{$\begin{array}{l}\text { Boundary location o } \\
\text { project activity area }\end{array}$} \\
\hline & Field name & Data type & $\begin{array}{l}\text { Allow } \\
\text { nulls }\end{array}$ & $\begin{array}{c}\text { Default } \\
\text { value }\end{array}$ & Domain & $\begin{array}{l}\text { Prec- } \\
\text { ision }\end{array}$ & icale & Length & \\
\hline & OBJECTID & Object ID & & & & & & & \\
\hline & Shape & Geometry & Yes & & & & & & \\
\hline & ProjSiteID & String & Yes & & & & & 10 & Project site unique identifier \\
\hline & SiteName & String & Yes & & & & & 20 & Site name \\
\hline & Shape_Length & Double & Yes & & & 0 & 0 & & \\
\hline & Shape_Area & Double & Yes & & & 0 & 0 & & \\
\hline
\end{tabular}
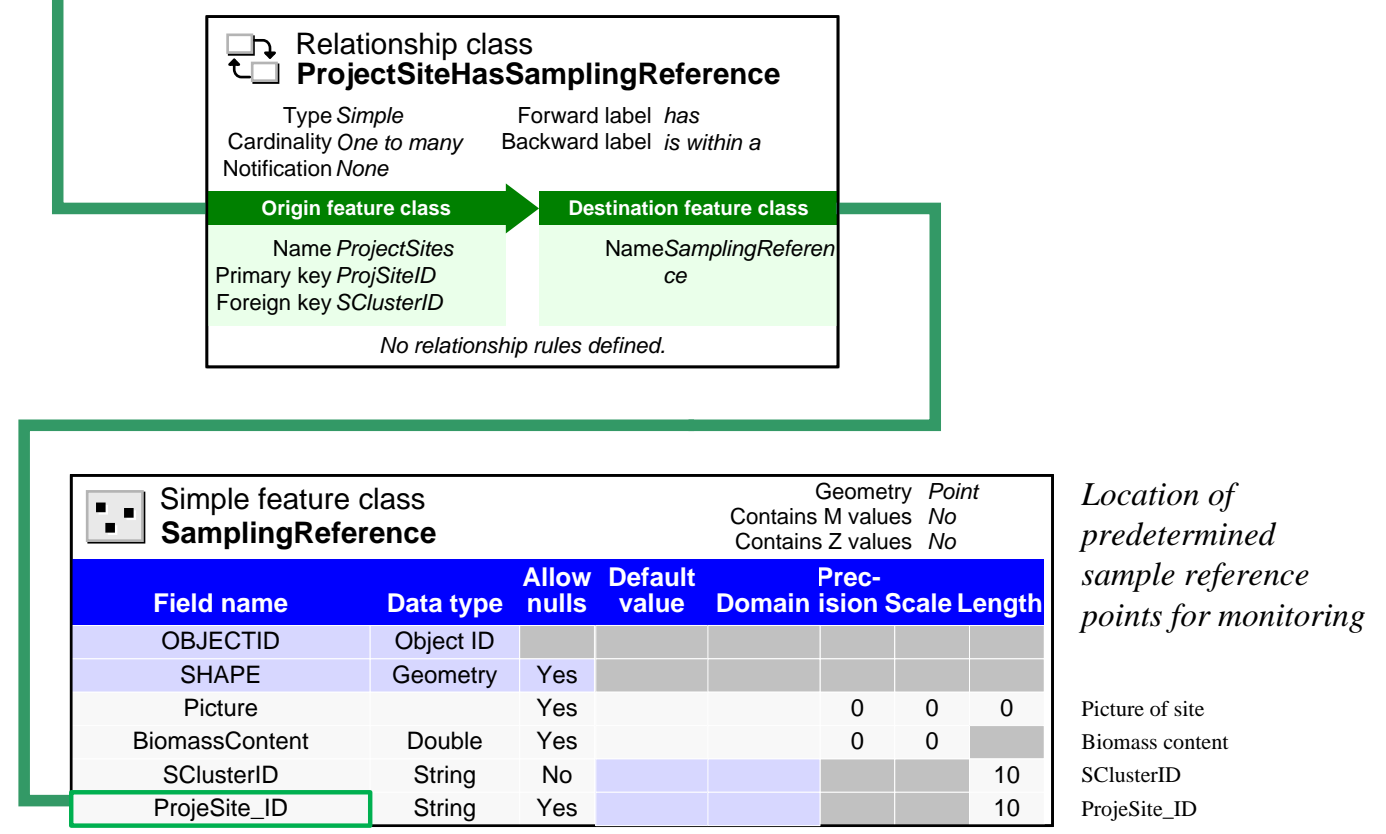

Figure 4.5: Instance diagrams of the relationship between project sites and sampling reference points

Reference sampling points (SamplingReference) are generated within a project site. These are systematic random points on which project monitoring and assessment will be based throughout the project cycle. They are arbitrarily located, and with a density of one mile apart. The class has a raster field that stores pictures (Picture) of sampling locations taken during field visit. The pictures ascertain the vegetation condition of the area during 
the time of monitoring. BiomassContent field represents a summation of biomass content in cubic meters of the associated permanent sample plots.

A one-to-many relationship exists between a project site and sampling points; a project site may contain one or many reference sampling points. The ProjectSiteID is the primary key of origin class (ProjectSite) that is used to link with a foreign key, ProjectSite_ID, of destination class (SamplingReference).

\subsubsection{Permanent Sampling Plots}

SamplePlots is a feature class of point locations of permanent sampling plots that are established during a biomass assessment process. Vegetation coverage of a plot is assessed in order to quantify the amount of biomass within a radius of seven meters around the plot (BiomassContent). The biomass content is later converted to equivalent carbon based on a carbon model. During the field measurement process, remarks on the condition and location information of the plots are made and stored in the class as Remark (Figure 4.6).

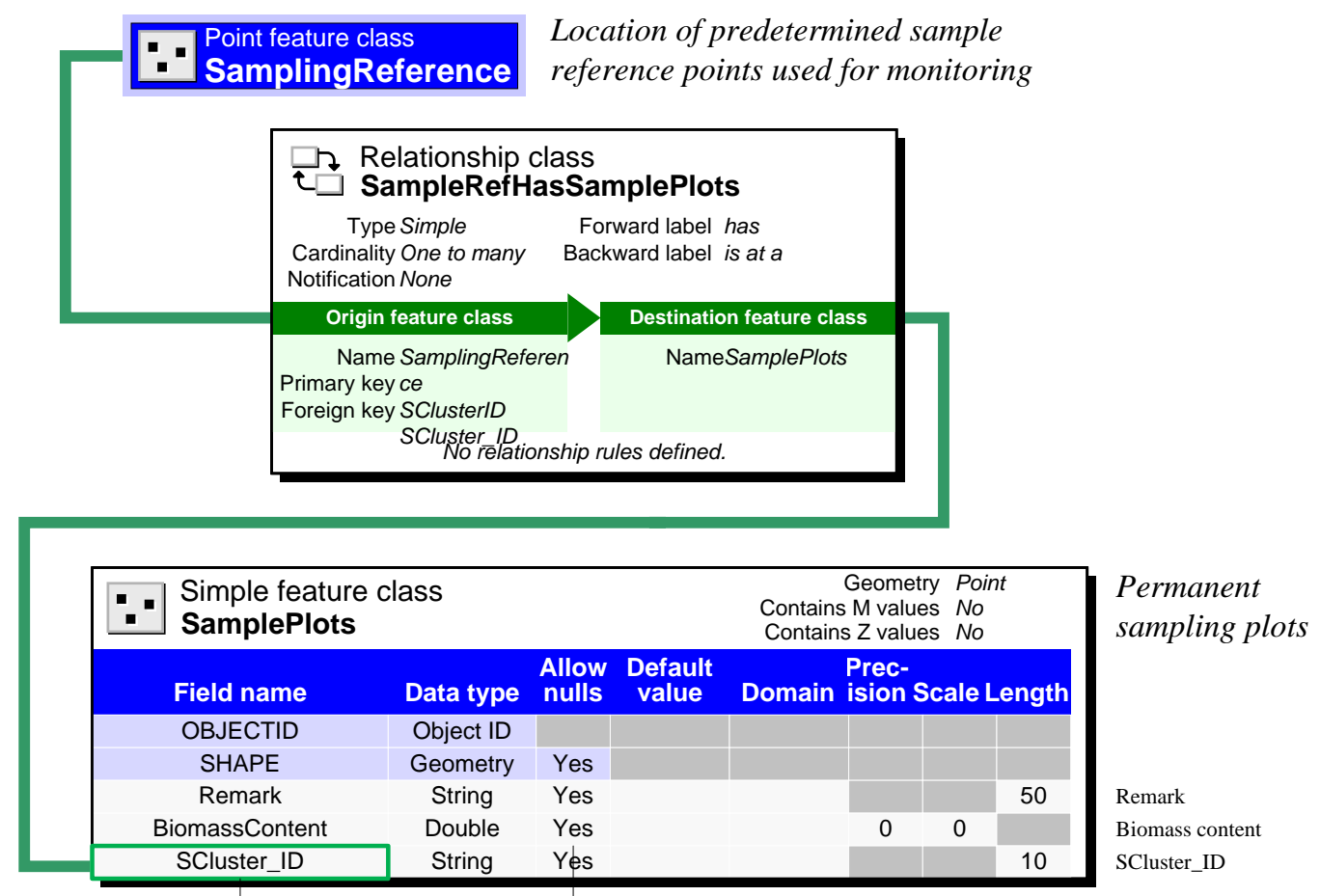

Figure 4.6: Permanent sampling plots feature class

Permanent sample plots are established around a sampling reference point. At each sampling reference point, four permanent sampling plots are laid with one being at the location of a reference sample point. The plots are 100 meters apart in the north-eastsouth order of direction beginning at a sampling reference point. The SClusterID and SCluster_ID are used as primary and foreign keys respectively to relate the SamplingReference feature class to the SamplePlots feature class with a one-to-many relationship. 


\subsubsection{Households}

The Households feature class is a key element on the database on which most project information is based and forms the granular unit for project monitoring and evaluation. This feature class defines the point location of households that are participating in the agroforestry project and own land. It gives a description of the conditions and structure of a household (Figure 4.7). Household are described by attributes of the family name (HouseholdName), number of members above and below the age of 18 years (Above18Yrs, Below18Yrs), and the total number of members (Size).

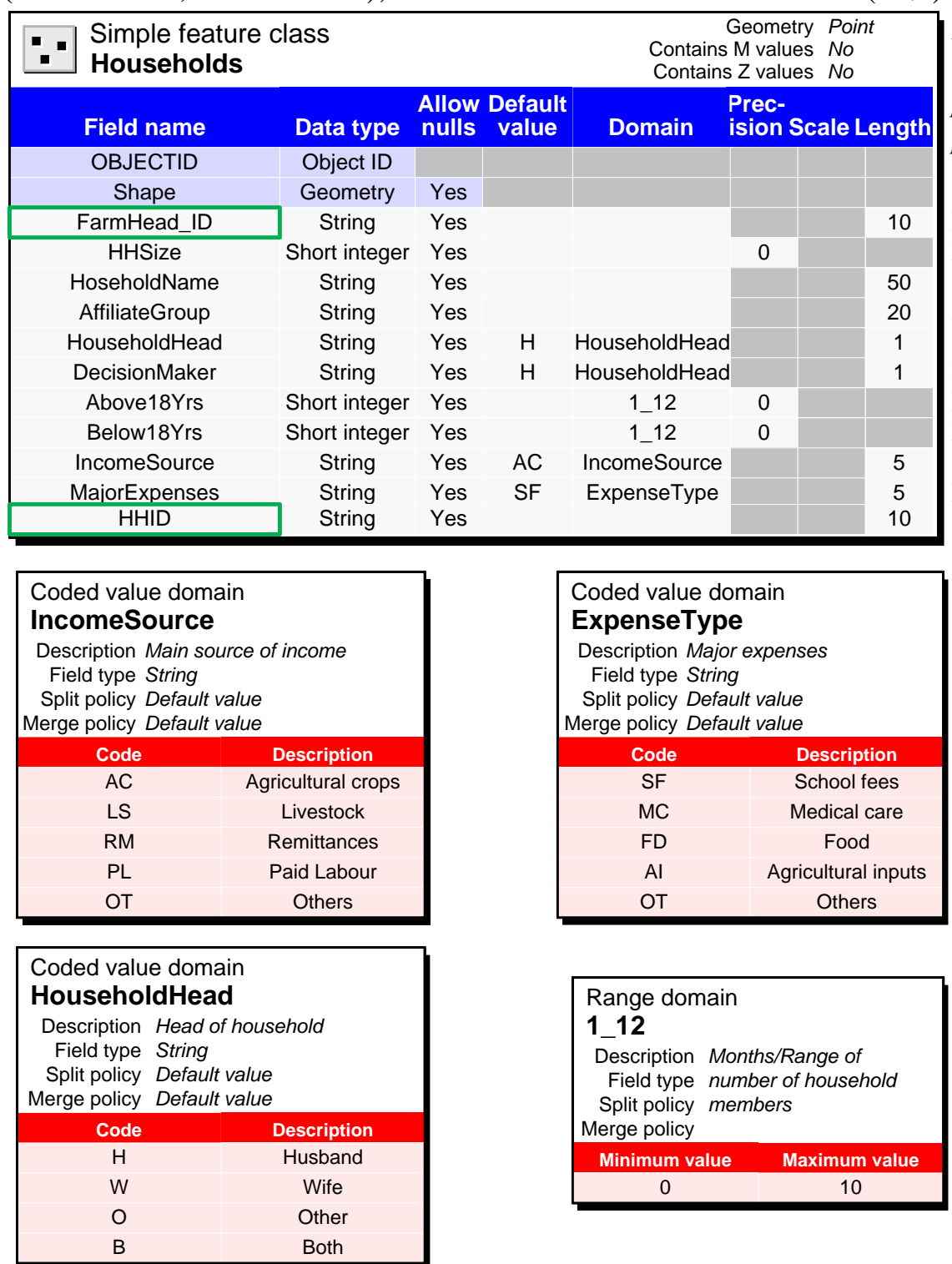

Figure 4.7: Household feature class and its domain tables

Other Households attributes are: the head of the household (HouseholdHead), the decision maker (DecisionMaker), major sources of income (IncomeSource), and the main household expenditure (MajorExpenses). Within the structure the Vi AFP projects, a 
household is a member of a group that is instrumental when administering trainings and evaluating projects. This is stored as an AffiliateGroup feature class attribute. Selected common sources of income and main types of household expenditure are considered in the carbon monitoring process. These selections are represented in the IncomeSource and ExpenseType domains. The Householdhead coded value domain defines the possible head of a household, whereas the 1_12 range domain specifies the range from which the number of family members is picked.

\subsubsection{Farm Land}

FarmLand is a database table with information on farms on which crops are planted and agroforestry practices are being practiced. These are farms owned by households participating in the Vi AFP agroforestry practices. The FarmLand table describes the type of land tenure (LandTenure), whether if it is individual ownership, family ownership, or lease (Figure 4.8). This ownership information is obtained from a domain list (LandTenure coded value domain) associated with the LandTenure attribute field. The coverage of major land uses within the farm land, and the total farm size are also recorded in acres (AgriculturalLand, Rangeland, Settlement, Otherareas). The major land uses are categorized as range land, settlement, and other land uses. The total acreage of land is stored in the TotalAcreage attribute field.

FarmLand table is related to OnFarmCoverTrees, CropProduction, and AgroforestryActivity tables (Figure 4.8). The three relationships have a cardinality of oneto-many. Trees, crops, and agroforestry activities are grown and practiced on farm lands; without farmlands these activities cannot exist. Therefore the relationship to these three tables with the FarmLand table is of a composite type. 


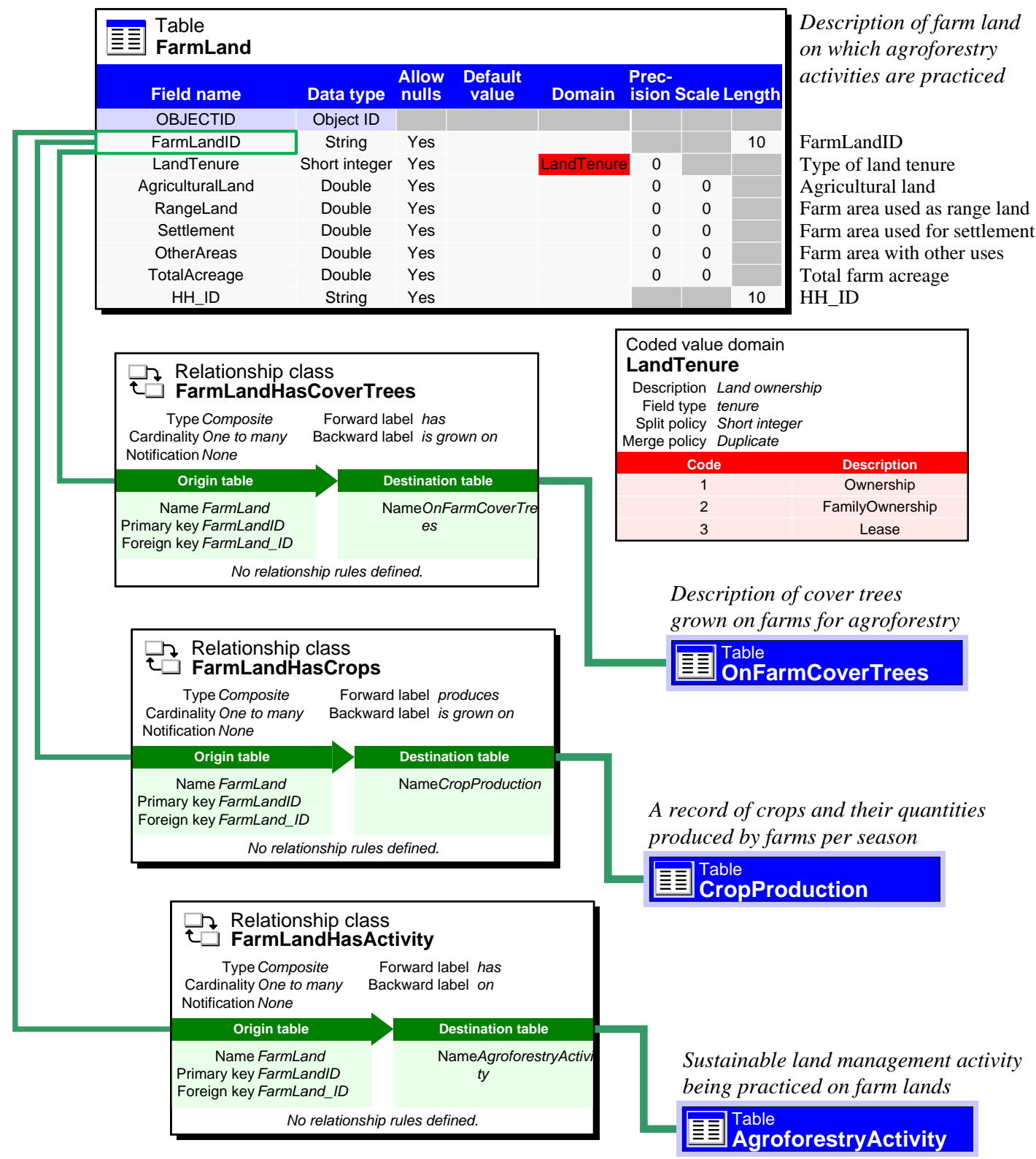

Figure 4.8: FarmLand class and related features

\subsubsection{Agroforestry Activity}

The AgroforestryActivity table describes the sustainable agroforestry activities practiced and monitored at a farm participating in the project (Figure 4.9). It consists of a crop composition scenario (Scenario) where a combination of specific crops is grown on a farm. Scenarios of the project are confined in a CropCompositionScenario domain table. The table indicates whether the various types of agroforestry activities, including reduced tillage, removal of residue, grazing of livestock, composting livestock manure, mulching, multi-cropping, intercropping, terracing, and green manure fallowing, are practiced at a farm, or not. This is indicated using a yes/no $\left(Y \_N\right)$ coded value domain. The type of crops used for fallowing are also selected from GreenManureCrop domain based on 
either recommended or commonly used crops within the project area. The length extent of terraces (TerracingLength) and the area of grazing livestock (GrazingArea) are also stored in the AgroforestryActivity database table.

The brand of nitrogen-phosphorous-potassium (NPK) fertilizers used to grow crops is described by the NPKFertilizerBrand attribute that has a coded value domain of the commonly used brands (NPKFertilizerBrand coded value domain). The quantity used in a growing season is stored as NPKQuantity. A relationship between Farmland and AgroforestryActivity exists to describe that one or more agroforestry activities can be practiced on a given farm.

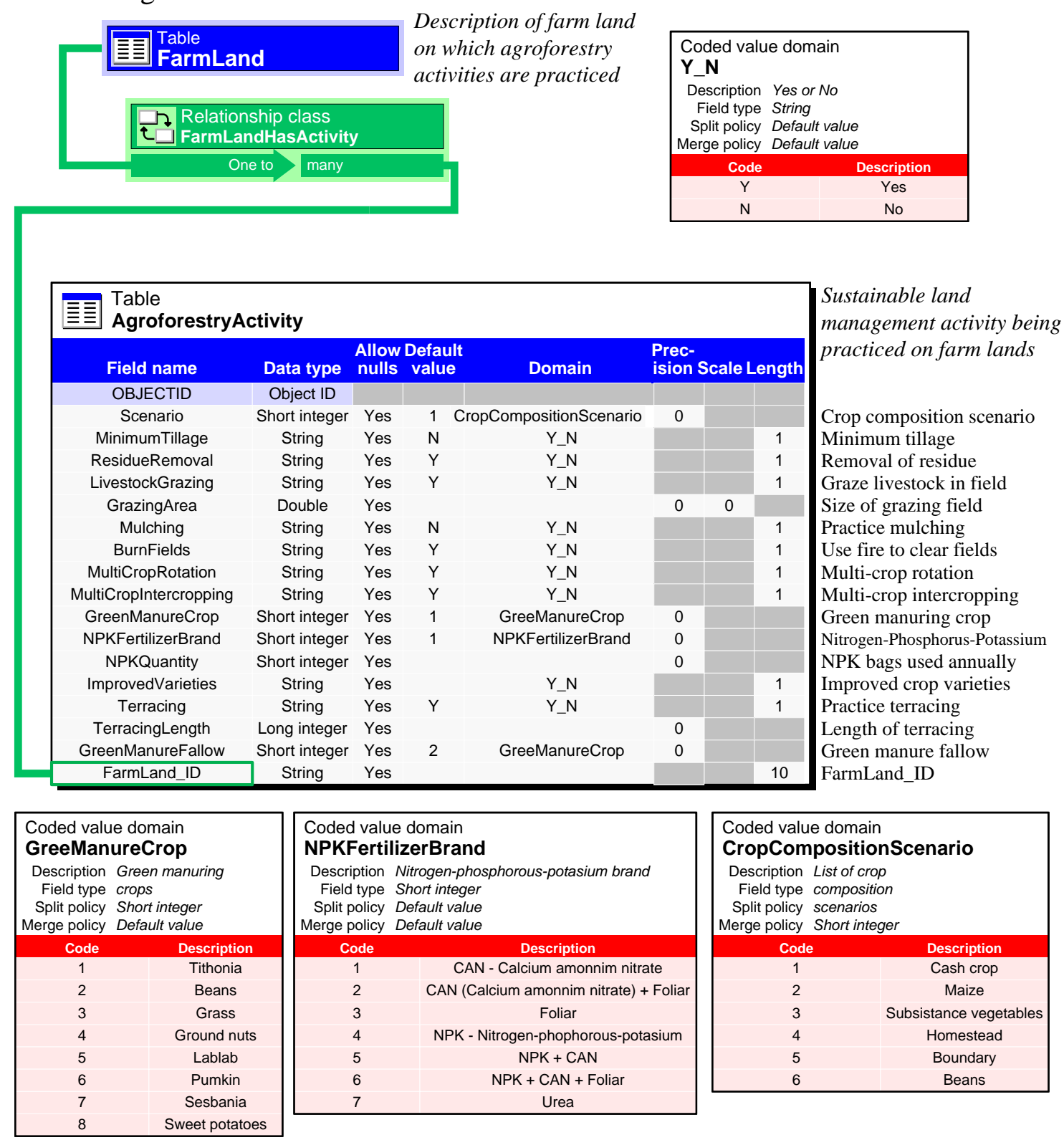

Figure 4.9: AgroforestryActivity table, domains, and it's relation to farm land 


\subsubsection{Crop Production and On-Farm Trees}

The CropProduction and OnFarmTrees (Figure 4.10) database tables contain descriptions of agroforestry crops produced, and trees grown on farms. These tables are used to keep track of the amount of harvests per season through the project time life.

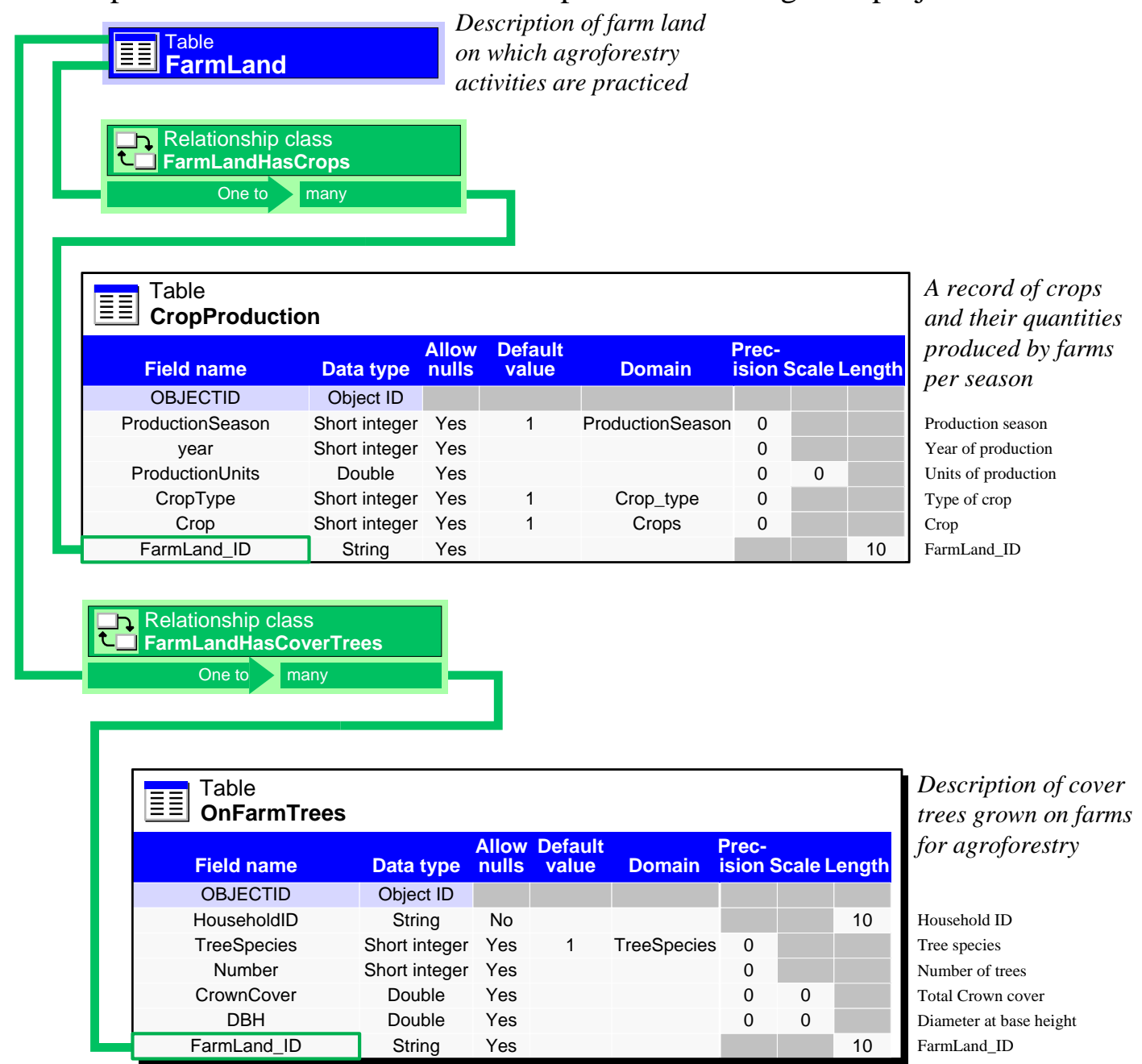

Figure 4.10: Crop production and on-farm trees database tables and their relation to farm land

The CropProduction table defines the name of crop and the type of crop by domain tables (Crop and CropType coded value domains) shown in Figure 4.11. CropType is categorized according to biomass potential and defined carbon pools on which the project is based. The CropProduction table also contains attributes describing the year (Year), the amount of produce harvested (ProductionUnits) and the season of harvesting (ProductionSeason) that have a coded value domain shown in Figure 4.11. The OnFarmTrees database table describes agroforestry trees grown on the farm land. Information on the tree species (TreeSpecies) and how many they are (Number) is stored in the table. Trees are described by the dimension of crown cover in meters (CrownCover) and diameter of the trunk measured at base height, measured in 
centimeters $(D B H)$. Based on the unique identifier of FarmLand_ID, a foreign key, CropProduction and OnFarmTrees tables are related to FarmLand database table.

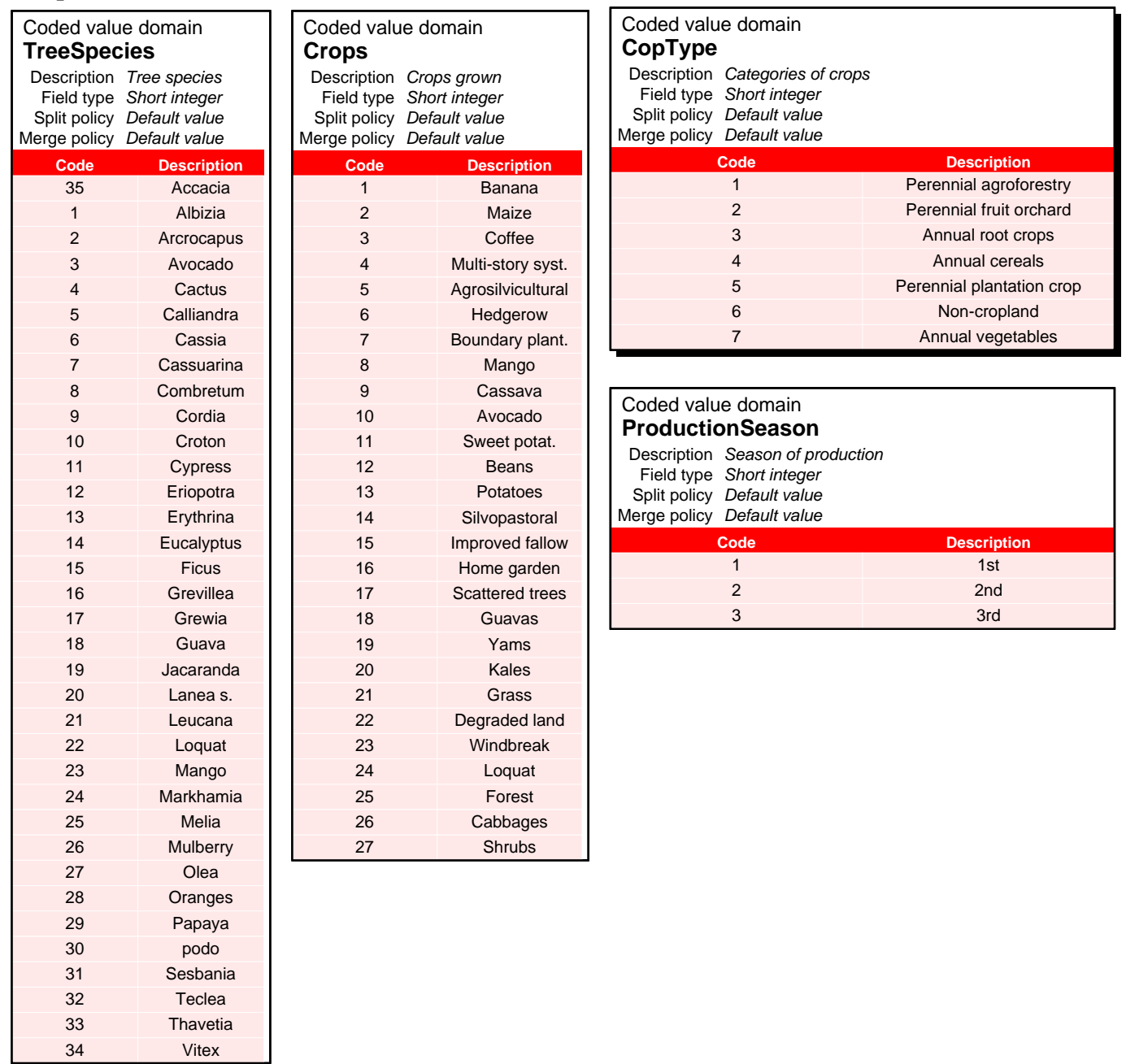

Figure 4.11: Domains of crops, tree species, and production season

\subsubsection{Farm Head and Financial Condition}

The FarmHead table contains information on a household head used as performance indicators of project impacts on financial and social condition of farmers. A description is given by age, sex, marital status, occupation, and education level (Figure 4.12). Selected common occupations and education levels are stored in domain tables. 


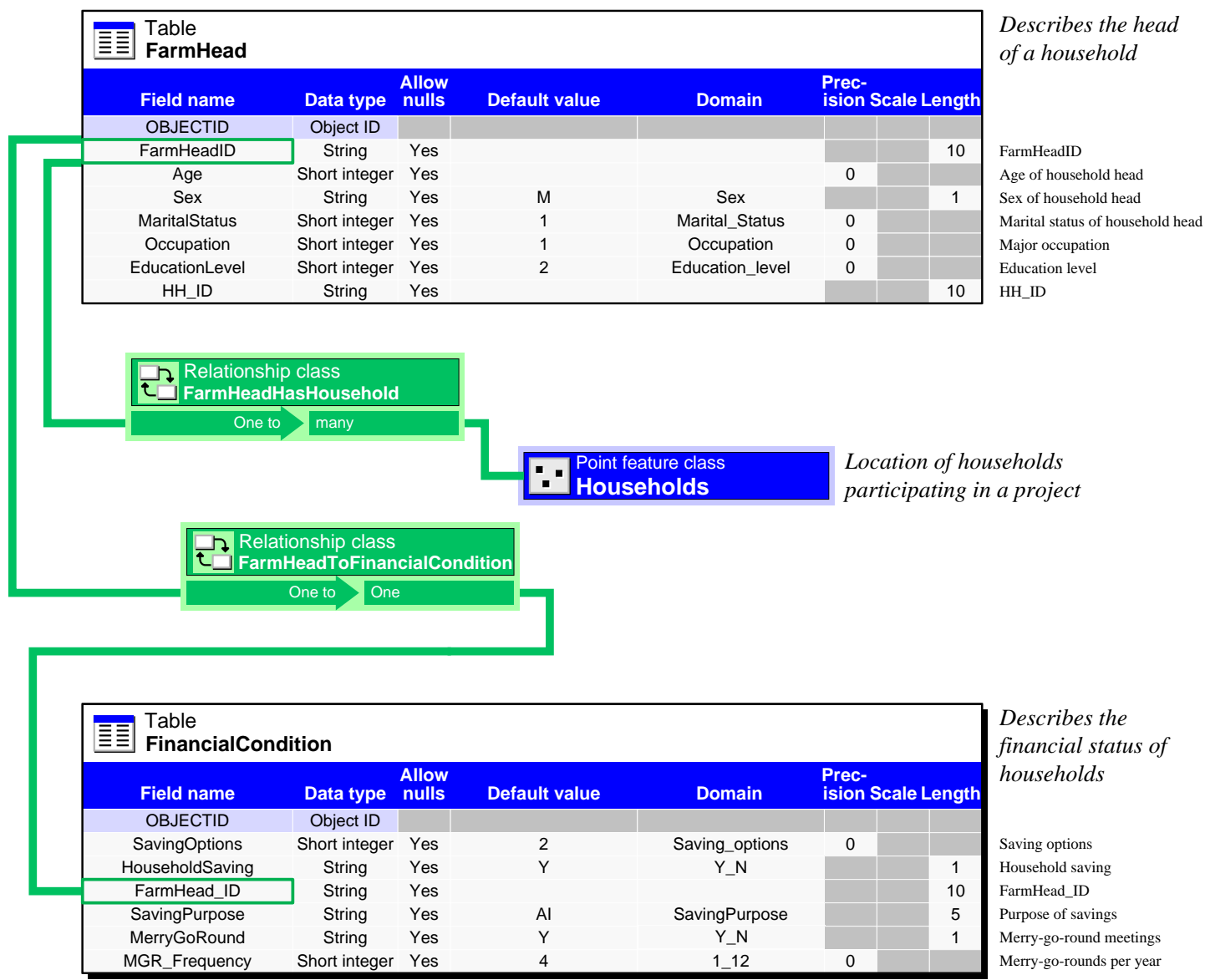

Figure 4.12: Instance of FarmHead data base table and its relationships with Households and FinancialCondition tables

The FinancialCondition table (Figure 4.12) describes the financial status of the household head. The attribute describes whether the head is saving for the household (HouseholdSaving), the purpose of savings (SavingPurpose), and options of how the savings are made (SavingOptions). Merry-go-round projects (MerryGoRound), where farmers pool together a sum of money that is given to one individual member of the group at a time, are recorded if the famer is participating. The frequency at which money is pooled to an individual per year is also recoded (MGR_Frequency). The financial condition of the head of a household is representative of that of the household and therefore a one-to-one relationship exists between the FarmHead and FinancialCondition database tables. The Farmhead table also has a one-to-many relationship with the Households feature class so as to accommodate cases of polygamous households.

Saving options available to farmers in the ViAFP project are contained in a domain table, Saving_options (see Figure 4.13). Similarly, main purposes for making savings and the frequency at which merry-go-rounds occur per year are contained in domain tables associated with FinancialCondition table. 

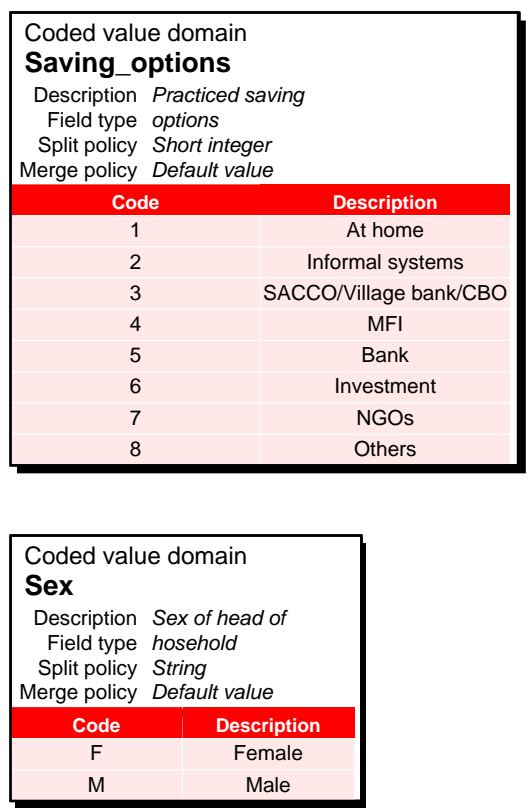

Coded value domain

SavingPurpose

Description Purpose for saving

Field type String

Split policy Default value

Merge policy Default value

\begin{tabular}{|c|c|}
\hline Code & Description \\
SF & School fees \\
Al & Agricultural inputs \\
LS & Livestock \\
LD & Land \\
CG & Consumer goods \\
EC & Enterprise capital \\
OT & Other \\
\hline
\end{tabular}

Coded value domain

Education_level

Description Education attained by

Field type household head

Split policy Short integer

Merge policy Default value

\begin{tabular}{|cc|}
\hline Code & Description \\
\hline 0 & None \\
1 & Primary \\
2 & Secondary \\
3 & Tertiary \\
\hline
\end{tabular}

Coded value domain

Marital_Status

Description Marital status

Field type Short integer

Split policy Default value

Merge policy Default value

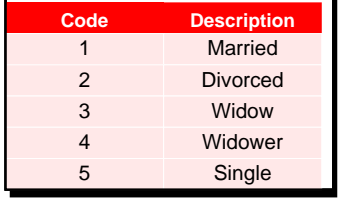

Single

Figure 4.13: Domain tables associated to FarmHead and FinancialCondition database tables

\subsubsection{Living Conditions}

The LivingConditions table shown in Figure 4.14 describes the living conditions of household and its wealth status. This information is important for monitoring the impact of implementing sustainable agroforestry projects on living conditions. This is based on the housing structure, availability of clean water, and food sufficiency. 


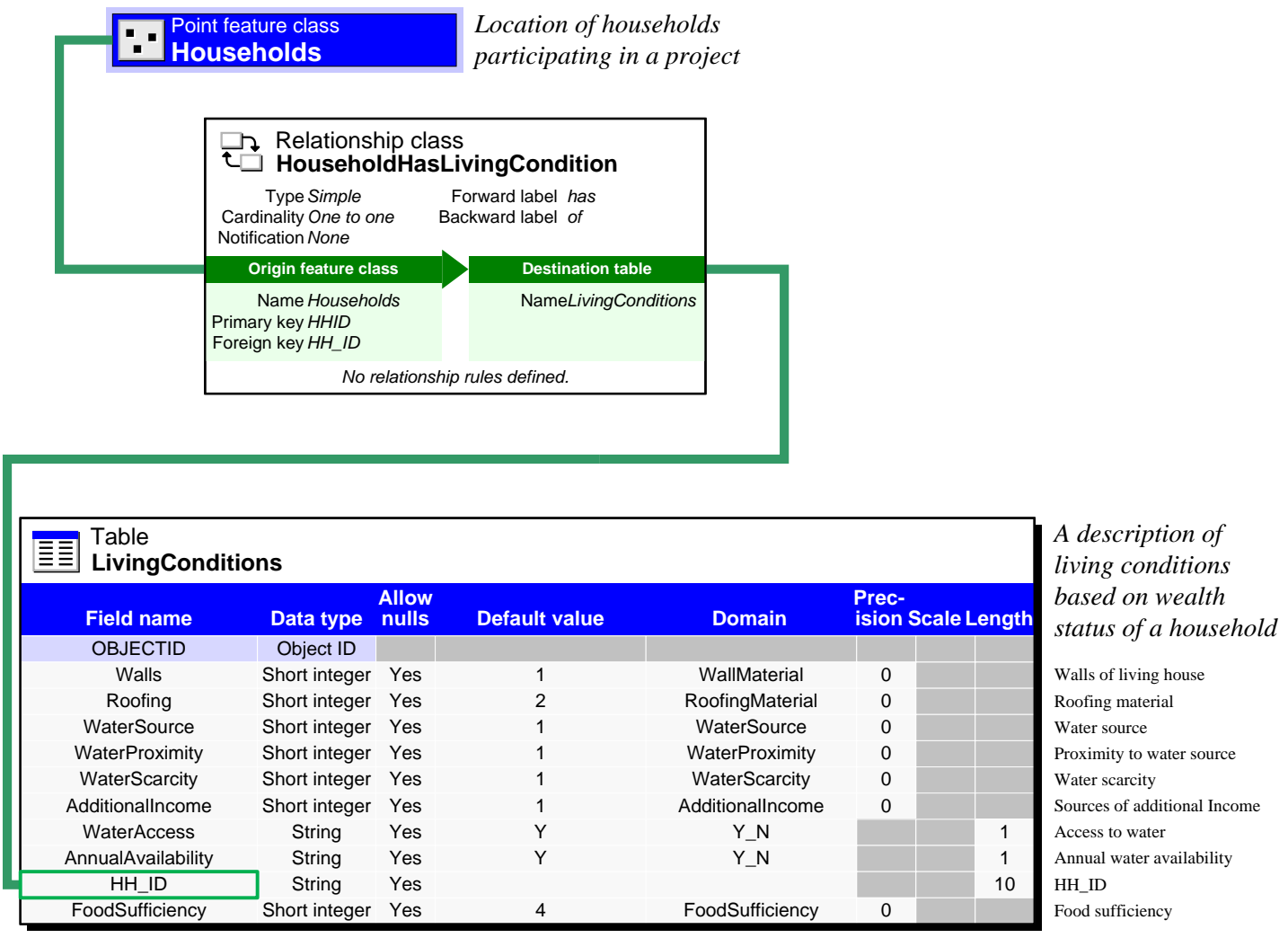

\section{Figure 4.14: Instance of LivingConditions table and its relationship with the Households feature class}

The LivingConditions table (see Fig 4.14) contains attributes of the type of walls (Walls) and the roofing material (Roofing) farmer's housing is made of. It has the source of water that supplies the household (WaterSource), accessibility to water sources (WaterAccess), proximity of a water source to household (WaterProximity), and the annual availability of water (AnnualAvailability). The table also stores the level of food sufficiency (FoodSufficiency), as well as additional source of income a household has (AdditionalIncome). Information in this table is mainly collected using field assessment questionnaires and, therefore, all descriptive attributes of LivingConditions table are contained in coded value domain tables (Figure 4.15). A one-to-one simple relationship exists between Households class and LivingConditions table. 


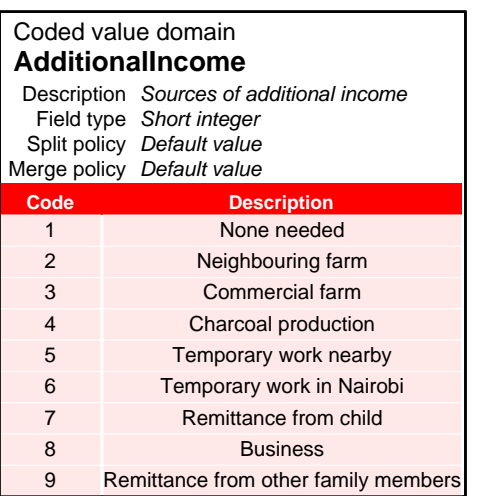

\begin{tabular}{|c|c|}
\hline \multicolumn{2}{|c|}{ Coded value domain } \\
WaterProximity \\
Description & Proximity to water source \\
Field type & Short integer \\
Split policy & Default value \\
Merge policy & Default value \\
\hline Code & Description \\
\hline 1 & Own-compound \\
2 & Neighborhood \\
3 & Beyond neighborhood \\
\hline
\end{tabular}

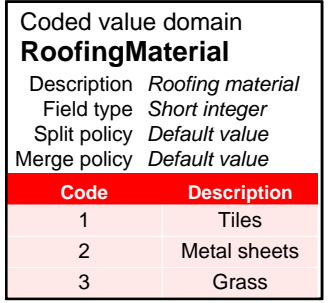

Coded value domain WaterSource

Description Source of water

Field type Short integer

Split policy Default value

Merge policy Default value

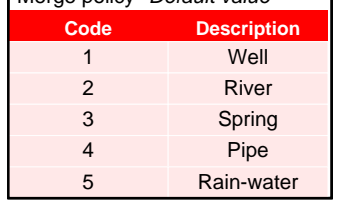

Coded value domain

WaterScarcity

Description Scarcity of water

Field type Short integer

Split policy Default value

Merge policy Default value

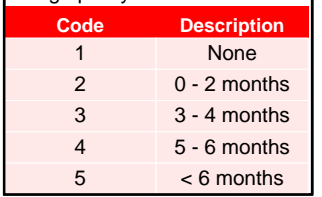

Coded value domain

WallMaterial

Description Material of house Field type walls

Split policy Short integer

Merge policy Duplicate

\begin{tabular}{|cc|}
\hline Merge policy & Duplicate \\
\hline 1 & Brick/Concrete \\
2 & Mud \\
3 & Timber \\
4 & Corrugated-iron \\
\hline
\end{tabular}

\section{Figure 4.15: Domains associated with LivingConditions database table}

\subsubsection{Livestock Husbandry}

The LivestockHusbandry table contains information about the type of livestock rearing system (GrazingType), the kind of livestock (Livestock), and the number of animals a household has (Number). The use of livestock compost in the farm is also stored in this table as the LivestockCompost attribute. The use of livestock compost is an indication of substituting the use of inorganic fertilizers on farms and thus maintaining the soil structure of a farm by not exposing it to artificial compounds. The type of livestock grazing gives an indication of the levels of farm defragmentation and productivity per unit farm area. A record or records of the types of livestock reared by a household is stored in a table. The domains associated with the LivestockHusbary table lists the type of livestock that are reared on farms and the type of grazing system used (Figure 4.16). A household can have one or many types of livestock; this relationship is represented by a one-to-many relationship between Households class and LivestockHusbandry table. 

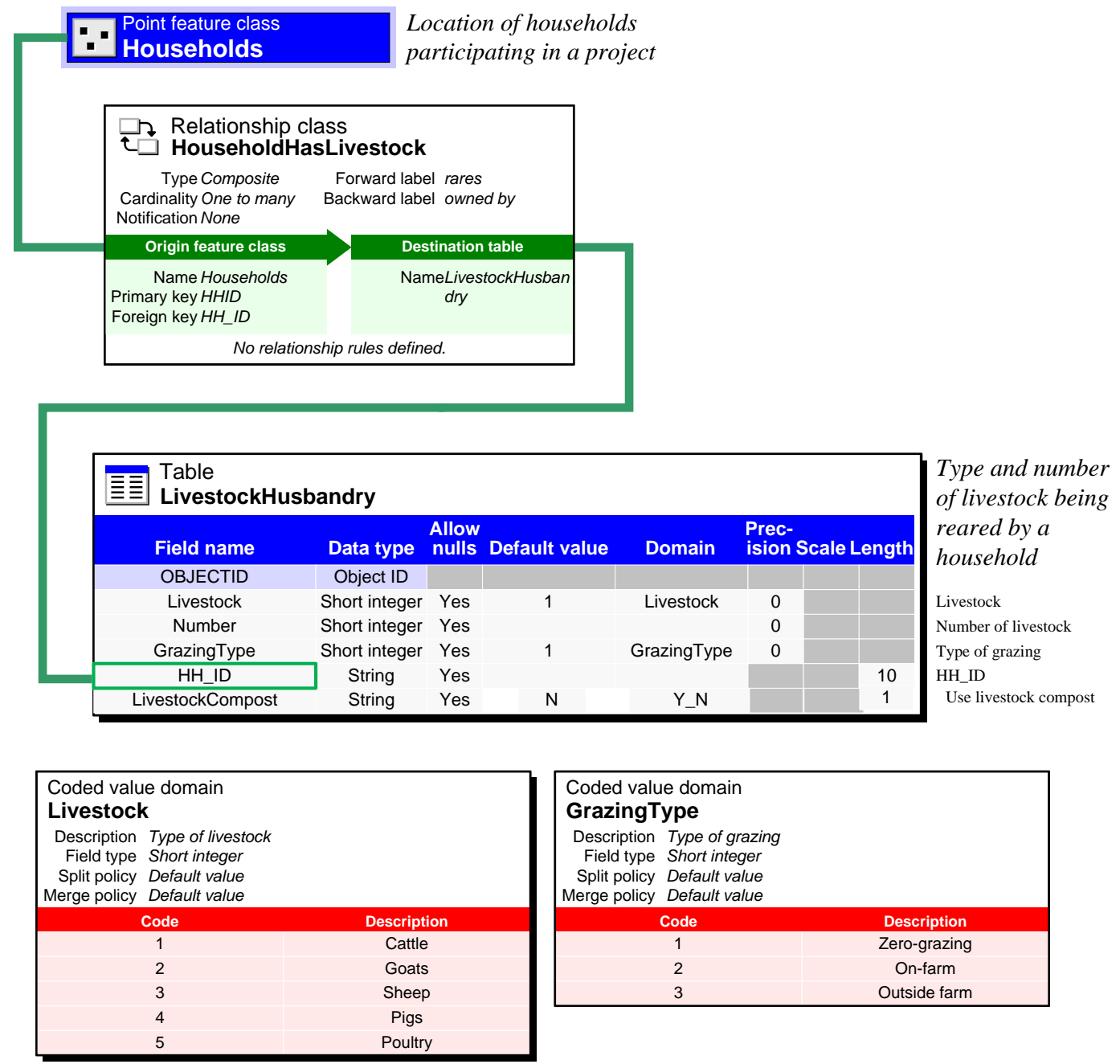

Figure 4.16: LivestockHusbandry table and related class and domains

\subsubsection{Administrative Boundaries}

Administrative boundaries are used to form a basis for managing projects within the organization. The KenyaBoundary, ProvinceBoundary, and DistrictBoundary feature classes show the political/administrative subdivisions in Kenya (Figure 4.17). The delineation of project region is based on district administrative boundaries. ProjectRegion is the general area where the Vi AFP can potentially implement sustainable agroforestry and carbon sequestration projects in the country. 


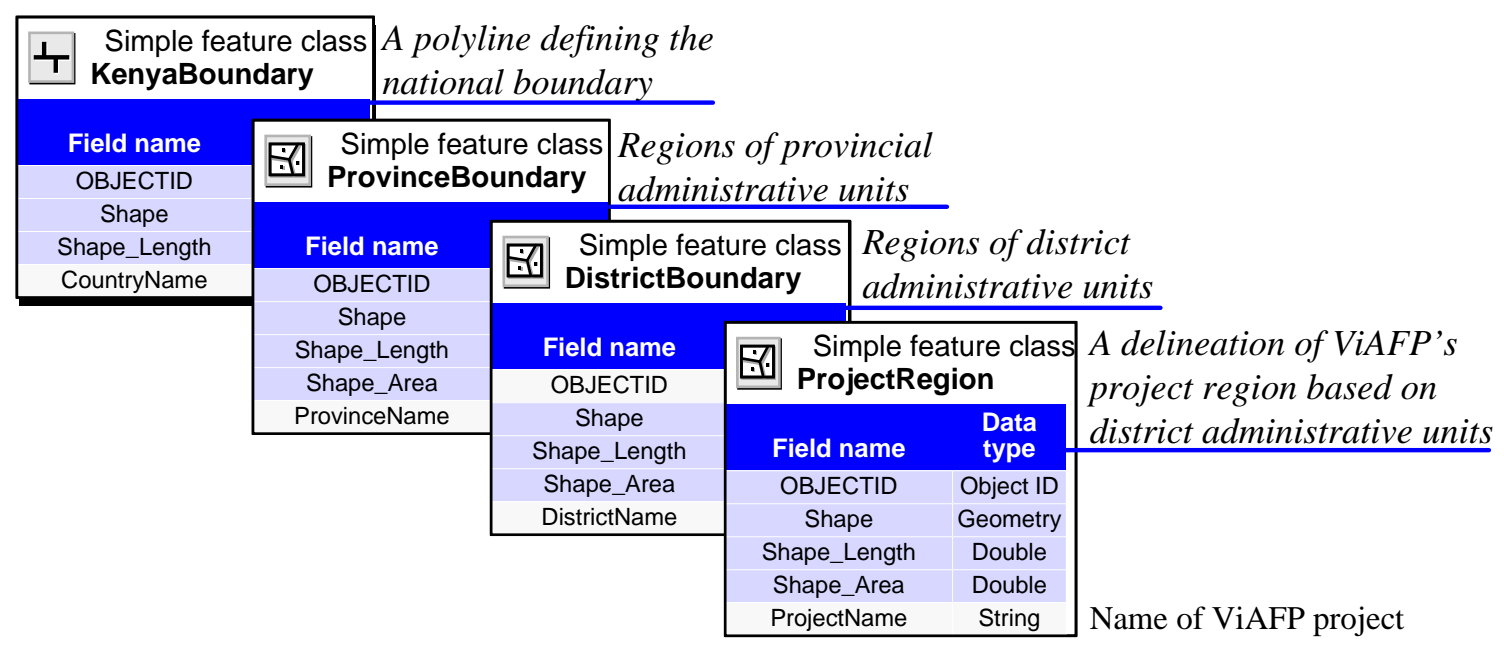

Figure 4.17: Feature classes of administrative boundaries

\subsubsection{Administrative and Market Places}

The AdministrativePlaces class represents point locations of structurally developed places that serve administrative and economic functions in an area (Figure 4.18). This base data set is important in identifying areas with a regional economic focus when implementing projects. Places are categorized into status of regional (province, district, division, or other) headquarters based on their functions and area of influence. In the data structure, a subtype of administrative places is used to categorize places based on the roles they play. They are also categorized into types based on population and capacity of infrastructure (Type). 


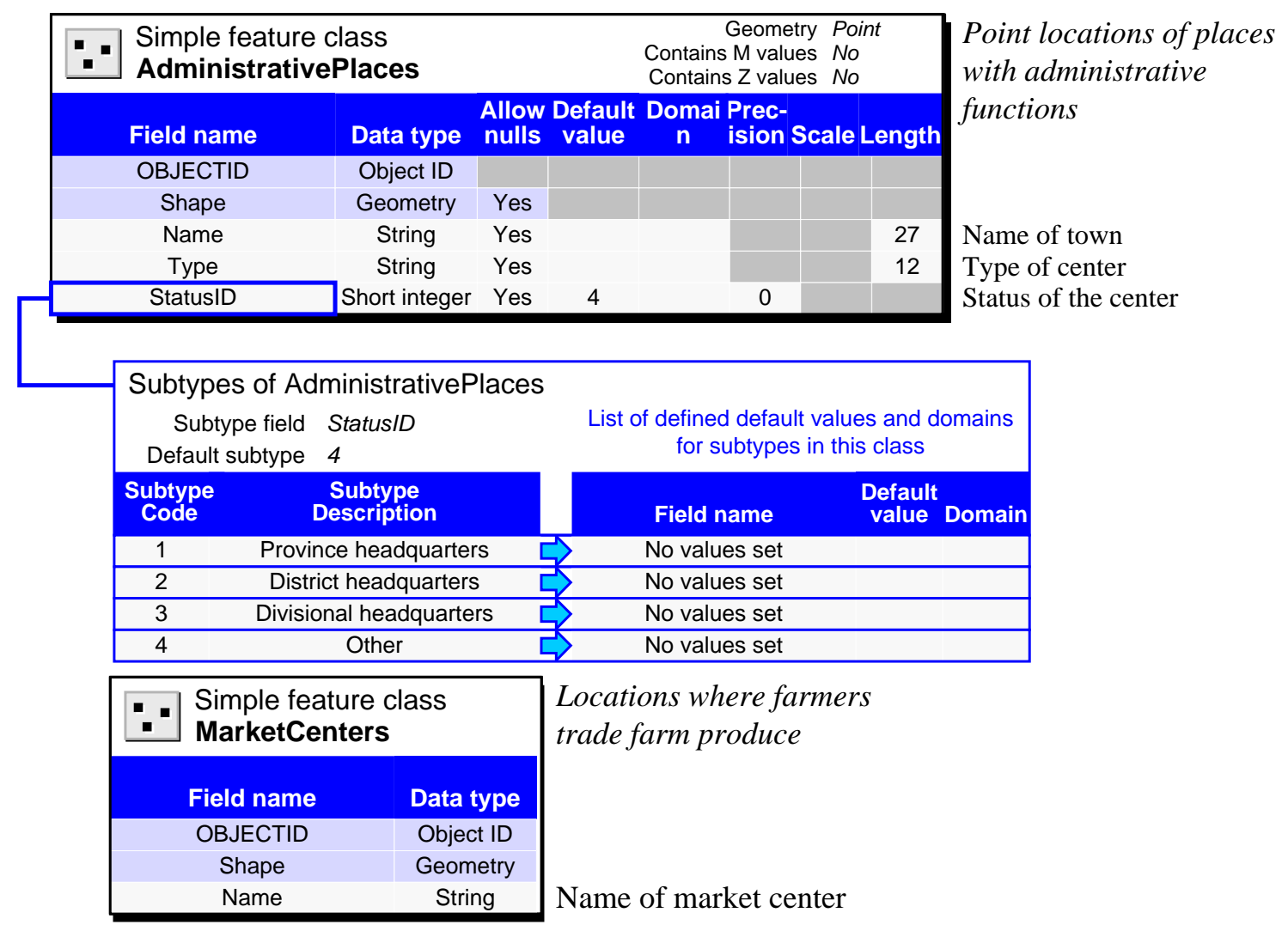

Figure 4.18: Administrative and market places

The MarketCenters feature class shows point locations with market facilities. Agroforestry farmers meet to trade their produce in market centers. These are also places at which farmers buy farm implements and hold area meetings.

\subsubsection{Roads}

The Roads class contains polylines that represent road center-lines and their descriptions. Road network is required when creating base maps of project areas and is important in project implementation and logistics planning. The Roads class has descriptive fields of the type of road surface (SurfType), surface condition (SurfCond), and the number of lanes (NumLanes) as shown in Figure 4.19. 


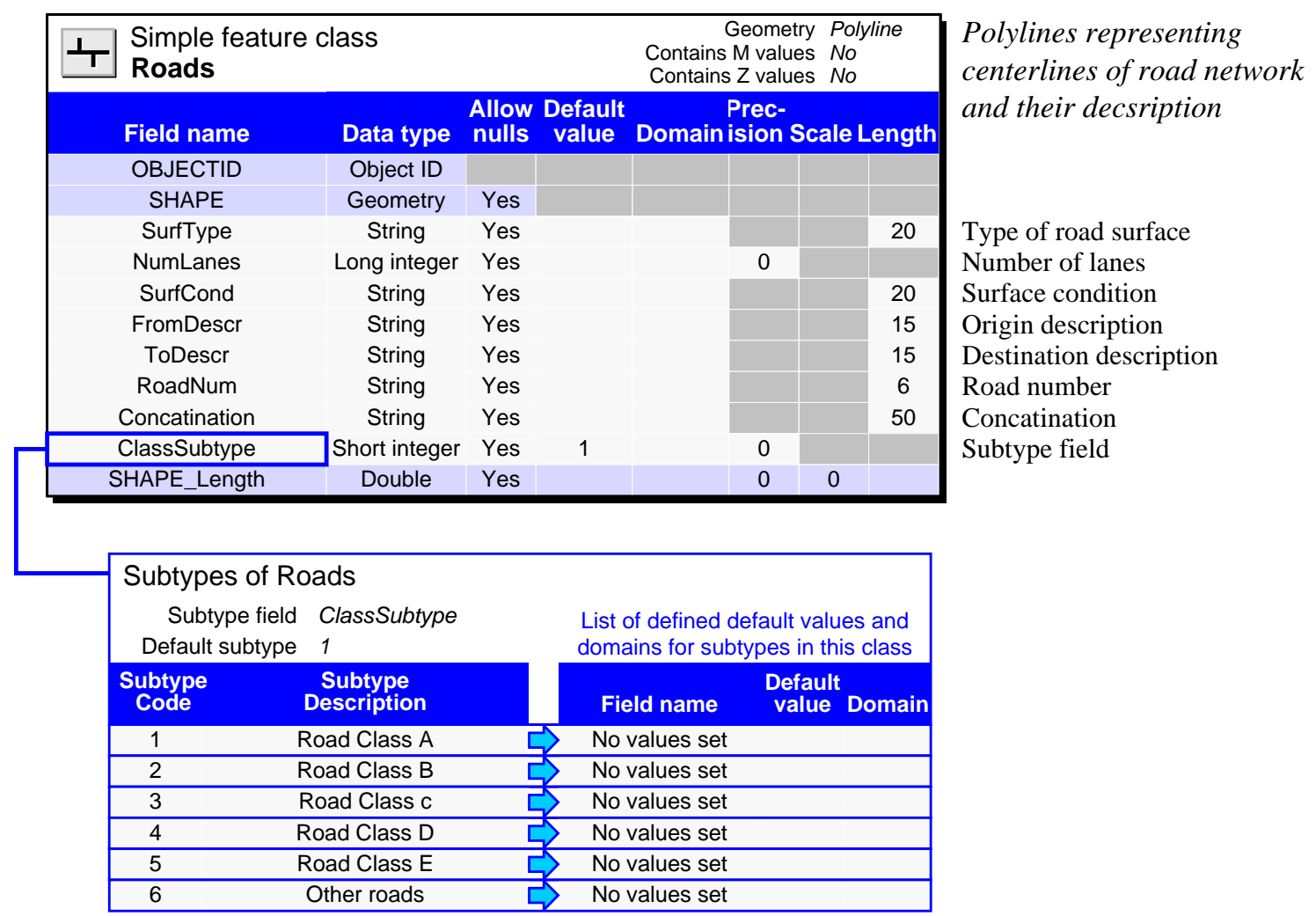

Figure 4.19: Roads feature class

Roads can be identified using either a combination of the origin and destination of a road section, the road number, or a concatenated name. The roads are categorized into classes based on traffic capacity, type of road surface and other design considerations. A subtype field, ClassSubtype, is used to categorize road classes into classes A, B, C, D, E, and other roads.

\subsubsection{Biophysical Data}

This is data relating to the land conditions of a region. The LandUse, Soils, and VegetationCover classes are used in creating base maps of project areas and sites (Figure 4.20). Knowledge of existing land use provides a basis to determine the baseline biomass content and hence estimate the potential of carbon emission reduction that can occur as a result of implementing a project. Similarly, soil condition and vegetation cover data are used in determinining the baseline biomass of an area during selection of sites to implement carbon sequestration projects. 


\begin{tabular}{|c|c|c|c|c|c|c|c|c|}
\hline $\begin{array}{ll}\text { Simple feat } \\
\text { LandUse }\end{array}$ & & & & \multicolumn{4}{|c|}{$\begin{aligned} & \text { Geometry } \text { Polygon } \\
& \text { Contains } \mathrm{M} \text { values No } \\
& \text { Contains Z values No }\end{aligned}$} & \multirow{2}{*}{$\begin{array}{l}\text { Region of similar } \\
\text { land uses }\end{array}$} \\
\hline Field name & Data type & $\begin{array}{l}\text { Allow } \\
\text { nulls }\end{array}$ & $\begin{array}{l}\text { Default } \\
\text { value }\end{array}$ & \multicolumn{4}{|c|}{$\begin{array}{c}\text { Prec- } \\
\text { Domain ision Scale Length }\end{array}$} & \\
\hline OBJECTID & Object ID & & & & & & & \multirow{5}{*}{ Land use code } \\
\hline Shape & Geometry & Yes & & & & & & \\
\hline LUCode & String & Yes & & & & & 20 & \\
\hline Shape_Length & Double & Yes & & & 0 & 0 & \multirow[b]{3}{*}{50} & \\
\hline Shape_Area & Double & Yes & & & 0 & 0 & & \\
\hline LandUse & String & Yes & & & & & & Type of land use \\
\hline \multicolumn{2}{|c|}{\begin{tabular}{|l|l} 
Simple feature class \\
Soils
\end{tabular}} & & & $\begin{array}{l}\text { Contains } \\
\text { Contain }\end{array}$ & $\begin{array}{l}\text { Geometry } \\
\text { s M values } \\
\text { is Z values }\end{array}$ & $\begin{array}{ll}y & P o \\
\text { is } & \text { No } \\
\text { s } & \text { No }\end{array}$ & lygon & \multirow{4}{*}{$\begin{array}{l}\text { Regions with } \\
\text { similar soil types }\end{array}$} \\
\hline Field name & Data type & $\begin{array}{l}\text { Allow } \\
\text { nulls }\end{array}$ & $\begin{array}{l}\text { Default } \\
\text { value }\end{array}$ & \multicolumn{4}{|c|}{$\begin{array}{c}\text { Prec- } \\
\text { Domain ision Scale Length }\end{array}$} & \\
\hline OBJECTID & Object ID & & & & & & & \\
\hline SHAPE & Geometry & Yes & & & & & & \\
\hline SUID & Double & No & & & 0 & 0 & & \multirow{4}{*}{$\begin{array}{l}\text { Soil Unit-ID } \\
\text { Kenya Soil Unit-ID }\end{array}$} \\
\hline Kenya_SUID & String & No & & & & & 10 & \\
\hline SHAPE_Length & Double & Yes & & & 0 & 0 & & \\
\hline SHAPE_Area & Double & Yes & & & 0 & 0 & & \\
\hline \multicolumn{2}{|c|}{ 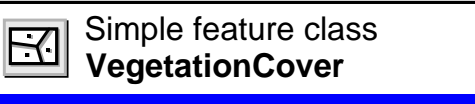 } & & & $\begin{array}{l}\text { Contains } \\
\text { Contain }\end{array}$ & $\begin{array}{l}\text { Geometry } \\
\text { s } M \text { values } \\
\text { is } Z \text { values }\end{array}$ & $\begin{array}{ll}y & P O \\
\text { is } & \text { No } \\
\text { s No }\end{array}$ & & \multirow{8}{*}{$\begin{array}{l}\text { Areas with } \\
\text { similar vegetation } \\
\text { cover }\end{array}$} \\
\hline Field name & Data type & $\begin{array}{l}\text { Allow } \\
\text { nulls }\end{array}$ & $\begin{array}{l}\text { Default } \\
\text { value }\end{array}$ & \multicolumn{4}{|c|}{$\begin{array}{c}\text { Prec- } \\
\text { Domain ision Scale Length }\end{array}$} & \\
\hline OBJECTID & Object ID & & & & & & & \\
\hline Shape & Geometry & Yes & & & & & & \\
\hline VegetationType & String & Yes & & & & & 100 & \\
\hline VegetationID & String & Yes & & & & & 10 & \\
\hline Shape_Length & Double & Yes & & & 0 & 0 & & \\
\hline Shape_Area & Double & Yes & & & 0 & 0 & & \\
\hline
\end{tabular}

Figure 4.20: Biophysical data

The LandUse attribute of the LandUse feature class describes areas of similar types of land use. A classification code (LUCode) is used to determine the descriptive land use name of a class. The Soils class has Soil unit identifier that is used to give a name to a soil class (Kenya_SUID). The VegetationCover class has the vegetation cover type that describes the vegetation existing at a given location (VegetationType). A coded identifier is used to link a certain vegetation cover type to its corresponding description (VegetationID).

\subsubsection{Hydrology}

Hydrology data contain information about rivers, river basins and wetlands (Figure 4.21). These are important during site the selection process of project sites. Wetlands are avoided, whereas river basins are seen as prime sites for carrying out agroforestry projects. 


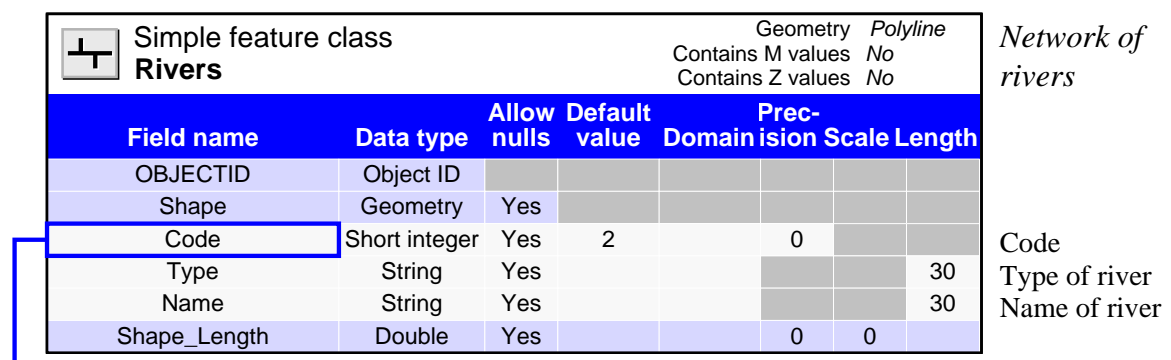

\begin{tabular}{|c|c|}
\hline \multicolumn{2}{|l|}{ Subtypes of Rivers } \\
\hline $\begin{aligned} \text { Subtype field } & \text { Code } \\
\text { Default subtype } & 2\end{aligned}$ & $\begin{array}{l}\text { List of defined default values and domains for } \\
\text { subtypes in this class }\end{array}$ \\
\hline $\begin{array}{cc}\begin{array}{c}\text { Subtype } \\
\text { Code }\end{array} & \begin{array}{c}\text { Subtype } \\
\text { Description }\end{array}\end{array}$ & $\begin{array}{l}\text { Default } \\
\text { value }\end{array}$ \\
\hline Permanent river & No values set \\
\hline Seasonal river & No values set \\
\hline Irrigation canal & No values set \\
\hline $\begin{array}{c}\text { Ditches } \\
\end{array}$ & No values set \\
\hline
\end{tabular}

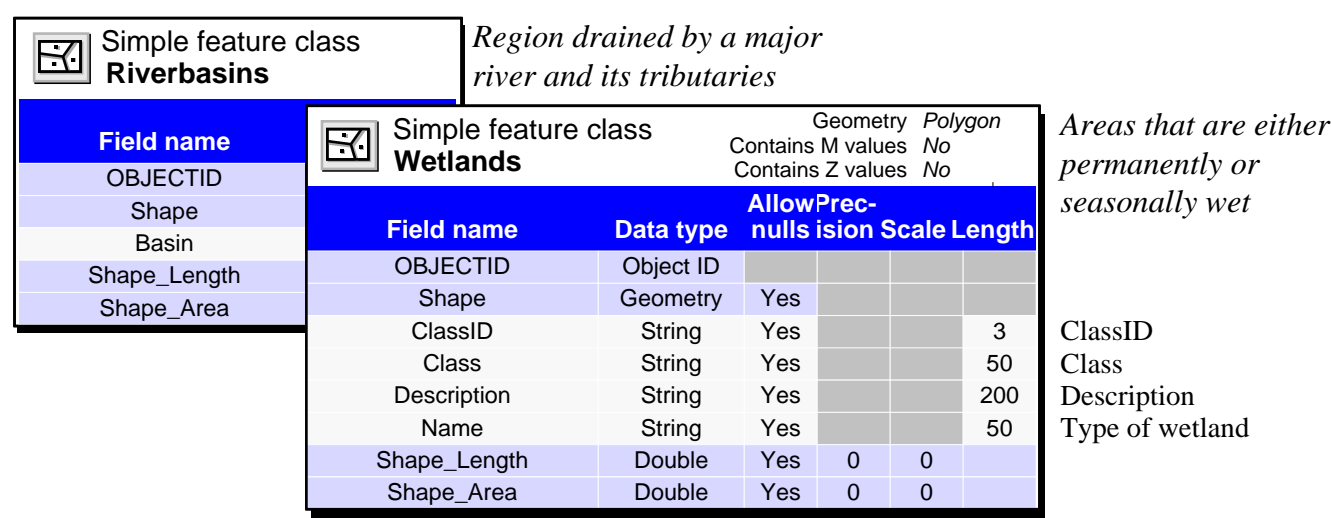

Figure 4.21: Hydorological data

Rivers are described by their names and type. A river can be seasonal, permanent, or man-made. Using a code field, rivers are categorized into subtypes of Permanent River, Seasonal River, irrigation canal, or dug ditches. The RiverBasin feature class has the name of the basin defined by a spatial boundary. The Wetlands feature class contains a description and type of wetland bounded by an area.

\subsubsection{Raster Catalog}

The raster catalog was used to hold a time series of Landsat satellite imagery obtained in 1975, 1990, and 2000. This series of images is used to perform change detection and to assess vegetation cover dynamics that have occurred over time. A vegetation cover change analysis is important in checking the impacts of the Vi AFP's projects on the environment and particularly on vegetation and forest cover. Three raster catalogs, Landsat 1975, Landsat1990, and Landsat2000 - were used to store Landsat satellite images taken at different times. Landsat1975 is a table of with two records that represent two image scenes taken in year 1975. Landsat1990 and Landsat2000 are data tables of four records, each record on the table representing image scenes taken in the corresponding years. 


\subsection{Data Sources}

Data for this project were obtained through various sources that range from within the organization to online sources. Table 4-3 describes the sources from which data used in this project were obtained.

\section{Table 4-3: Data Sources}

\begin{tabular}{|l|l|}
\hline Source & Data \\
\hline The SCC Vi Agroforestry Programme & $\begin{array}{l}\text { Households, Sampling reference points, Sample } \\
\text { plots, Project sites, Project region, Agroforestry } \\
\text { activity, Crop production, Farm head, Farm } \\
\text { land, Financial condition, Livestock husbandry, } \\
\text { Living conditions, On-farm-tree cover }\end{array}$ \\
\hline Kenya Central Bureau of Statistics & $\begin{array}{l}\text { Administrative boundaries, Administrative } \\
\text { places, Market centers, Roads, Rivers and Lakes }\end{array}$ \\
\hline ESRI ArcGIS Online services & Shaded relief_2D, streets, satellite imagery \\
\hline $\begin{array}{l}\text { International Livestock Research } \\
\text { Institute }\end{array}$ & $\begin{array}{l}\text { Agro-ecological zones, wetlands, River basins, } \\
\text { Wetlands, Soils, Vegetation cover }\end{array}$ \\
\hline $\begin{array}{l}\text { Food and Agricultural Organization } \\
\text { (FAO) }\end{array}$ & Land use/land cover data \\
\hline
\end{tabular}

While sourcing for data, the project considered issues of currency, completeness, data accuracy, and logical consistency. Majority of data obtained did not have comprehensive metadata. However metadata was provided for data and information products developed by the project.

\subsection{Data Collection Methods}

This project made use of data from an ongoing agroforestry project. This is a first project of its kind in which data collection methods are still under test. However, varying data collection methods were employed in creating these data. The data used can be broadly categorized as those collected and created by the client and those that were sourced from secondary sources.

Most of the data sets used in this project were obtained from secondary sources. This ranged from online sources, government agencies, to partner organizations. A sample ground truthing was done by visiting the project area. During the process, using GPS, point locations of the households were collected. Questionnaires were also administered to participating households. The questionnaires are used to collect the socio-economic performance indicators for the project. All farmers participating in the carbon project fill farmer's self assessment questionnaires, one to establish the baseline condition at project onset, and subsequent ones used to determine the status at a given time. 


\subsection{Data Scrubbing and Loading}

Data scrubbing is the process of preparing data into a format that can be readily loaded into a database. Due to diverse sources of data, varying approaches were used to prepare data before loading them to the Vi AFP database.

The primary source of data collection for the organization was through questionnaires and interviews with farmers. The resulting data was then stored in documents and spread sheets in Microsoft Excel that required scrubbing before being loaded into a database. This data was processed and converted into the database tables before loading them. Processing entailed identifying and grouping together fields of information as they appeared in the database tables. Field data types were defined at this stage also. Data in Microsoft Word documents was first converted to Microsoft Excel. This was followed by converting excel spreadsheets into database files that were then loaded into the Geodatabase.

Other data that were sourced from secondary sources required preprocessing prior to loading it to the database. Data scrubbing involved filtering attribute information of secondary data to suit the requirements of the Vi AFP database schema. In most cases, attributes not required by the project were dropped, and in some cases, new attribute fields were derived from a combination of existing attribute fields. The extent of spatial data was clipped to the project area before loading the data into the database.

At this stage, primary and foreign keys that participated in logical attribute relationships were defined and created for each data set. Domains were also set for data that contained domain restrictions. Domain database tables were derived from raw data and later appended to the database. This was a time consuming exercise necessary to maintain the database relationships, and therefore its usability.

\subsection{Summary}

This chapter describes how the Vi AFP database system was designed. Every GIS relies on a sound geodatabase to sufficiently model geographic features and attributes upon which the client's analysis and required information products development depend. The client's data requirements guided the choice of the database model that was implemented. Among the factors considered in designing the geodatabase were satisfying information requirements of the client, providing a natural and easy-to-understand structuring of information, and the ability to support processing requirements and performance.

This chapter also explained in detail the constituents of the implemented database. Feature classes and attributes contained in each feature class were explained and how they met the needs of information products. The main sources and methods of data were also discussed. GIS is new to the organization and most of the base data sets were obtained from secondary sources. Agroforestry project-related data was available in spread sheets which required scrubbing before they were loaded into the database. Scrubbing and loading methods were also discussed in this chapter. 



\section{Chapter 5 - Database Implementation}

This chapter discusses in detail the procedures taken to implement an internet-based GIS for the Vi Agroforestry Programme (Vi AFP). It is an account of the project workflow activities discussed earlier in Chapter 3. This section will discuss the steps taken and results obtained by conducting a requirement analysis, designing the system, and developing a Web GIS.

\subsection{Requirements Analysis}

A GIS user needs assessment was conducted with the goal of identifying and collecting information useful in designing a GIS system that meets the requirements of the organization. The exercise helped to establish the need for GIS at the Vi AFP. Specific objectives for conducting a requirement analysis included:

- Identifying the end users of a GIS system,

- Educating users with respect to GIS needs,

- Identifying information products,

- Identifying data requirements for information products,

- Prioritizing data requirements and products,

- Determining GIS functional requirements (hardware/software/future training and expertise).

Key people responsible for implementing and monitoring projects were identified and selected to provide user needs. Particularly, the monitoring and evaluation team of the Vi AFP were the major participants in the process. Selected staff from all four country offices in Rwanda, Tanzania, Uganda, and Kenya participated in the providing their expected requirements of a GIS. Vertical hierarchy of the organization was represented in the process by collecting views from top management through to field extension officers.

A combination of questionnaires and telephone interviews were used to carry out the user needs assessment. A field visit to selected project sites also provided a deeper understanding of the monitoring procedures currently used by the organization. Similarly, analyses of the organization's strategic plan, as well as documented carbon monitoring procedures, were carried out. In this process, use case scenarios were identified and documented. The completion of the requirement analysis made it possible to create a list of required information products which were then used to create a master input data list.

\subsubsection{Use Cases}

The user requirement process identified several use case scenarios that are listed in this section. The use cases outlined the sequence of interactions between actors in the carbon monitoring process and the system required in order to execute each task that satisfies a project goal. They represent a functional decomposition of the problem domain. The use cases identified included:

- Use case for mapping a project area 
- Use case for carrying out a baseline biomass assessment

- Use case for monitoring carbon at project sites

- Use case for reporting project status.

A detailed description of these use cases is found on Appendix D. Use cases were important in determining the functional requirements and defining the scope of the system.

\subsubsection{Information Product Descriptions (IPD's)}

From the user needs assessment, information products are gathered and documented in form an information products description (IPD) document. IPDs are important planning tools that collate and summarize the essential information about the user's expectations of a system. Map requirements were identified and tabulated (Table 5-1).

Table 5-1: Map requirements for project monitoring

\begin{tabular}{|l|l|}
\hline Map requirement & Description \\
\hline Standard Project Region Map & $\begin{array}{l}\text { Area covering all potential sustainable land management } \\
\text { (SLM) adoption areas to be included in the project. This } \\
\text { area remains permanent throughout the project lifetime; it } \\
\text { should therefore encompass all potential project sites. }\end{array}$ \\
\hline Potential SLM activity map & $\begin{array}{l}\text { Areas within a project area with the exception of urban } \\
\text { areas, rivers, lakes, military zones, and other non-suitable } \\
\text { areas. }\end{array}$ \\
\hline Stratified SLM activity map & $\begin{array}{l}\text { Potential areas stratified according to a defined criterion } \\
\text { (land-use, soils, and climatic conditions). Resulting strata } \\
\text { represent different agro-ecological zones. }\end{array}$ \\
\hline Potential SLM adoption map & $\begin{array}{l}\text { Indicates areas within a stratified region where farmers } \\
\text { committed themselves to adopt SLM practices on their } \\
\text { farmlands. }\end{array}$ \\
\hline
\end{tabular}

The key information products were identified and are described in Appendix E. 


\subsubsection{Master Input Data List (MIDL)}

The Vi AFP master input data list (MIDL) contains all the data sets in a database required to generate identified information products described earlier. The list contains information about data identification, data volume considerations, and source data availability and cost (Table 5-2).

Because various users have different names for the same data set, each one was assigned a unique data set number (Data set \#) that was standard to all users. The volume of data required was determined so as to estimate disk storage space needed for the $\mathrm{Vi}$ AFP database. Some data required conversion to GIS-readable formats. Conversion and pre-processing required an additional space and this affected the overall strategy for data storage and handling. Outlining data characteristics helped in guiding the database design and selection of software and hardware. It also determined what data input methods were required. Facts about data availability and cost were important in guiding the choice of whether to re-create data or edit and update existing commercial or government data. In most cases, existing data from the government and other secondary sources were edited and used. During this process, the quality of obtained data was checked to ensure that they met the accuracy standard for creating the desired information products. 
Table 5-2: Master Input Data List for ViAFP

\begin{tabular}{|c|c|c|c|c|c|c|c|c|c|c|c|c|c|c|}
\hline \multirow[b]{2}{*}{ 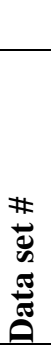 } & \multicolumn{2}{|c|}{ Data identification } & \multicolumn{8}{|c|}{ Data Volume Considerations } & \multicolumn{4}{|c|}{ Data availability } \\
\hline & 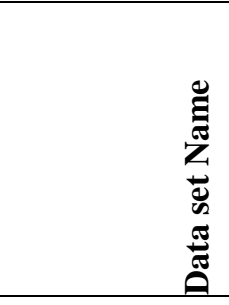 & 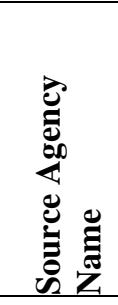 & 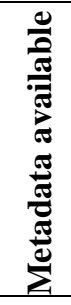 & 营 & 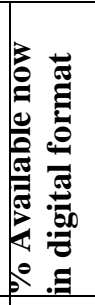 & 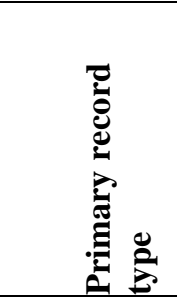 & 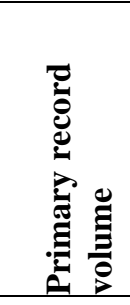 & 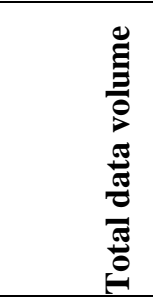 & 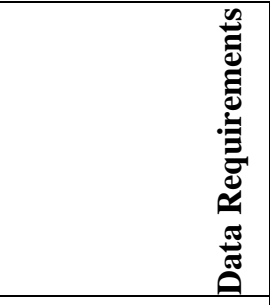 & 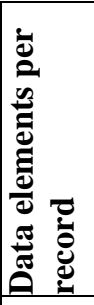 & 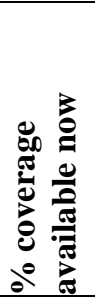 & 忌 & 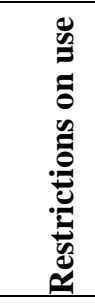 & 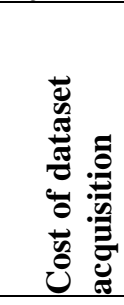 \\
\hline 1 & $\begin{array}{l}\text { Biomass } \\
\text { assessment } \\
\text { sample plots }\end{array}$ & ViAFP & Yes & $\begin{array}{l}\text { GPS } \\
\text { download } \\
\text { s }\end{array}$ & $\begin{array}{l}10 \\
0 \\
\end{array}$ & Shapefile & $200 \mathrm{~KB}$ & $\begin{array}{l}\text { Not yet } \\
\text { defined }\end{array}$ & $\begin{array}{l}\text { GPS data } \\
\text { collection }\end{array}$ & 5 & 100 & 2009 & None & $\begin{array}{l}\text { Project } \\
\text { budget }\end{array}$ \\
\hline 2 & $\begin{array}{l}\text { Agroforestry } \\
\text { techniques }\end{array}$ & ViAFP & Yes & $\begin{array}{l}\text { ftp } \\
\text { download }\end{array}$ & 60 & $\begin{array}{l}\text { Excel } \\
\text { spread } \\
\text { sheet }\end{array}$ & $<10 \mathrm{MB}$ & $\begin{array}{l}\text { Not yet } \\
\text { defined }\end{array}$ & Text input & 17 & 50 & 2009 & None & $\begin{array}{l}\text { Project } \\
\text { budget }\end{array}$ \\
\hline 3 & $\begin{array}{l}\text { Crop } \\
\text { production }\end{array}$ & ViAFP & Yes & $\begin{array}{l}\text { ftp } \\
\text { download }\end{array}$ & 50 & $\begin{array}{l}\text { Excel } \\
\text { spread } \\
\text { sheet }\end{array}$ & $<5 \mathrm{MB}$ & $\begin{array}{l}\text { Not yet } \\
\text { defined }\end{array}$ & Text input & 6 & 50 & 2009 & None & $\begin{array}{l}\text { Project } \\
\text { budget }\end{array}$ \\
\hline 4 & $\begin{array}{l}\text { Livestock } \\
\text { husbandry }\end{array}$ & ViAFP & Yes & $\begin{array}{l}\text { ftp } \\
\text { download }\end{array}$ & 50 & $\begin{array}{l}\text { Excel } \\
\text { spread } \\
\text { sheet }\end{array}$ & $<5 \mathrm{MB}$ & $\begin{array}{l}\text { Not yet } \\
\text { defined }\end{array}$ & Text input & 5 & 50 & 2009 & None & $\begin{array}{l}\text { Project } \\
\text { budget }\end{array}$ \\
\hline 5 & $\begin{array}{l}\text { Farmer living } \\
\text { conditions }\end{array}$ & ViAFP & Yes & $\begin{array}{l}\text { ftp } \\
\text { download }\end{array}$ & 50 & $\begin{array}{l}\text { Excel } \\
\text { spread } \\
\text { sheet }\end{array}$ & $<5 \mathrm{MB}$ & $\begin{array}{l}\text { Not yet } \\
\text { defined }\end{array}$ & Text input & 10 & 80 & 2009 & None & $\begin{array}{l}\text { Project } \\
\text { budget }\end{array}$ \\
\hline 6 & $\begin{array}{l}\text { Agro- } \\
\text { ecological } \\
\text { Zones }\end{array}$ & ILRI & Yes & $\begin{array}{l}\text { http } \\
\text { download }\end{array}$ & $\begin{array}{l}10 \\
0\end{array}$ & Shapefile & $<1 \mathrm{MB}$ & $<1 \mathrm{MB}$ & $\begin{array}{l}\text { Reprojection, } \\
\text { data cleaning }\end{array}$ & 1 & 50 & 1983 & None & None \\
\hline 7 & $\begin{array}{l}\text { Reference } \\
\text { Sample points }\end{array}$ & ViAFP & Yes & $\begin{array}{l}\text { File } \\
\text { transfer }\end{array}$ & $\begin{array}{l}10 \\
0 \\
\end{array}$ & Shapefile & $50 \mathrm{~KB}$ & $50 \mathrm{~KB}$ & $\begin{array}{l}\text { GPS data } \\
\text { collection }\end{array}$ & 5 & 100 & 2008 & None & $\begin{array}{l}\text { Project } \\
\text { budget }\end{array}$ \\
\hline 8 & Households & ViAFP & Yes & $\begin{array}{l}\text { File } \\
\text { transfer }\end{array}$ & 10 & Shapefile & $50 \mathrm{~KB}$ & $50 \mathrm{~KB}$ & $\begin{array}{l}\text { GPS data } \\
\text { collection }\end{array}$ & 12 & 100 & 2008 & None & $\begin{array}{l}\text { Project } \\
\text { budget }\end{array}$ \\
\hline
\end{tabular}




\begin{tabular}{|c|c|c|c|c|c|c|c|c|c|c|c|c|c|c|}
\hline \multirow[b]{2}{*}{ 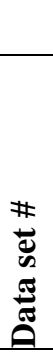 } & \multicolumn{2}{|c|}{ Data identification } & \multicolumn{8}{|c|}{ Data Volume Considerations } & \multicolumn{4}{|c|}{ Data availability } \\
\hline & 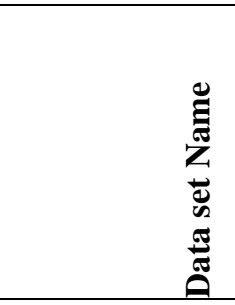 & 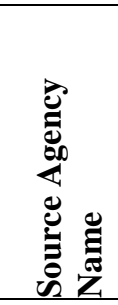 & 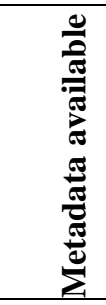 & 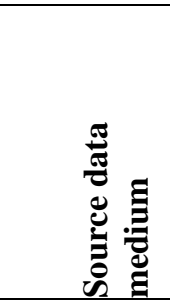 & 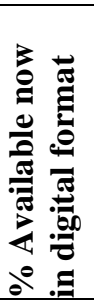 & 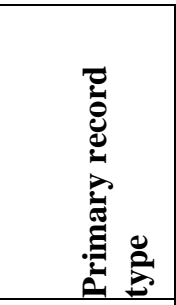 & 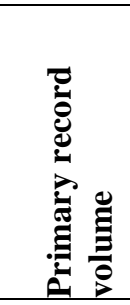 & 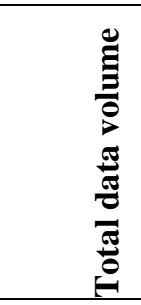 & & 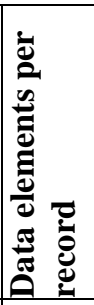 & 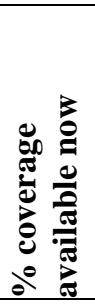 & 勇 & 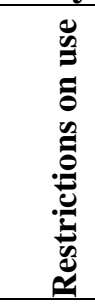 & 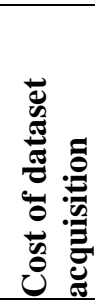 \\
\hline 9 & Project sites & ViAFP & Yes & $\begin{array}{l}\text { File } \\
\text { transfer }\end{array}$ & 100 & Shapefile & $50 \mathrm{~KB}$ & $50 \mathrm{~KB}$ & $\begin{array}{l}\text { Data cleaning } \\
\text { and loading }\end{array}$ & 4 & 100 & 2008 & None & None \\
\hline 10 & Land use & FAO & Yes & $\begin{array}{l}\text { File } \\
\text { transfer }\end{array}$ & 100 & Shapefile & $2 \mathrm{MB}$ & $2 \mathrm{MB}$ & $\begin{array}{l}\text { Reprojection, } \\
\text { data cleaning }\end{array}$ & 5 & 100 & 2003 & None & None \\
\hline 11 & Soils & ILRI & Yes & $\begin{array}{l}\text { File } \\
\text { transfer }\end{array}$ & 100 & Shapefile & $200 \mathrm{~KB}$ & $200 \mathrm{~KB}$ & $\begin{array}{l}\text { Reprojection, } \\
\text { data cleaning }\end{array}$ & 5 & 100 & 1997 & None & None \\
\hline 12 & $\begin{array}{l}\text { Vegetation } \\
\text { cover }\end{array}$ & ILRI & Yes & $\begin{array}{l}\text { File } \\
\text { transfer }\end{array}$ & 100 & Shapefile & $250 \mathrm{~KB}$ & $250 \mathrm{~KB}$ & $\begin{array}{l}\text { Reprojection, } \\
\text { data cleaning }\end{array}$ & 5 & 100 & Unknown & None & None \\
\hline 13 & $\begin{array}{l}\text { Administrative } \\
\text { places }\end{array}$ & CBS & None & $\begin{array}{l}\text { File } \\
\text { transfer }\end{array}$ & 100 & Shapefile & $350 \mathrm{~KB}$ & $350 \mathrm{~KB}$ & $\begin{array}{l}\text { Data cleaning } \\
\text { and loading }\end{array}$ & 4 & 100 & 2000 & None & None \\
\hline 14 & $\begin{array}{l}\text { Administrative } \\
\text { boundaries }\end{array}$ & CBS & None & $\begin{array}{l}\text { File } \\
\text { transfer }\end{array}$ & 100 & Shapefile & $2 \mathrm{MB}$ & $2 \mathrm{MB}$ & $\begin{array}{l}\text { Data cleaning } \\
\text { and loading }\end{array}$ & 3 & 100 & 2000 & None & None \\
\hline 15 & Roads & CBS & None & $\begin{array}{l}\text { File } \\
\text { transfer }\end{array}$ & 100 & Shapefile & $5 \mathrm{MB}$ & $5 \mathrm{MB}$ & $\begin{array}{l}\text { Data cleaning } \\
\text { and loading }\end{array}$ & 10 & 100 & 2000 & None & None \\
\hline 16 & Rivers & ICRAF & None & $\begin{array}{l}\text { File } \\
\text { transfer }\end{array}$ & 100 & Shapefile & $5 \mathrm{MB}$ & $5 \mathrm{MB}$ & $\begin{array}{l}\text { Reprojection, } \\
\text { data cleaning }\end{array}$ & 5 & 100 & 2006 & None & None \\
\hline 17 & River basins & ILRI & Yes & $\begin{array}{l}\text { File } \\
\text { transfer }\end{array}$ & 100 & Shapefile & $150 \mathrm{~KB}$ & $150 \mathrm{~KB}$ & $\begin{array}{l}\text { Reprojection, } \\
\text { data cleaning }\end{array}$ & 4 & 100 & Unknown & None & None \\
\hline 18 & Wetlands & ILRI & Yes & $\begin{array}{l}\text { File } \\
\text { transfer }\end{array}$ & 100 & Shapefile & $50 \mathrm{~KB}$ & $50 \mathrm{~KB}$ & $\begin{array}{l}\text { Reprojection, } \\
\text { data cleaning }\end{array}$ & 7 & 100 & Unknown & None & None \\
\hline 19 & $\begin{array}{l}\text { Landsat image } \\
\text { time series }\end{array}$ & NASA & Yes & $\begin{array}{l}\text { ftp } \\
\text { download }\end{array}$ & 100 & $\begin{array}{l}\text { Raster } \\
\text { image }\end{array}$ & $600 \mathrm{MB}$ & $600 \mathrm{MB}$ & $\begin{array}{l}\text { Image pre- } \\
\text { processing }\end{array}$ & 1 & 100 & $\begin{array}{l}1975,1990, \\
2000\end{array}$ & None & None \\
\hline
\end{tabular}

Key: ILRI = International Livestock Research Institute, ICRAF = International Center for Research in Agroforestry, FAO = Food and Agricultural Organization of the United Nations, CBS = Central Bureau of Statistics of Kenya, 


\subsection{Data Design}

This section discusses the considerations made in designing the system based on the data requirements and information products that were expected from the GIS. Once a list of user requirements was tabulated, a data design process was conducted. The two key objectives were to create a data design that represented the real world in a useful way and to ensure that required functionalities like scalability, speed, and the ability to handle complex data structure were incorporated into the system.

\subsubsection{System Scope}

IPDs and MIDL documents supported the process of evaluating the scope of the Vi AFP system. The evaluation process was important in order to guide further implementation of a database. For this project, scope identified data priorities, data handling loads, data storage and security, and data readiness. Since all information products could not be created at the same time, a prioritization of information products was done according to relative importance of the contribution of each product to Vi AFP's objectives. A scoring method was used to rank which information products would be delivered first. Based on this ranking, datasets for producing respective information products were also ranked (Table 5-3).

Table 5-3: Prioritization of project data sets

\begin{tabular}{|l|l|l|l|}
\hline Dataset needed & Data source & $\begin{array}{l}\text { Priority } \\
\text { ranking }\end{array}$ & Justification \\
\hline $\begin{array}{l}\text { Administrative } \\
\text { boundaries }\end{array}$ & $\begin{array}{l}\text { Government } \\
\text { agency, CBS } \\
\text { Kenya }\end{array}$ & 1 & $\begin{array}{l}\text { This dataset is immediately required to } \\
\text { establish the project region boundaries } \\
\text { before the onset of a project. }\end{array}$ \\
\hline $\begin{array}{l}\text { Locations of } \\
\text { households and } \\
\text { farmers records of } \\
\text { living conditions, } \\
\text { financial conditions, } \\
\text { and household } \\
\text { composition. }\end{array}$ & Field mapping & 2 & $\begin{array}{l}\text { This is one of the most immediately needed } \\
\text { data that has to be collected from the field. } \\
\text { It is specific to the projects being } \\
\text { undertaken by the organization and cannot } \\
\text { obtained externally. It shows the scope of } \\
\text { project operations. }\end{array}$ \\
\hline $\begin{array}{l}\text { Agroforestry } \\
\text { techniques and crop } \\
\text { production }\end{array}$ & $\begin{array}{l}\text { Field } \\
\text { questionnaires }\end{array}$ & 3 & $\begin{array}{l}\text { The objective of the organization is to } \\
\text { facilitate farmers to engage in sustainable } \\
\text { agroforestry techniques that improve their } \\
\text { productivity. This dataset forms the core of } \\
\text { ViAfP mandate. They are required at } \\
\text { project onset in order to plan for project } \\
\text { execution. }\end{array}$ \\
\hline $\begin{array}{l}\text { Land use / land cover, } \\
\text { rivers, wetlands, and } \\
\text { lakes }\end{array}$ & $\begin{array}{l}\text { Commercial } \\
\text { providers of } \\
\text { Satellite } \\
\text { imagery }\end{array}$ & 4 & $\begin{array}{l}\text { This is a dataset of priority that is required } \\
\text { for identifying potential project areas } \\
\text { within a project region. Urban areas, rivers, } \\
\text { lakes, and wetlands are eliminated from the } \\
\text { project area. Land use/Land cover dataset } \\
\text { is also used in planning to conduct baseline } \\
\text { surveys of new project areas. }\end{array}$ \\
\hline
\end{tabular}




\begin{tabular}{|c|c|c|c|}
\hline Dataset needed & Data source & $\begin{array}{l}\text { Priority } \\
\text { ranking }\end{array}$ & Justification \\
\hline Agro-ecological zones & ILRI & 5 & $\begin{array}{l}\text { Agro-ecological dataset is used to stratify } \\
\text { project areas into different categories of } \\
\text { carbon pools. This allows for accurate } \\
\text { evaluation of carbon emission reductions. } \\
\text { It helps to prioritize potential regions for } \\
\text { expanding projects to. }\end{array}$ \\
\hline $\begin{array}{l}\text { Reference sampling } \\
\text { clusters }\end{array}$ & $\begin{array}{l}\text { Predetermined } \\
\text { and generated } \\
\text { by the project }\end{array}$ & 6 & $\begin{array}{l}\text { This dataset forms the foundation of a } \\
\text { monitoring framework. Point locations } \\
\text { generated will be the reference for } \\
\text { conducting baseline biomass assessment } \\
\text { and the subsequent periodic biomass } \\
\text { assessments. }\end{array}$ \\
\hline $\begin{array}{l}\text { Permanent sampling } \\
\text { plots }\end{array}$ & Field mapping & 7 & $\begin{array}{l}\text { The outcome of implementing sustainable } \\
\text { farming techniques is to enhance soil } \\
\text { carbon sequestration. Carbon emission } \\
\text { reductions are periodically evaluated at } \\
\text { locations of permanent sampling plots. }\end{array}$ \\
\hline $\begin{array}{l}\text { Biophysical data } \\
\text { (Soils, vegetation } \\
\text { cover, river basins) }\end{array}$ & ILRI & 8 & $\begin{array}{l}\text { Soils data and vegetation cover information } \\
\text { is required to stratify project sites into } \\
\text { carbon pools for accurate baseline biomass } \\
\text { assessment. Status of soil quality is } \\
\text { required as a way of evaluation land } \\
\text { resource improvements that shall guarantee } \\
\text { sustained production. It is however not an } \\
\text { immediate requirement as impacts of } \\
\text { practicing farming techniques are not } \\
\text { experienced immediately. }\end{array}$ \\
\hline Crop database & $\begin{array}{l}\text { World } \\
\text { Agroforestry } \\
\text { database }\end{array}$ & 9 & $\begin{array}{l}\text { It is important to know crop types, where } \\
\text { they are suitable to grow, and their carbon } \\
\text { sequestration value. }\end{array}$ \\
\hline Trees database & $\begin{array}{l}\text { World } \\
\text { Agroforestry } \\
\text { database }\end{array}$ & 10 & $\begin{array}{l}\text { Different trees have varying agro-forestry } \\
\text { values and carbon sequestration } \\
\text { capabilities differ, thus, it is important to } \\
\text { know these variables }\end{array}$ \\
\hline Economic condition & $\begin{array}{l}\text { Farmers self } \\
\text { assessment } \\
\text { questionnaire }\end{array}$ & 11 & $\begin{array}{l}\text { One of the indicators of success is } \\
\text { improved economic status in regions where } \\
\text { projects are being practiced. This } \\
\text { evaluation comes later after project } \\
\text { implementation and thus this dataset is not } \\
\text { of immediate need. }\end{array}$ \\
\hline Population density & $\begin{array}{l}\text { Central Bureau } \\
\text { of Statistics of } \\
\text { Kenya }\end{array}$ & 12 & $\begin{array}{l}\text { The span of influence of ViAFP projects is } \\
\text { based on the ratio of people adopting } \\
\text { recommended systems as well as the } \\
\text { overall influence to the general population } \\
\text { in an area. This dataset will be required } \\
\text { later during project evaluation and for } \\
\text { reporting }\end{array}$ \\
\hline
\end{tabular}




\begin{tabular}{|l|l|l|l|}
\hline Dataset needed & Data source & $\begin{array}{l}\text { Priority } \\
\text { ranking }\end{array}$ & Justification \\
\hline $\begin{array}{l}\text { Base map data } \\
\text { (Roads, market } \\
\text { centers) }\end{array}$ & $\begin{array}{l}\text { Central Bureau } \\
\text { of Statistics of } \\
\text { Kenya }\end{array}$ & 13 & $\begin{array}{l}\text { The significance of this data is in } \\
\text { preparation of base maps. They provide an } \\
\text { indication of the location of projects with } \\
\text { respect to existing infrastructure and help } \\
\text { to evaluate market options of farm } \\
\text { produce. }\end{array}$ \\
\hline
\end{tabular}

The developed IPDs and MIDL documents were used to calculate a quantifiable data handling load for the software and hardware. "The amount of computational work required to produce an information product depends on processing complexity and data volume," (Tomlinson, 2007, p. 62). This allowed estimation of the number of workstations needed by the Vi AFP, based on work required to produce information product. A high or low estimate of workstation processing complexity was used for the Vi AFP system, based on the number of steps it took to create an information product and the number of advanced functions (Table 5-4).

Table 5-4: Workflow for processing data

\begin{tabular}{|c|c|c|c|}
\hline Source Format & Functions & $\begin{array}{l}\text { Estimated } \\
\text { required } \\
\text { time }\end{array}$ & Destination Format \\
\hline GPS field data & $\begin{array}{l}\text { - GPS data download/file transfer } \\
\text { - Display and edit/clean } \\
\text { - Add attributes } \\
\text { - Export to database } \\
\text { - Update }\end{array}$ & $\begin{array}{l}2 \text { weeks (this } \\
\text { is a } \\
\text { continuous } \\
\text { exercise) }\end{array}$ & $\begin{array}{l}\text { - point shapefile } \\
\text { (Biomass sampling } \\
\text { plots, households) } \\
\text { - Polygons shapefile } \\
\text { of project sites } \\
\text { - Polyline shapefile: } \\
\text { Access routes to } \\
\text { project sites }\end{array}$ \\
\hline $\begin{array}{l}\text { Hard copy forms } \\
\text { of field } \\
\text { questionnaires }\end{array}$ & $\begin{array}{l}\text { - Input data to spread sheet } \\
\text { - Define, clean and edit data } \\
\text { attribute fields } \\
\text { - Join with farmers locations }\end{array}$ & 1 week & Database table \\
\hline $\begin{array}{l}\text { Landsat Satellite } \\
\text { imagery }\end{array}$ & $\begin{array}{l}\text { - Data transfer } \\
\text { - Geometric correction and image } \\
\text { rectification } \\
\text { - Image classification } \\
\text { - Change detection analysis }\end{array}$ & 2 weeks & $\begin{array}{l}\text { - Land use classes } \\
\text { - Vegetation cover } \\
\text { change analysis } \\
\text { - Base satellite images }\end{array}$ \\
\hline $\begin{array}{l}\text { Spread sheets of } \\
\text { Biomass content at } \\
\text { sample plots }\end{array}$ & $\begin{array}{l}\text { - Define attribute fields and formats } \\
\text { - Add attribute fields } \\
\text { - Export to database }\end{array}$ & 3 weeks & Database table \\
\hline $\begin{array}{l}\text { Coverage of soil } \\
\text { types }\end{array}$ & $\begin{array}{l}\text { - File transfer } \\
\text { - Format conversion } \\
\text { - Create godatabase feature }\end{array}$ & 2 days & Polygon feature class \\
\hline
\end{tabular}




\begin{tabular}{|c|c|c|c|}
\hline Source Format & Functions & $\begin{array}{l}\text { Estimated } \\
\text { required } \\
\text { time }\end{array}$ & Destination Format \\
\hline $\begin{array}{l}\text { Tables of Crop } \\
\text { database }\end{array}$ & $\begin{array}{l}\text { - Define attribute fields and formats } \\
\text { - Add attribute fields } \\
\text { - Export to database }\end{array}$ & 2 days & Database table \\
\hline $\begin{array}{l}\text { Shapefile of Trees } \\
\text { database }\end{array}$ & \multirow[t]{3}{*}{$\begin{array}{l}\text { - File transfer } \\
\text { - Create geodatabase feature }\end{array}$} & 2 days & Polygon feature class \\
\hline $\begin{array}{l}\text { Shapefile: Agro- } \\
\text { ecological zones }\end{array}$ & & 2 days & Polygon feature class \\
\hline $\begin{array}{l}\text { Shapefile: } \\
\text { Economic } \\
\text { distribution }\end{array}$ & & 2 days & Polygon feature class \\
\hline $\begin{array}{l}\text { Coverage: } \\
\text { Population density }\end{array}$ & $\begin{array}{l}\text { - File transfer } \\
\text { - Conversion to feature lass } \\
\text { - Conversion to raster dataset }\end{array}$ & 4 days & Raster feature class \\
\hline
\end{tabular}

An analysis of functions that are required was also made. Functions were categorized into classes depending on how frequently they are used (Table 5-5). Class 1 functions are those that are most frequently used and are mandatory for a suitable system to have.

Table 5-5: Functions that generate information products

\begin{tabular}{|c|c|c|}
\hline Function & $\begin{array}{l}\text { Class of } \\
\text { functions }\end{array}$ & Description \\
\hline Attribute query & & Essential functions that the system rely \\
\hline Create list & Class 1 & $\begin{array}{l}\text { heavily on them. The system should } \\
\text { perform them optimally and reliably. }\end{array}$ \\
\hline Graphic overlay & \multirow{11}{*}{ Class 2} & \multirow{11}{*}{$\begin{array}{l}\text { These are important functionalities that } \\
\text { are heavily used and the system must be } \\
\text { tested for. }\end{array}$} \\
\hline Area calculation & & \\
\hline $\begin{array}{l}\text { Basic system capabilities } \\
\text { (Data input, scale change, } \\
\text { display, edit, label, symbolize, } \\
\text { plot) }\end{array}$ & & \\
\hline Spatial query & & \\
\hline Centroid calculation & & \\
\hline $\begin{array}{l}\text { Attribute operations (join, } \\
\text { update, modify) }\end{array}$ & & \\
\hline Raster clip & & \\
\hline Land cover classification & & \\
\hline Random point generation & & \\
\hline Vegetation change analysis & & \\
\hline GPS downloads & & \\
\hline
\end{tabular}




\begin{tabular}{|l|l|l|}
\hline Function & $\begin{array}{l}\text { Class of } \\
\text { functions }\end{array}$ & Description \\
\cline { 1 - 1 } $\begin{array}{l}\text { Satellite image preprocessing } \\
\text { (Geometric and radiometric } \\
\text { corrections) }\end{array}$ & Class 3 & $\begin{array}{l}\text { These are critical functions that are } \\
\text { rarely used. They are used mostly at the } \\
\text { start or end of preparing selected } \\
\text { information products. Others can be } \\
\text { Raster mosaic }\end{array}$ \\
\cline { 1 - 1 } Publish data to web services & & usen new data is obtained. \\
\hline Serve web maps & & \\
\hline
\end{tabular}

Data volume was also categorized as either high or low depending on the amount and number of data sets a system used to produce an information product (Table 5-6). Based on the data handling load required by the system, three standard workstations and one server were recommended for the Vi AFP system.

Table 5-6: Assisting workstations for creating information products

\begin{tabular}{|c|c|c|}
\hline $\begin{array}{l}\text { Processing } \\
\text { complexity }\end{array}$ & Data volume to be handled & $\begin{array}{l}\text { Type of workstation } \\
\text { required }\end{array}$ \\
\hline High & High & High-end \\
\hline High & Low & High-end or standard \\
\hline Low & High & Standard \\
\hline Low & Low & Standard \\
\hline \multicolumn{3}{|c|}{$\begin{array}{l}\text { High-end: Quad-Core Intel }{ }^{\circledR} \text { Xeon }{ }^{\circledR} \text { Processor T7400 } \\
\text { Standard: Intel }{ }^{\circledR} \text { Core }^{\text {TM} 2 ~ D u o ~ P r o c e s s o r, ~ I n t e l ~}{ }^{\circledR} \text { T3400 }\end{array}$} \\
\hline \multicolumn{3}{|c|}{$\begin{array}{l}\text { Note: Adapted from Thinking about GIS: Geographic Information System Planning for } \\
\text { Managers (3rd Edition ed.). (p.70), by R.Tomlinson, 2007, Redlands: ESRI Press. } \\
\text { Copyright } 2007 \text { by ESRI Press. }\end{array}$} \\
\hline
\end{tabular}

The computational power requirements are relatively simple, whereas the storage dimensions can be categorized as low for this system. For data sets that were identified, a storage capacity of $150 \mathrm{~GB}$ per workstation was sufficient. This factors at least $50 \%$ extra for indexing and data handling. The recommended security levels included tiered secured log-in credentials and RAID level one protections on the workstations. A server workstation running on a multi user Microsoft Windows server platform was recommended to run the ArcGIS server for the Web GIS. This server workstation would have a RAID level zero protection on the server. An additional network-based mass storage system for the server was recommended to be established at a different Vi AFP office for enhanced security and ease of rebuilding databases in case of a disaster.

\subsubsection{Conceptual and Logical Data Design}

A conceptual design is a high-level description of a system. A review of the data earlier identified during system scoping, was used to develope a conceptual data design. An analysis of the operations of the organization resulted in three sections: project definition and identification, project actors, and monitoring framework. Logical linkages of data were identified and implemented for the database. Data characteristics and attributes of each data set determined the system architecture of the Vi AFP. 


\subsubsection{Physical Data Design}

The development of a physical data design is a culmination of building a geodatabase. This was done in three phase. In the first phase, a prototype of Vi AFP database was developed, followed by a pilot phase, and finally a third phase of creating a production geodatabase. This was an iterative process; the database structure was reviewed and necessary adjustments made.

The first phase of created a prototype database of the Vi AFP based on outlined data requirements. A physical database model was implemented from scratch using ArcCatalog. This process was guided by the conceptual data model created earlier (Figure 5.1).

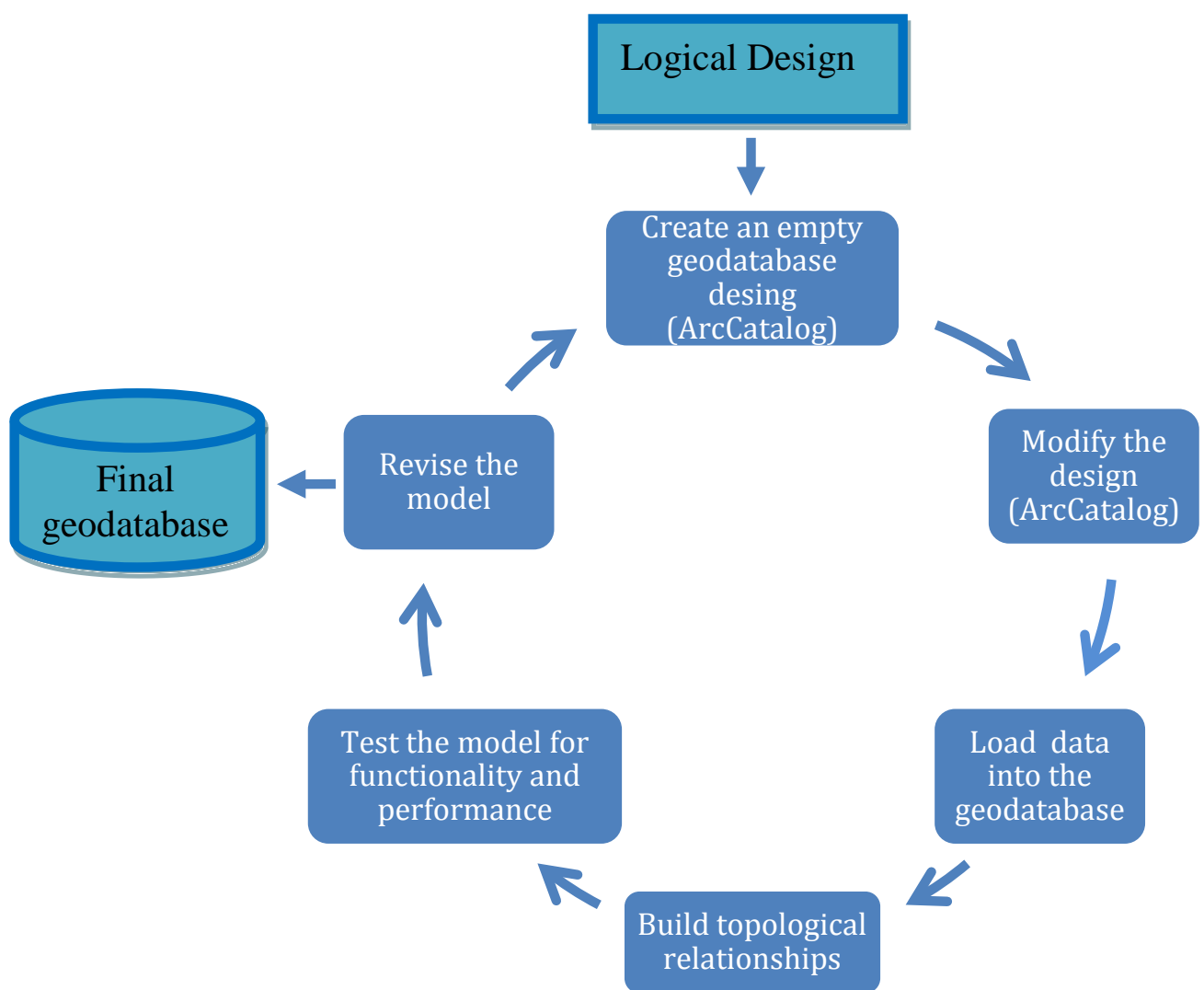

Figure 5.1: Building the Vi AFP Database. Adapted from "Designing Geodatabases,” by D. Arctur \& M. Zeiler, 2004, p. 377. Copyright 2004 by ESRI Press

The next stage in developing a physical data design was to modify the design in ArcCatalog. This was a time consuming process that sought to eliminate differences between the logical design and the physical database. Changes were made to accommodate new requirements as the client continued to review the database. While the understanding of the project grew, changes to the schema also had to be made.

After the development of a physical geodatabase in ArcCatalog, data was loaded into the geodatabase. A simple ArcCatalog data loader tool was used to input data to simple 
features. For complex data with composite relationships, like Households and ProjectSites feature classes, the data loader tool in ArcMap was used.

The fourth stage when building the physical Vi AFP database was to create topological relationships. This was done after loading data into the schema. Geodatabase topologies defining the behavior of datasets were implemented.

The next stage was testing and revising the database. Workflows were tested by creating sample data products, performing analyses using database data, and checking for topological errors. Sample data was edited to check whether data properties were preserved during editing.

\subsection{Unit Testing}

Functional, component, and performance tests conducted during the database development contributed to the success of implementing a Web GIS for the Vi AFP. Testing was done to ensure that the developed database could support real workflows. A testing plan and approach were prepared in the form of a scripted test (Appendix D). The main objectives of the testing process was to verify that system requirements were met, all data required for carbon project monitoring were accommodated in the database, and that database performance was acceptable. A unit type test was carried out during the development stage. System and acceptance tests could not be conducted until the database was implemented at the client's site. Data from the database was used in the analysis, and to prepare the information products discussed earlier. Sample data was edited and its behavior monitored.

A testing criterion for the database was designed to guide the scripted testing process. Three considerations were made as shown in Table 5-7.

\section{Table 5-7: Testing criteria}

\begin{tabular}{|l|l|}
\hline Criteria & Test action \\
\hline \multirow{5}{*}{ Data structure and attribute content } & $\begin{array}{l}\text { Logical relationships between related tables } \\
\text { exist as in reality }\end{array}$ \\
\cline { 2 - 2 } & $\begin{array}{l}\text { Domains and subtypes enforce data } \\
\text { integrity during editing and analysis }\end{array}$ \\
\hline \multirow{2}{*}{ Database Performance } & Acceptable layer fetch times \\
\cline { 2 - 2 } Schema check-in/check-out & Acceptable layer draw times \\
\hline \multirow{2}{*}{ Logical relationships are maintained } \\
\cline { 2 - 2 } & $\begin{array}{l}\text { Schema attributes, domains and subtypes } \\
\text { are maintained }\end{array}$ \\
\hline
\end{tabular}

The Geodatabase Toolset extension for ArcGIS was used to perform draw performance testing. Performance test pinpoints layers that may be bottlenecks of slow map refresh and shows the relative costs of opening a cursor and looping through returned features. Each element was inspected for the amount of time it takes to draw constituent features (draw time) and the amount of time it takes to retrieve them from a database (Figure 5.2). Comparison of draw times for each features identifies those that are overly high, a corrective measure could then be made. Relatively high fetch times often resulted because of un-indexed fields or use of high precision. 


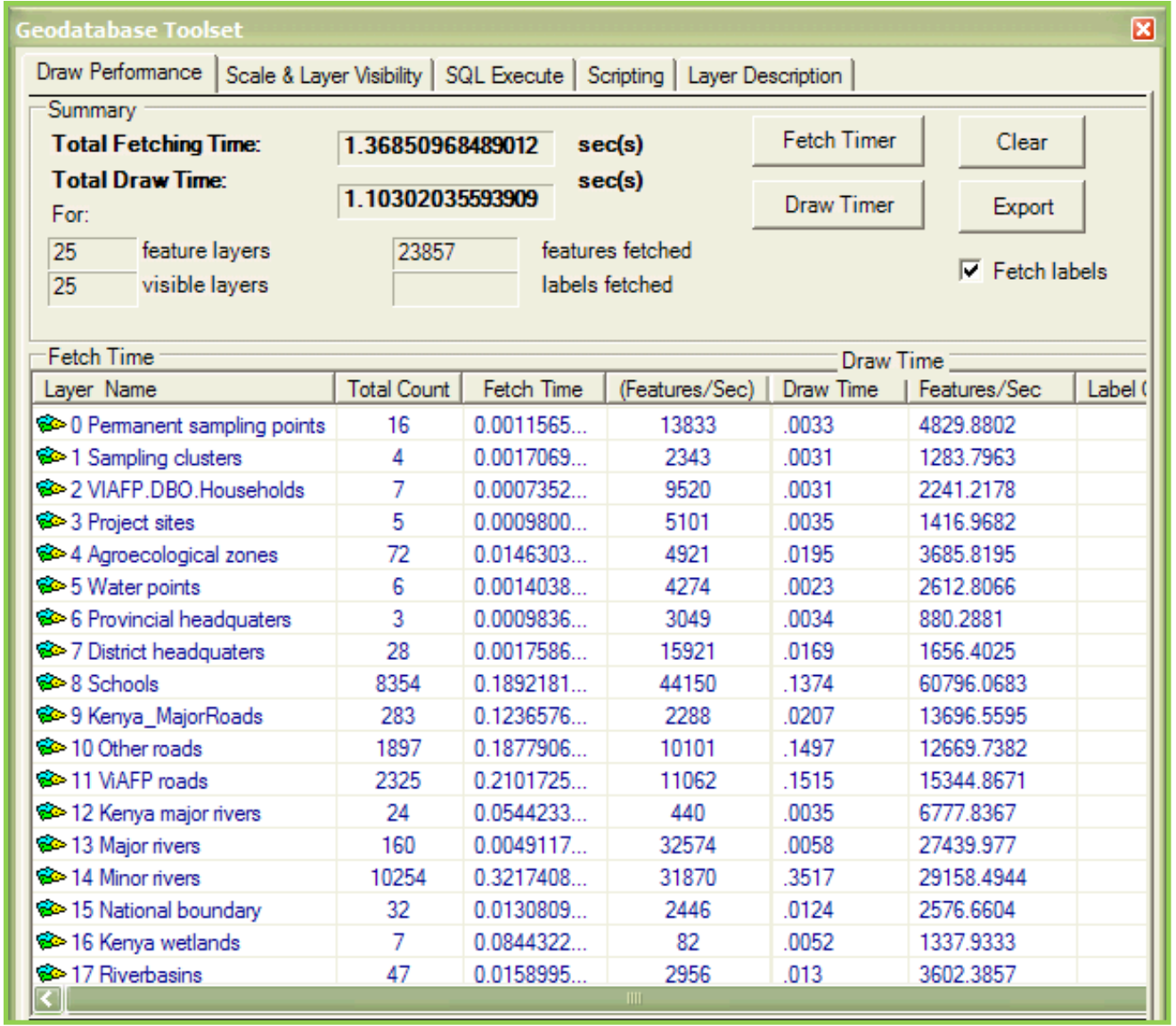

Figure 5.2: Testing geodatabase elements for draw and fetch times 


\section{Chapter 6 - Web Mapping Application Implementation}

A web page was created to provide information via the internet. The web page is an enduser interface containing map navigation tools that allows users to pan, zoom in and out, and move through previous and next map extents. Web applications were also built into the web page to answer questions such as "where is a certain project being carried out?", "Which households are participating to implement a certain project?" "Where are the areas that have the potential of sequestering a certain amount of carbon emissions?” This section discusses the implementation process used to create a web mapping application (Figure 6.1).

Having operated and collected information for over 25years, the Vi AFP required a tool to communicate its successes and information about its projects to a wider audience. The organization required an internet-based tool to share spatial information about the location and coverage of projects with its donors, as well as with collaborating partners. Carbon sequestration through agroforestry projects requires modern means of advocating for it in the region and the world at large. By sharing project progress and information over the internet, the Vi AFP enhances its policy to advocate for such projects. This also establishes the credibility with potential donors and carbon credit buyers that the methods used to monitor carbon emission reductions work.

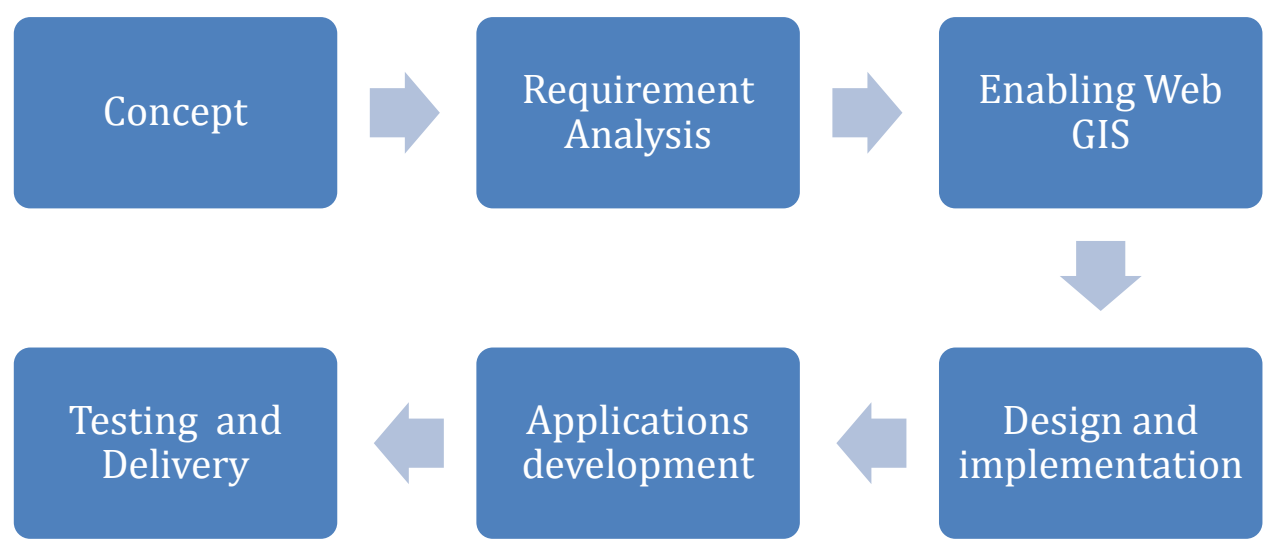

\section{Figure 6.1: Web GIS development process}

The process of developing the Web GIS began with establishing the concept followed by carrying out of requirement analysis to determine its purpose. The next step was to enable a GIS for the web through a data preparation process, map authoring, and publishing information. This was followed by designing the web page, and creating web mapping applications. Finally, the web mapping application was subjected to various tests to verify that it met the requirements. These steps are discussed in detail as follows. 


\subsection{Requirement Analysis}

A requirement analysis was carried out with the client so as to determine the purpose of a Web GIS, what data to be shared, the target audience, and what programming approach was to be used. The main purpose of Vi AFP's Web GIS was to create an interactive map-based source of information on agroforestry projects being implemented by the organization. The objective was to provide online users with an interface to locate and view maps of the project sites; and to obtain additional information about projects at a particular location.

The requirement analysis process selected the type of data that could be allowed for public access. Base map data, monitoring framework, and participating households' data to be used in the process were identified. The Web GIS was to be hosted at the client's offices in Kisumu, Kenya, where there are notably low internet connectivity conditions. For this reason, a light-weight development application was chosen. JavaScript Application Programming Interface (API) for ArcGIS was used to program the web applications. JavaScript API is an open source programming application that does not require a license to be purchased as with other existing development applications that were considered.

\subsection{Enabling GIS For the Web}

The process of enabling the Web GIS entailed four major steps: data preparation, authoring information products, publishing of services, and using them (Figure 6.2).

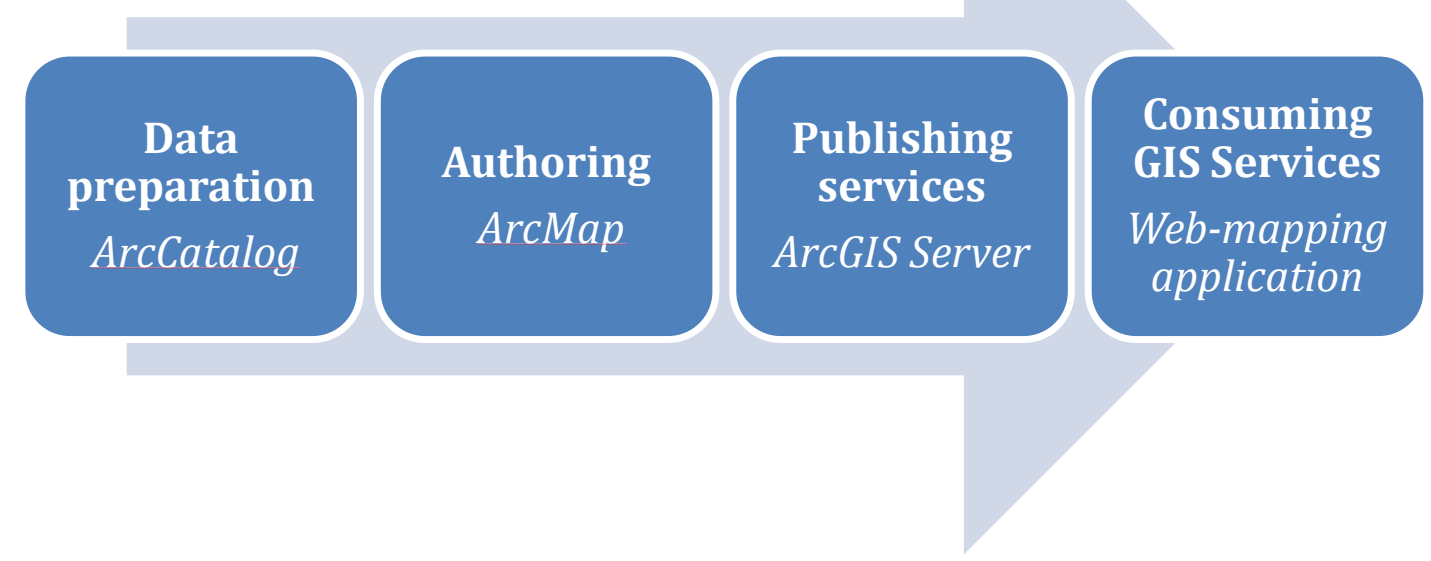

Figure 6.2: Steps to GIS on the web

Data preparation was done using ArcCatalog to identify selected data sets to be used in developing GIS web applications. Maps of the project sites were authored in ArcMap. The project created desktop map applications that were published and consumed by the web mapping applications. The purpose of creating these applications was to provide operational data to support the functionalities of web applications. The applications utilized data residing in the implemented database. These maps were then published 
using ArcGIS to create map services that were used in building web mapping applications.

Two kinds of ArcGIS map services were created for use in the web mapping applications: base map and operational map services. A base map service is a geographic frame of reference that is reusable in multiple applications. It was designed with the objective of increasing the performance of the application. This is because it does not need to be redrawn when a user pans or zooms around the project area. On the other hand, operational map services focused on the project of interest. These services support the functionality of the developed application and are displayed on top of the base map. The operational map service developed contains the carbon project monitoring reference framework, sample plot data, household data, and other project-specific information that change over time. Layers used in building map applications were drawn from the project map service.

This project also made use of online map service resources that provided additional base map information covering areas beyond the project's extent. ArcGIS Online map services were used to provide a visually appealing shaded relief base map, satellite imagery, and street networks. The project, therefore, created a mash-up that made use of project-specific data and online resources.

\subsection{Optimizing Web Services}

Caching is one major way of optimizing web maps and improving the performance of map services to run more effectively and faster. Caching is the process whereby a server draws the entire map at different predetermined scales and stores copies of the images. The resulting map cache represents a snapshot of a map at any particular point in time. These images can then be distributed to users when they request a map of a particular area at a particular scale, without having to wait for the server to draw a map for every request.

Project map services were cached to provide the desired speed and efficiency of a light-weight application. This project adopted an ArcGIS Online tile scheme to provided tile specifications during caching. The caching process created PNG images of $512 \mathrm{x}$ 512pixel size. PNG8 provided the desired transparency capabilities for this project and has the advantage of taking up less storage space with minimal information loss. This outweighs its inability to display more than 256 colors. In the quest to meet the needs of low connectivity users and maintain desired performance, this project created simple applications that do not require rendering of over 256 colors.

Performance of the project web services was also evaluated for undesirable layer properties that can decrease the service performance. Figure 6.3 shows the service evaluation process that utilizes a Map Cache tool in ArcMap. All issues identified were resolved so as to improve the performance of the Vi AFP map services. 


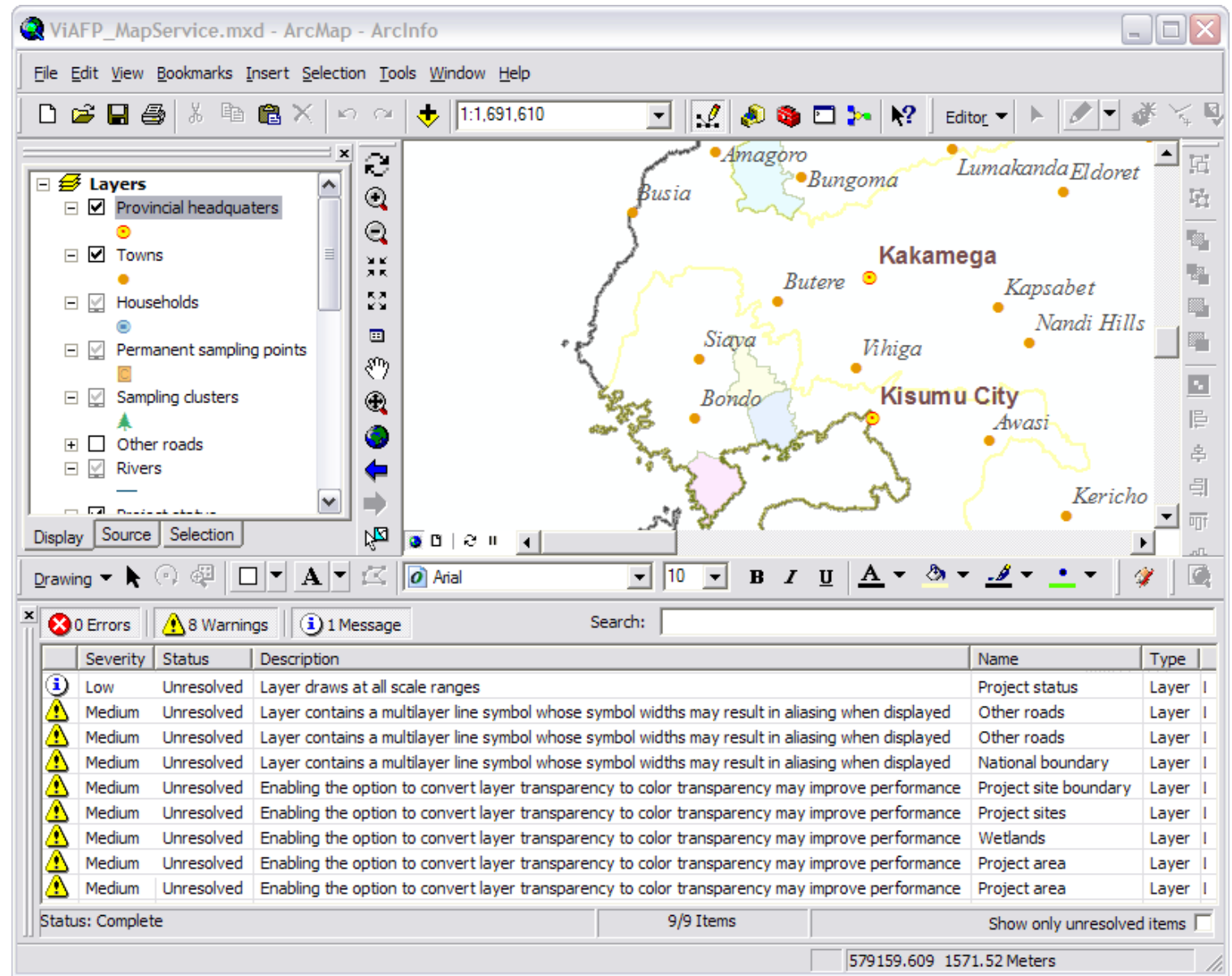

Figure 6.3: Optimizing web services in ArcMap

\subsection{Web Application Interface Design}

The next stage was to design and create a web page interface for sharing spatial information and project related information. The factors considered included:

- Response time

- Graphics and plug-ins

- Maintaining the look and feel of existing Vi AFP's main web page

- Screen resolution

- Browser types and versions

A graphically simple web page with limited graphics besides the map section was designed for this project and plug-ins were also avoided because response time is significantly affected by the amount of graphics on a page. The graphics that were used were compressed to an optimal screen resolution size. It was also recommended that the organization upgrade its internet connection from the current $256 \mathrm{Kbps}$ to at least a 512Kbps connection.

The project sought to maintain the look and feel the Vi AFP's existing main web page by maintaining the outline format and title pane contents. A comparison of the two sites is shown in Figure 6.4. 
Figure 6.4: Layout comparison of Vi AFP's main web page and the designed web mapping application page

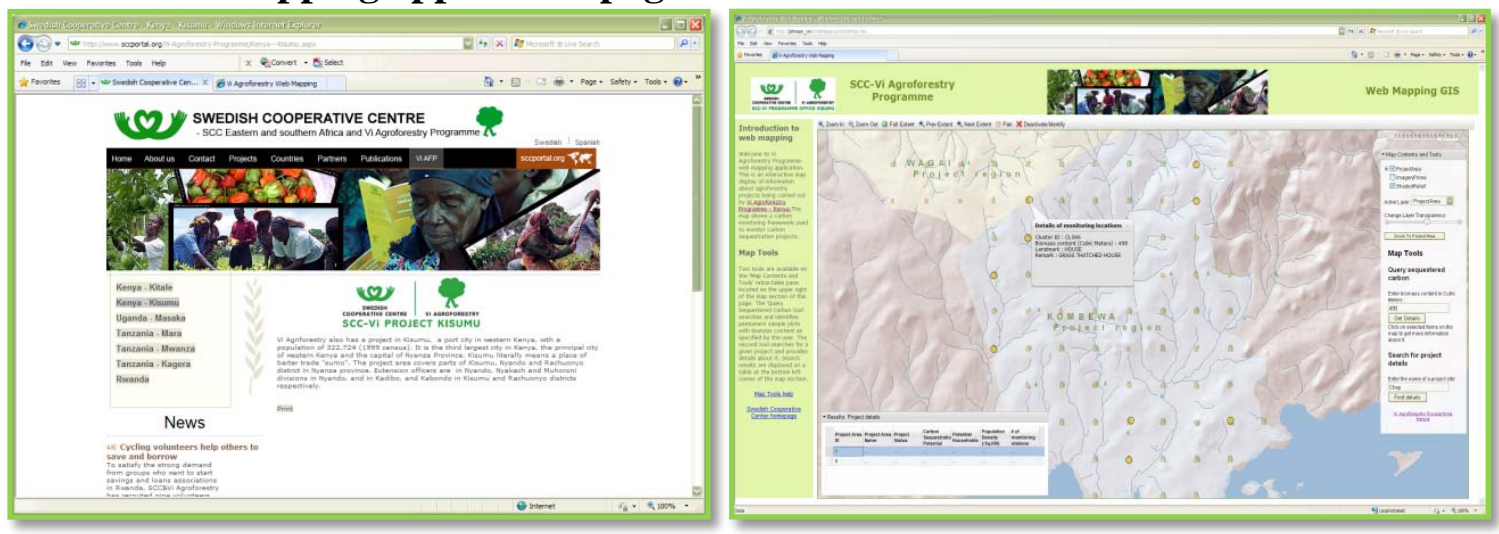

The web page was designed for a minimum browser resolution of $1024 \times 768$ pixels and took into considerations users who would use the page at a size that is not maximized (Figure 6.5). The page has a flexible width where the map section was programmed to automatically resize and does not require a user to scroll horizontally.

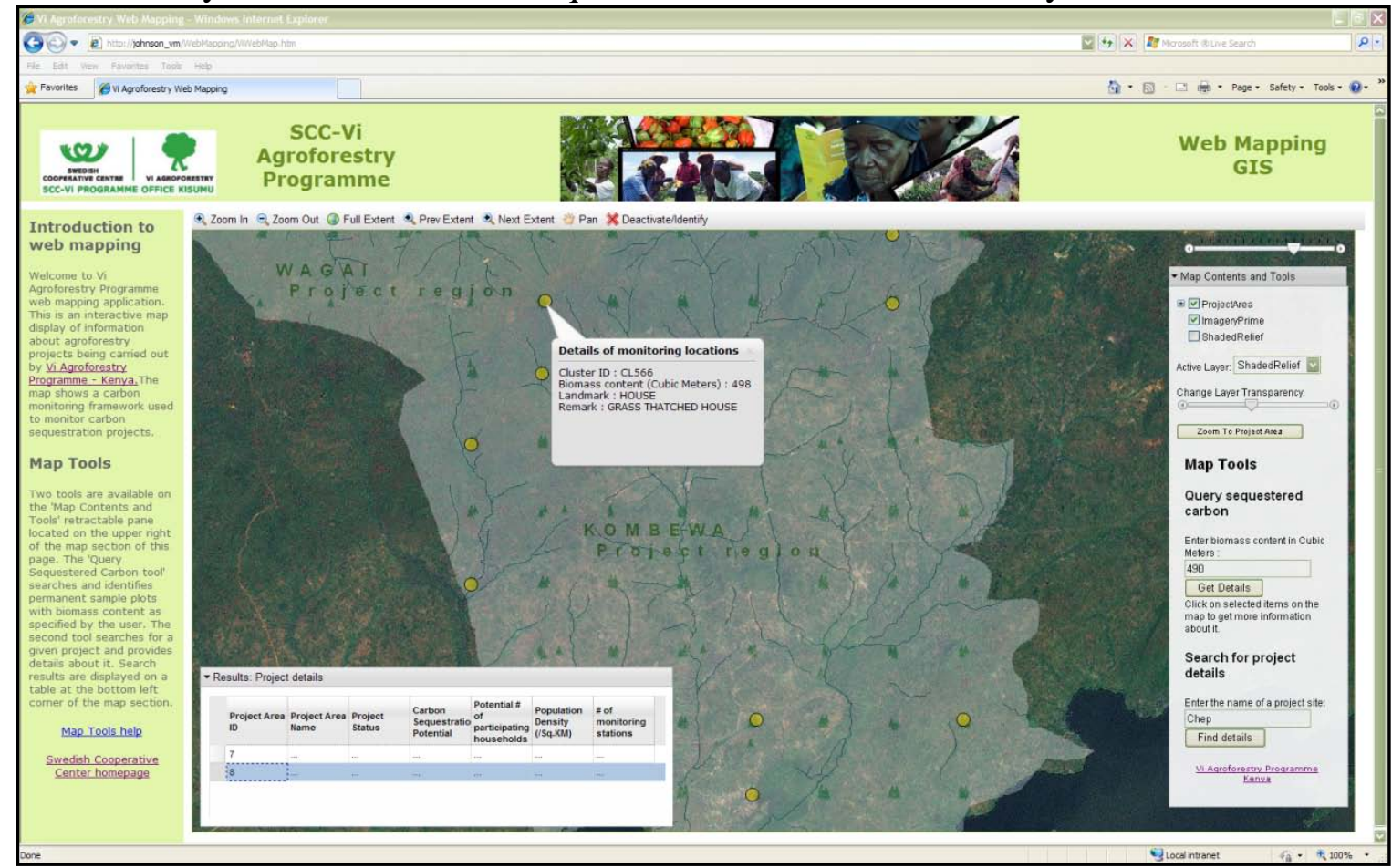

Figure 6.5: The Vi AFP web mapping application page

The web page uses retractable panes in order to maximize the map section. It also supports numerous map services where a user can select one or more map service to be displayed at a time. The transparency levels of each map service can be adjusted to give a desired cartographic impression that is appealing for communicating results (Figure 6.6). 


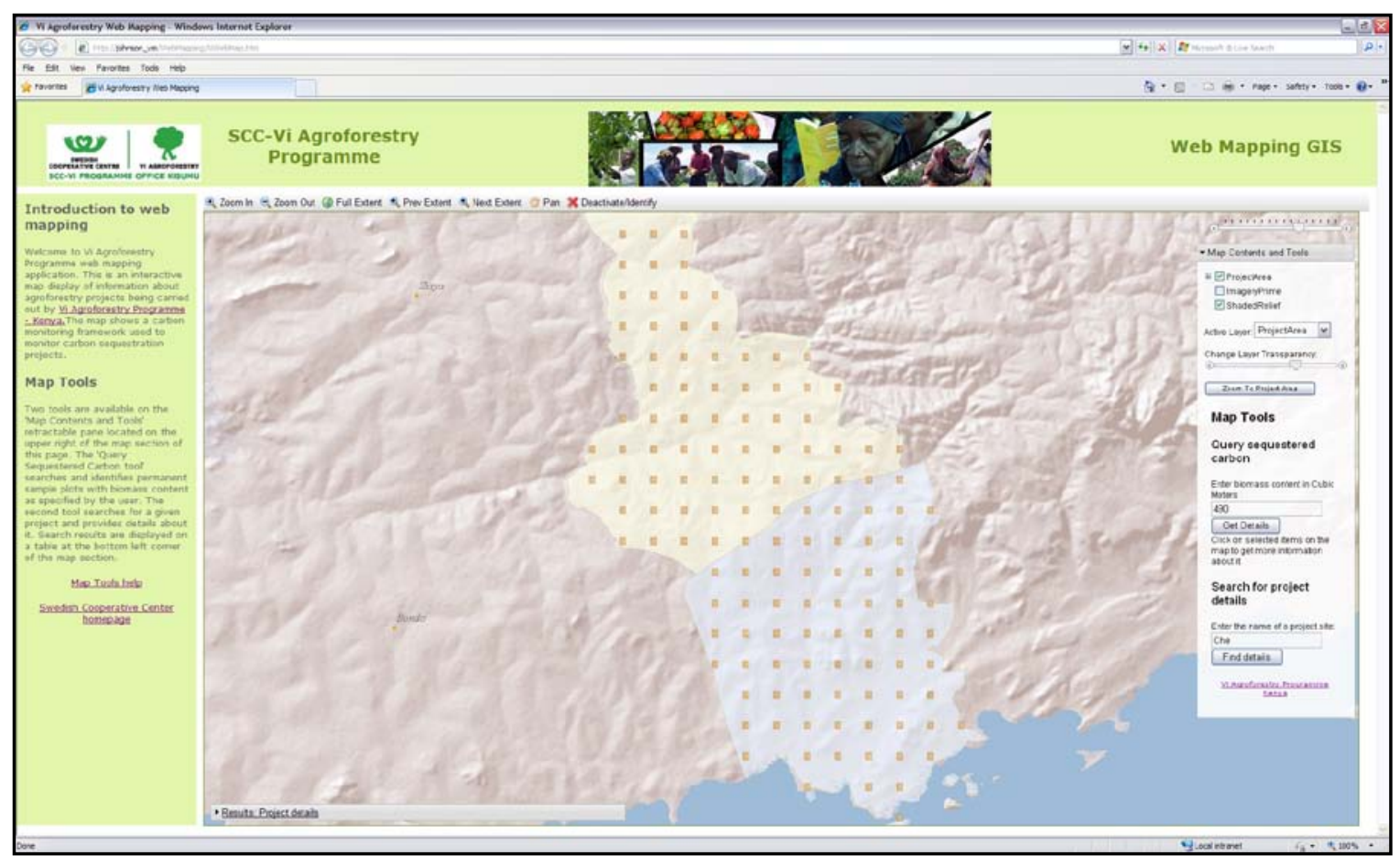

Figure 6.6: The Vi AFP web application map services

\subsection{Applications Development}

The design of the web page considered several factors including target audience and purpose. The audience was the most important factor to be considered during the design. This project designed a web mapping application that targeted the Vi AFP donors, potential donors, and partners interested in carbon sequestration projects. The main purpose of the web mapping application was to create an interactive map-based source of information about carbon sequestration projects that the organization is carrying out. The application allows users to locate and view maps of project sites, and obtain additional information about projects.

A server-side web programming approach was used to develop a web mapping application in which the server executes code when map server operations are called up by a user. Resulting HTML/DHTML is returned by the server and the user's browser sees only the results. With a server-side programming approach, less code is downloaded to the end-user's browser; therefore a fast response over low internet connectivity can be attained. There are also fewer compatibility issues with different versions of browsers that a diversified user group uses. Another advantage of server-side programming is that users can be allowed access to data in a spatial database, but code remains hidden.

Server-side programming also has some disadvantages that are worth highlighting. A request has to make a round-trip from the user to the server and from the server to the user in order to be executed. This leads to a slower response than a client-side setup. Some functions must also occur on the client side, such as drag-box zoom on a map and opening a pop-up window or a new site to display results. A server-side application approach also requires support for server-side code. 
ArcGIS Online map services were used to complement the two map services created by this project in section 6.2 in implementing web mapping application. These secondary services provided base map data of satellite imagery, streets, and relief display.

A retractable pane (Map Contents and Tools) at the top right corner of the map section was created to contain tools used to interact with the map (Figure 6.7). On the panel, the users can check what layers are to be displayed (or hidden) on the map at a particular time. Users can also alter transparency of an active layer and enables creating a view of two complementing layers at a time. A zoom to area button is useful to zoom back to the project area at any point while a user is interacting with the application.

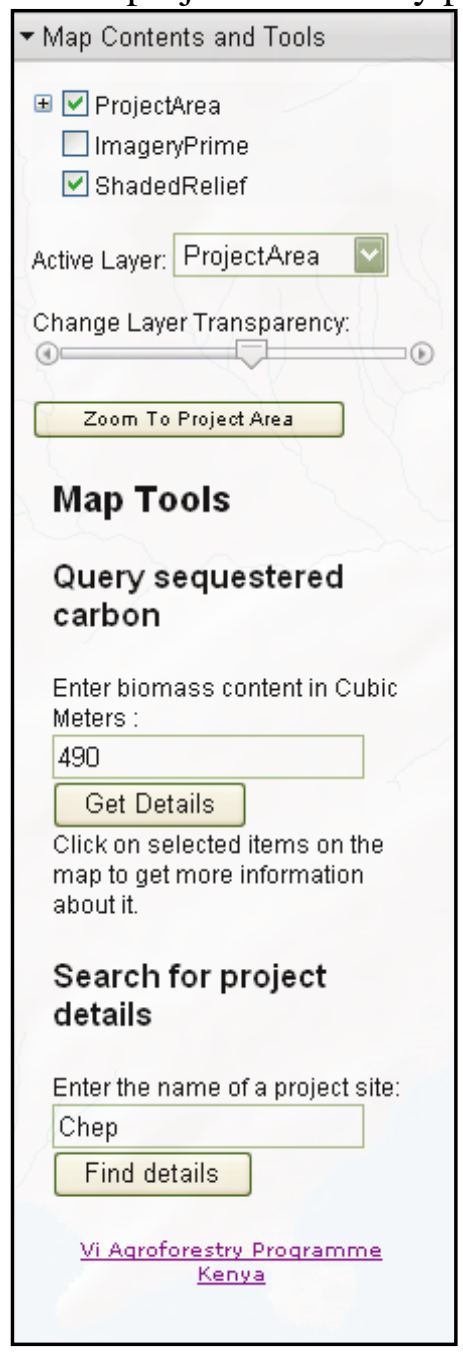

Figure 6.7: Map contents and tools panel

This project developed two custom applications: a Search Project Details tool and a Carbon Content Query tool. The functions and results of these tools will be discussed under the results section in Chapter 7 . 


\subsection{Web Application Test and Deployment}

The web mapping application was subjected to a performance test before deploying it into production. Two main criteria of throughput and response time were used to measure performance. Throughput is the amount of work done by the server in a unit time. Response time is the user-perceived time that elapses between sending a request and receiving a response. This time consists of client processing time, network time, and server processing time (Peng \& Tsou, 2003). Figure 6.8 shows a sample response time of the Vi AFP web mapping application. On opening a map page, a total of 28 requests are sent to the server. The requests retrieved 12 tile map images excluding image icons used for navigation tools and title pane.

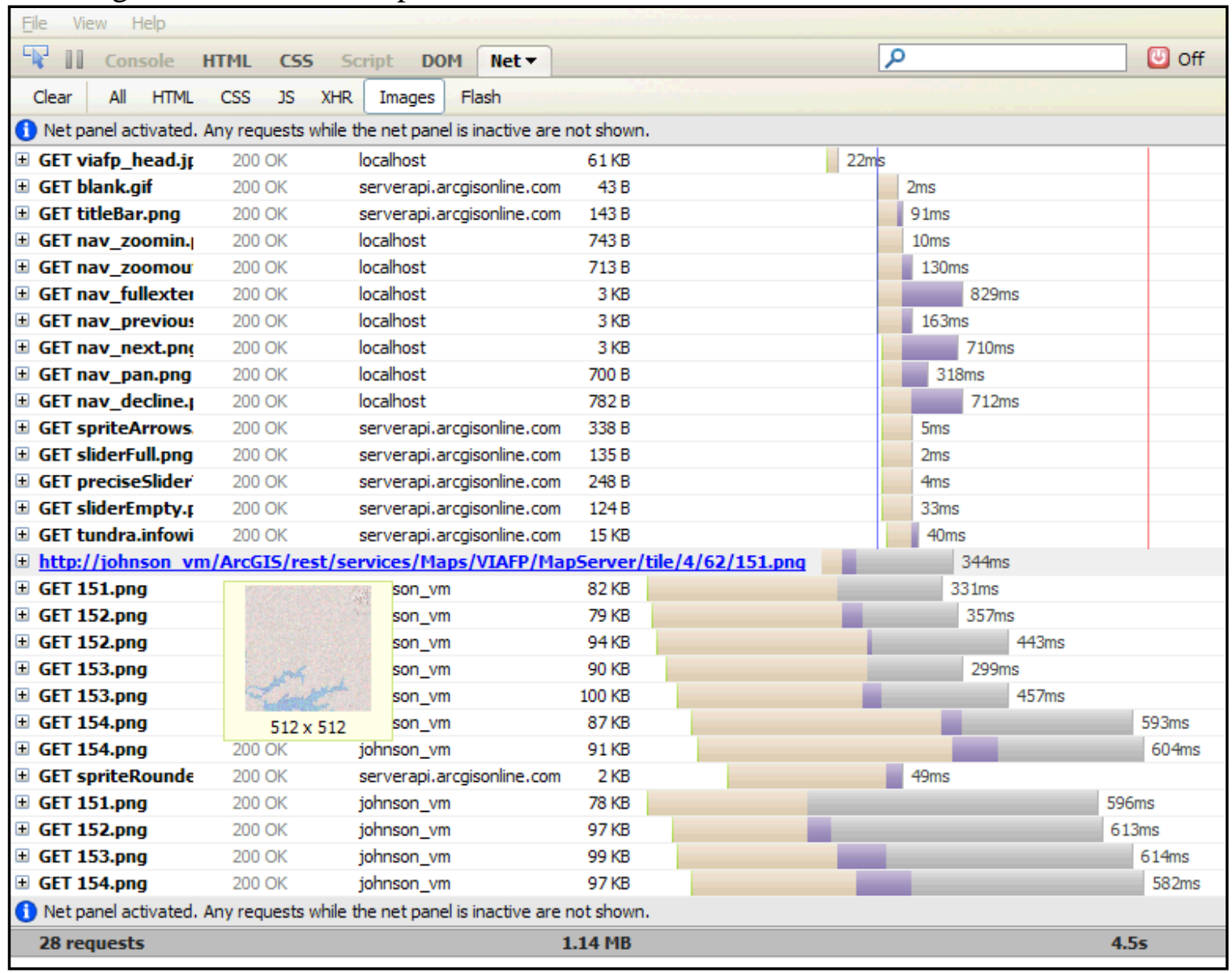

Figure 6.8: Application test statistics of the Vi AFP web mapping application 



\section{Chapter 7 - Results and Analysis}

This chapter discusses project results and analysis. The designed system components and developed tools are described in detail. While this project implemented a Web GIS to support implementation and monitoring of carbon sequestration, the goal was to establish a GIS framework to support subsequent analysis. For this reason, a limited GIS analysis within the scope of the project was conducted. Two major system components were created:

- A spatial database that forms a repository for the organization's spatial data and other non-spatial information pertinent to the performance and monitoring of carbon sequestration projects.

- A web mapping application that communicates spatial information and attribute data of projects being carried out by the Vi AFP.

\subsection{Carbon Sequestration Monitoring Database}

This project created a database to support the monitoring and evaluation of carbon sequestration in agroforestry projects of the Vi AFP. The implemented database has the capacity to capture and store all data variables necessary to monitor carbon over time. The system stores project performance indicators and the client's base data needs, and collate diverse sources of data that are collected using different means. The carbon monitoring process that the project database sought to support has defined procedures and operations acceptable to the Vi AFP, donors, and the carbon market. The database sought to mimic the client's monitoring procedures as to how data is collected and in what format it is. Field data collection procedures were analyzed and translated into a database structure that maintained real logical relationships between data elements. Through an analysis of requirements and an iterative consultation process with the client, the database design created catered to the needs of a carbon monitoring framework.

The Vi AFP currently does not have a comprehensive GIS to support carbon monitoring projects. At present, efforts are underway to complete a pilot phase of data collection. The project-specific data that was available for this project was therefore limited to the pilot sample collected within selected project sites. A carbon monitoring framework contains a project area with defined reference sampling points and permanent sample plots (Figure 7.1). It also has the geographic locations of households participating in a project. The database was designed to supports the carbon project implementation and monitoring needs identified during the user needs assessment. The needs encompassed maintaining accurate location information of monitoring plots and creating map products required for planning, implementation, and monitoring processes, all of which were supported by the database. 


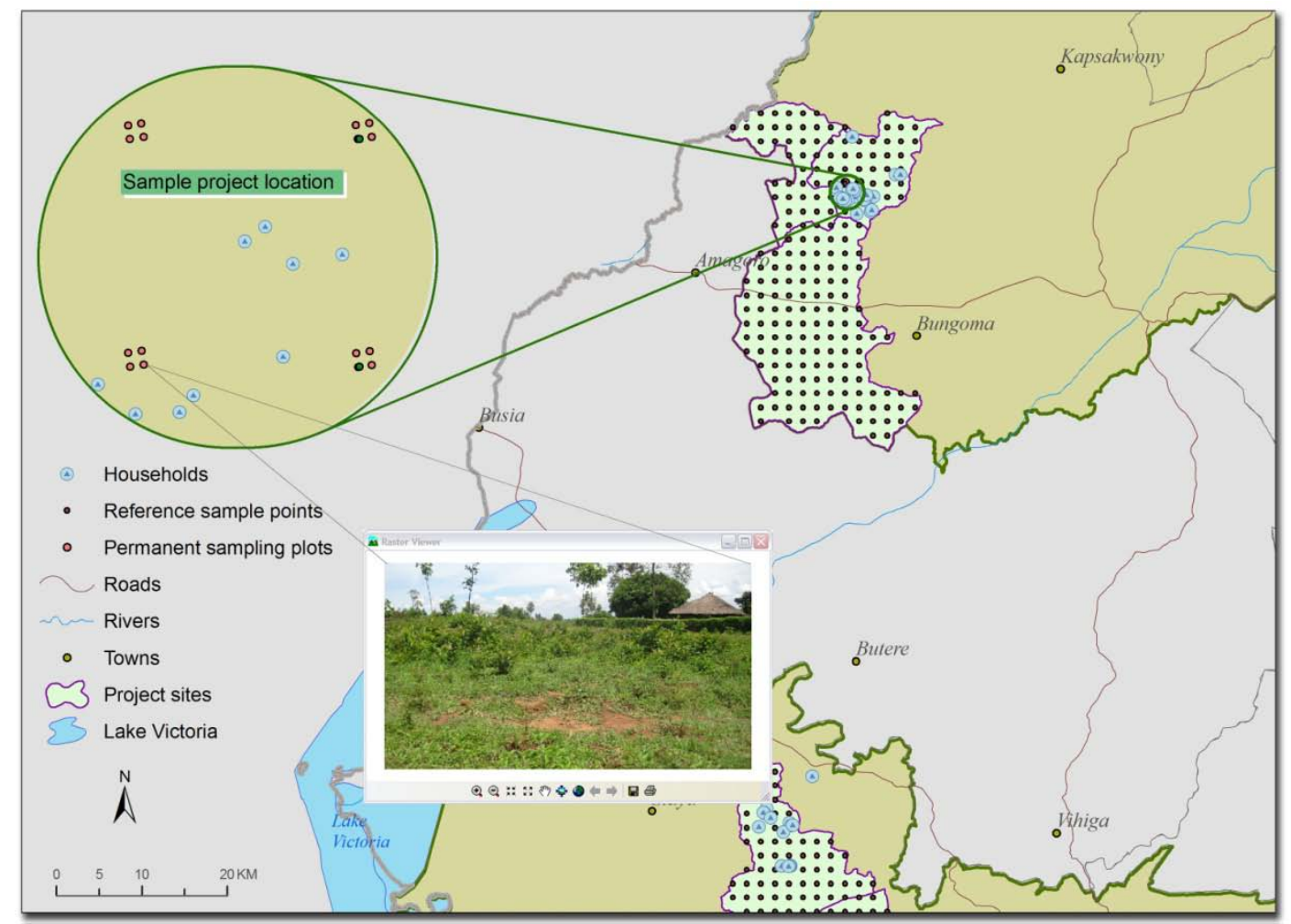

Figure 7.1: Monitoring framework supported by the designed database

Project region identification and preliminary mapping is carried out using satellite imagery, administrative boundaries, hydrological data, and land use/land cover data. The selection of a project region is to a great extent guided by the goals of the organization in undertaking a project at a particular region. The preliminary map covers as much as possible all the potential areas where a project can be implemented (Figure 7.2). The yellow boundary is the region with a potential to implement carbon projects. 


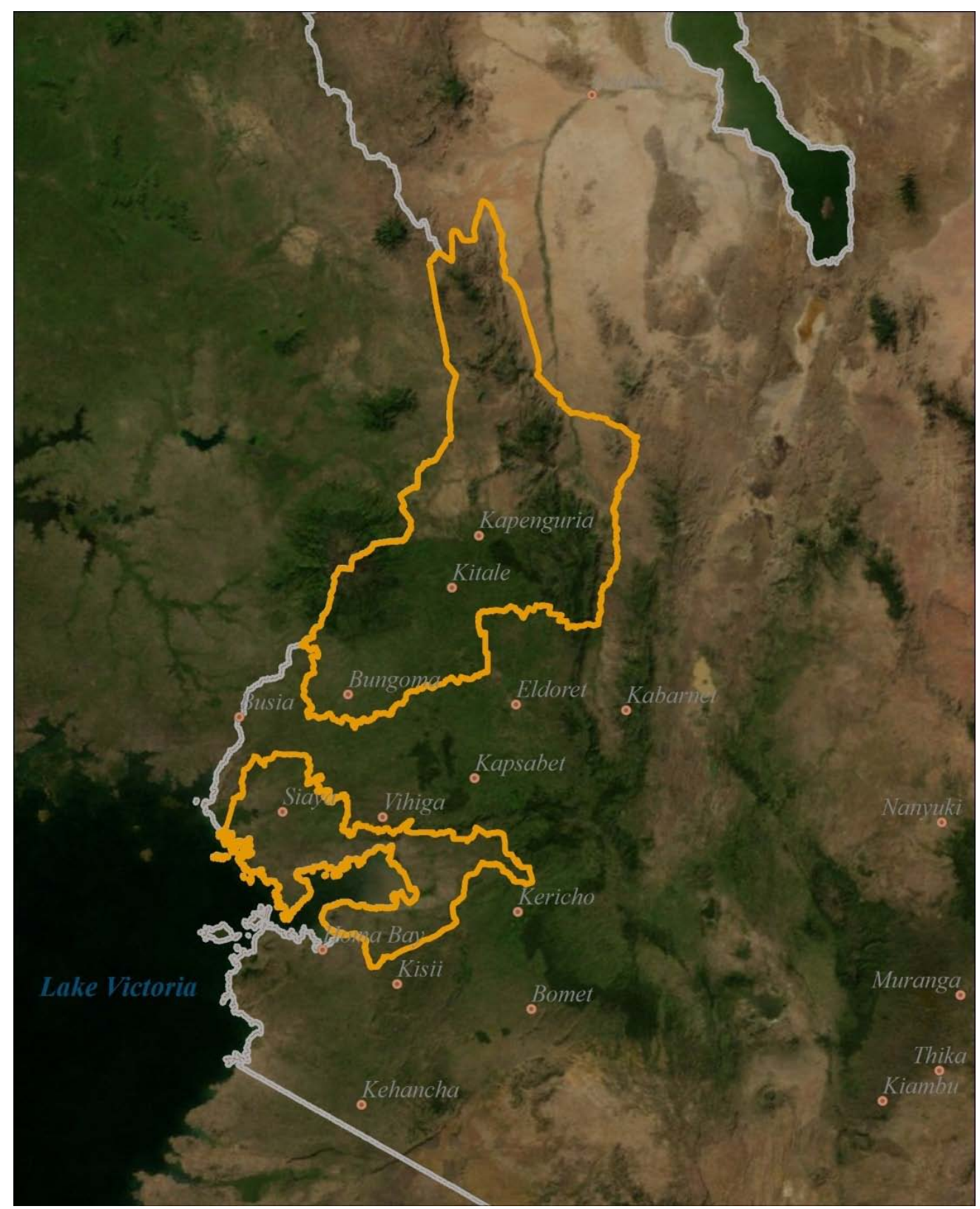

\section{Figure 7.2: Standard project region map}

Once a project region has been identified, a selection of potential project sites is defined with supporting data from the database. Remote sensing techniques are used to carry out a vegetation cover change analysis over time. Areas that have been deforested are prioritized as high potential. This process involves using a series of Landsat satellite images and land use/land cover data set to identify potential areas for carbon sequestration. Base data is then used to eliminate zoned areas like urban centers, military zones, lakes, wetlands, etc. Roads and road reserves are also eliminated when calculating carbon pools of a given project area (Figure 7.3). 


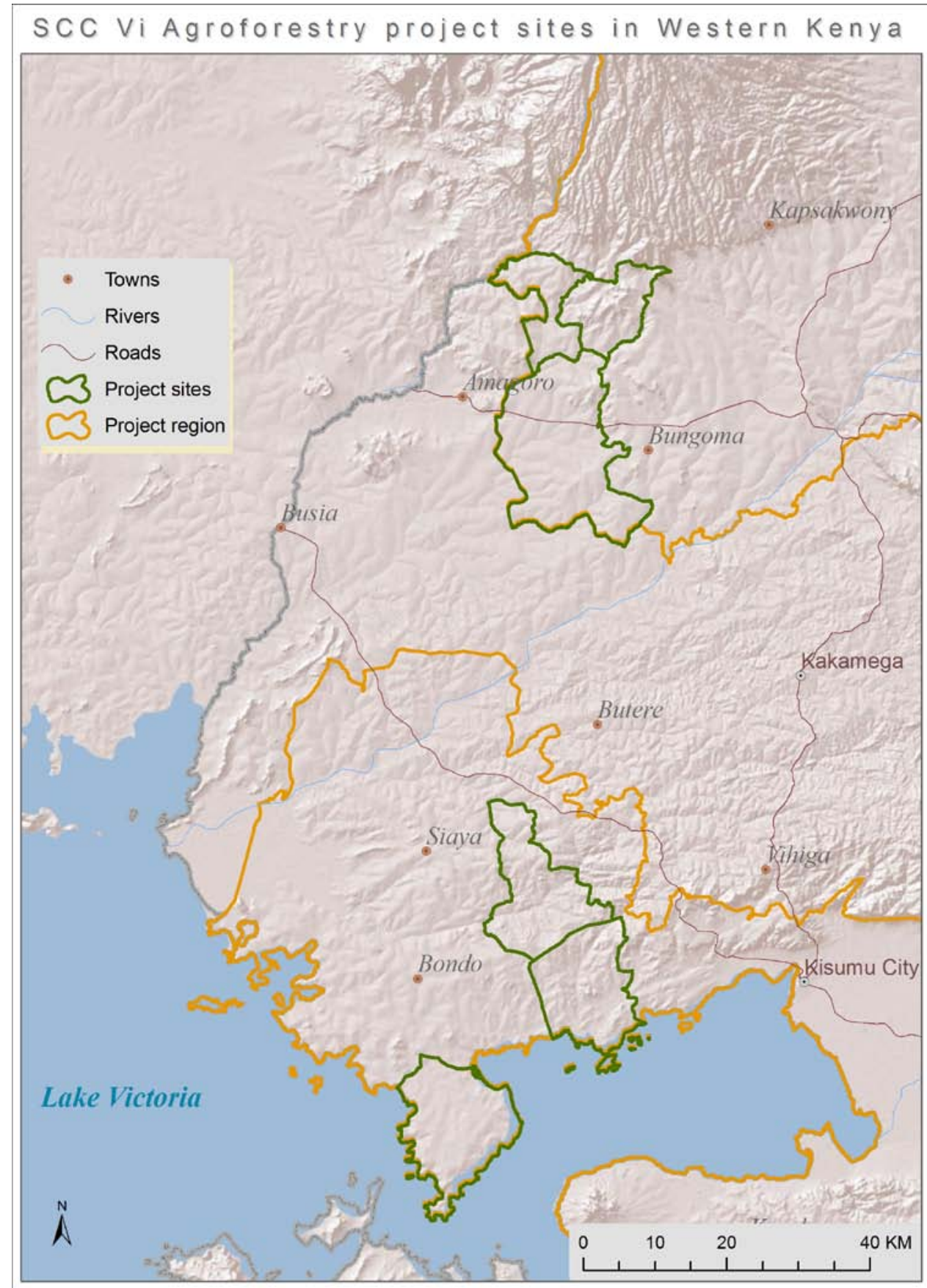

Figure 7.3: Potential sustainable land management (SLM) map of project sites

After establishing project sites, a baseline biomass assessment is conducted to determine a basis from which carbon emission reductions will be calculated. A monitoring reference network is first established guided by the carbon project model being adopted by the organization. Because biomass measurements cannot be made at every point of a project area, a statistical sample of locations is selected. This process utilizes GIS capability to generate systematic random point locations at the project sites. These points form reference sample locations that will be used to monitor biomass changes throughout a project's life span (Figure 7.4). 


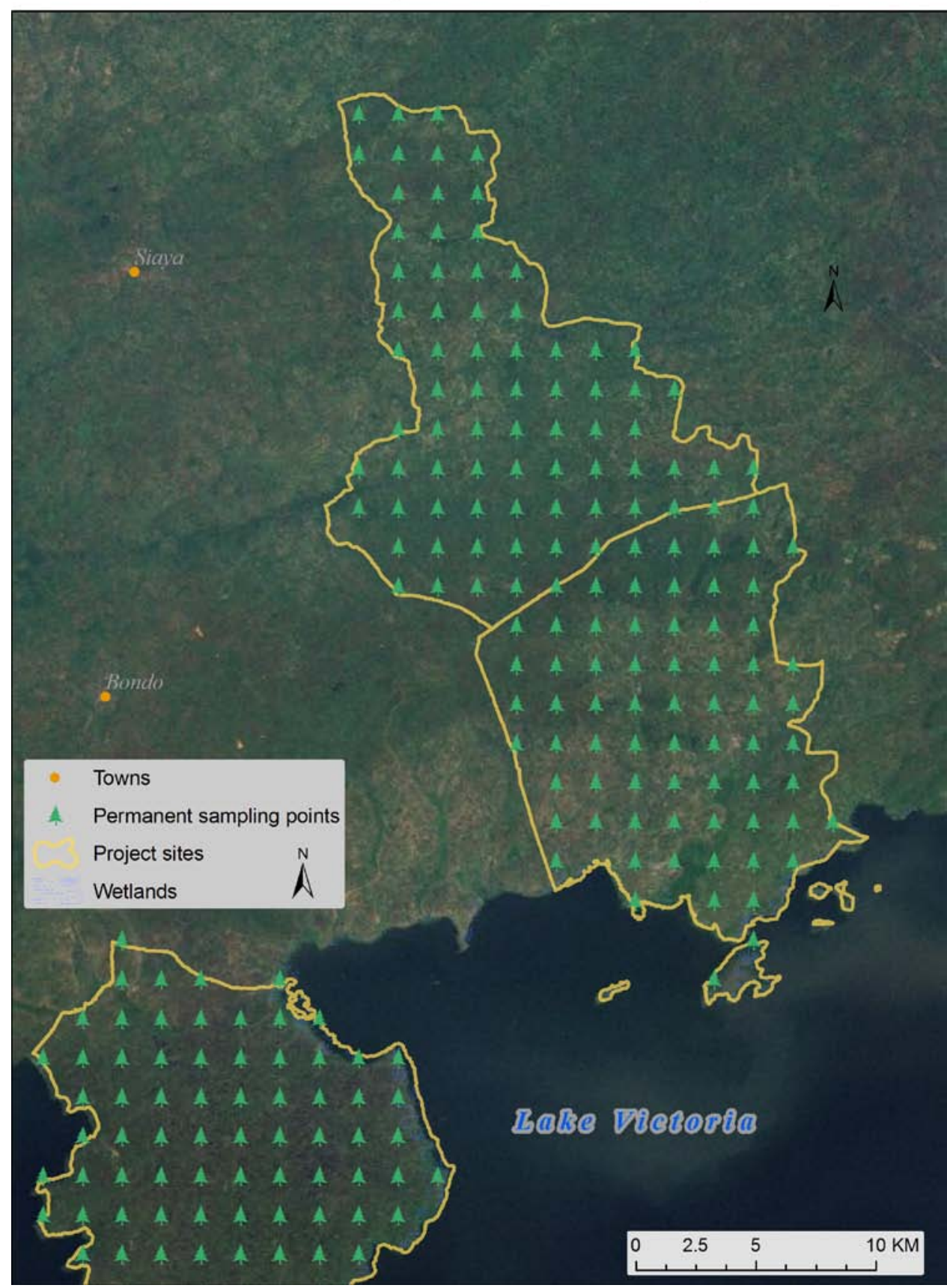

\section{Figure 7.4: Reference sample points used for project monitoring}

The next step in the monitoring process is to stratify project sites according to a defined criteria based on biophysical factors such as land-use, soils, rainfall, and climatic conditions. This allows for more accurate calculation for varying carbon pools at a project site, thus increasing the accuracy of quantifying carbon emission reductions. The database contains agro-ecological zones data set developed to provide data for such a stratification procedure. An overlay process is performed on the agro-ecological zones 
and the project sites to stratify the sites (Figure 7.5). This process results in assigning the type of agro-ecological zone to the reference sampling points.

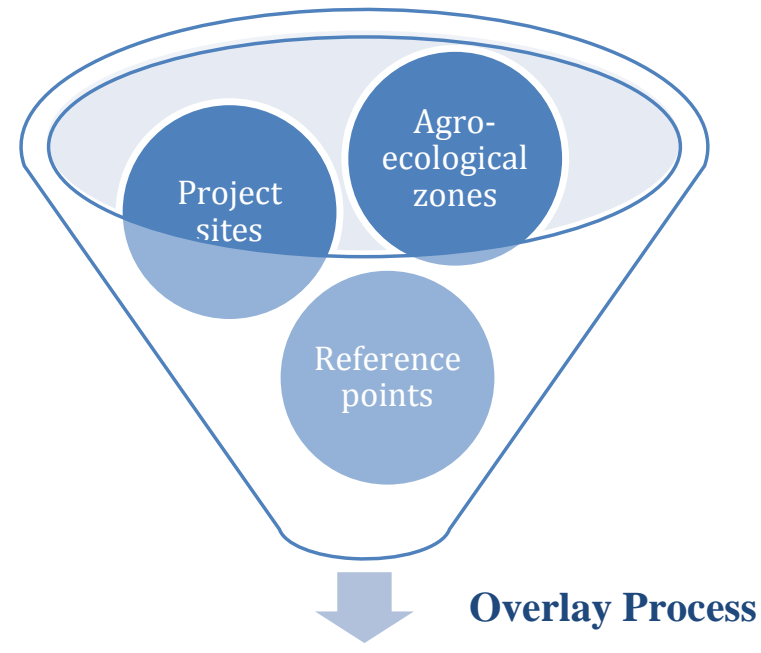

Stratified project sites

\section{Figure 7.5: Stratification of project sites}

The resulting strata represent agro-ecological zones that exist in a project site (Figure 7.6). Each stratum has unique properties that are considered in calculating the biomass content at a particular area. 


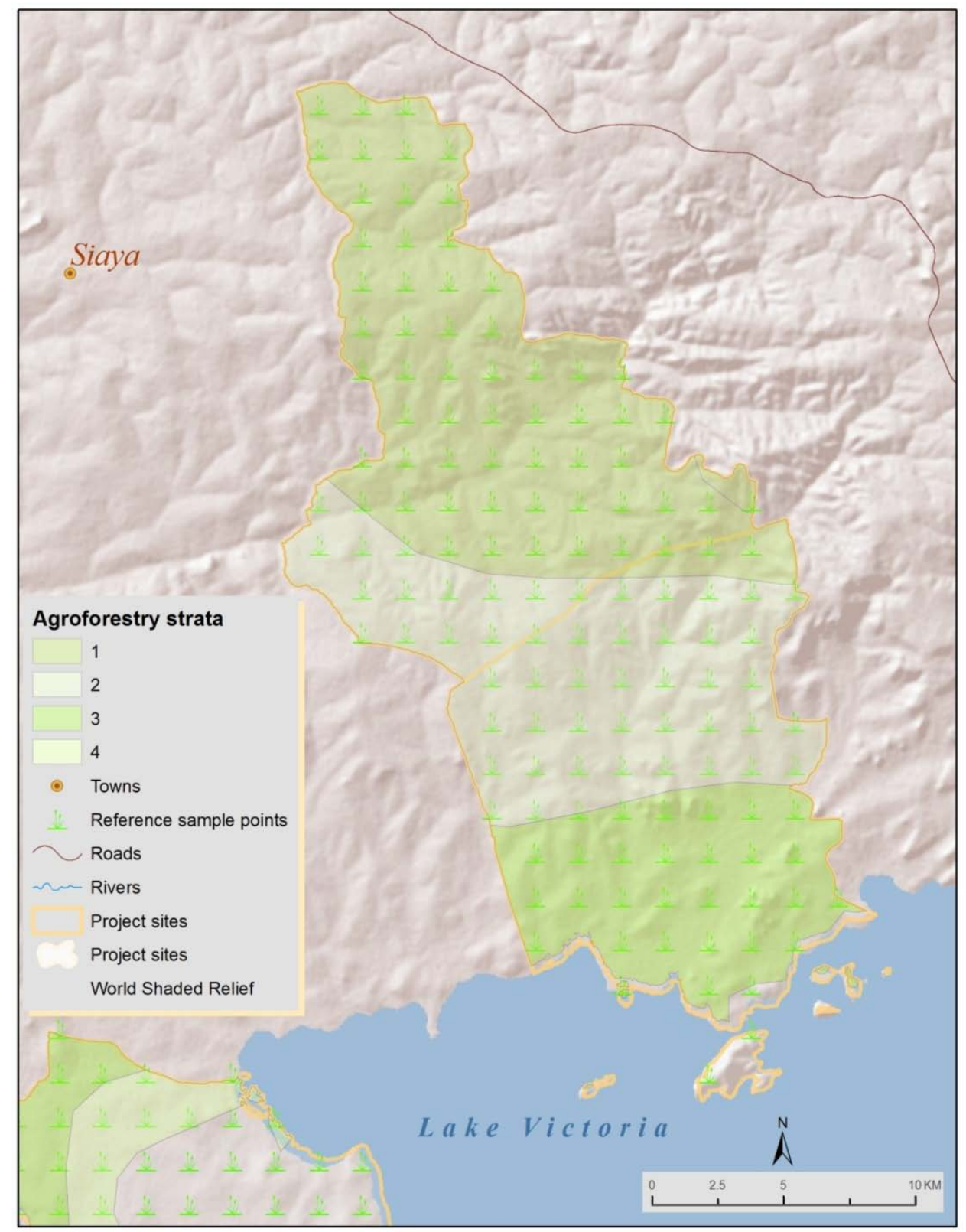

Figure 7.6: Potential SLM adoption map of stratified project sites

\subsection{Web Mapping Application}

This project authored and published map services using data from the developed database. Map services were authored with the objective of availing the content information to internet-based users through Web GIS applications. The services also supported the functionalities of two major Web application tools developed: a project details search tool and a carbon content query tool. The tools targeted project stakeholders and partners interested in carbon projects in the region. The database that was implemented (discussed in Chapter 5) provided data that is required to develop an online Web GIS application for an internet audience. 


\subsubsection{Carbon Content Query Tool}

The carbon content query tool provides information about potential areas that can sequester carbon credits of a given volume in cubic meters. A user is presented with an input box where a numeric value that defines the minimum amount of carbon emissions that can be sequestered at a given place. The tool returns a selection of places where there is a potential of sequestering at least the entered volume of carbon. The user can then click on the results to obtain more details about that area (Figure 7.7).

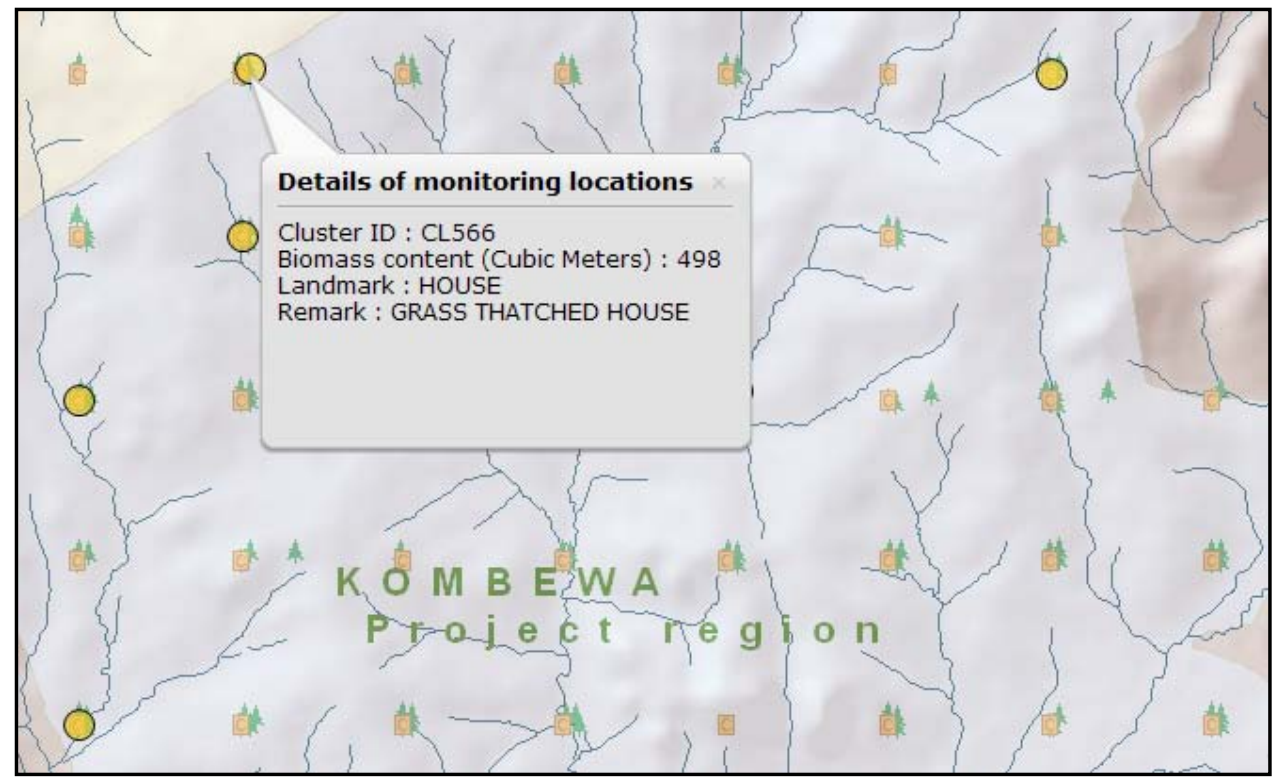

Figure 7.7: Query tool results

When a user enters a value, the value is used in a query to filter attribute details of sample plots. The query used is:

query. where = "Biomass_content $>$ " + Sampling_points; 


\subsubsection{Search Project Details Tool}

A tool to search and locate projects being carried out by the organization was created. The tool uses the search task in the JavaScript API for ArcGIS. It searches selected fields of an identified layer in the database and returns matching results. The tool returns attribute information a tabular form. Attributes returned include current status of the project (active or inactive), the potential amount of carbon that can be sequestered, potential total number of households that can participate in a project, the population density of the site, and the number of reference monitoring stations for carbon measurements (Figure 7.8).

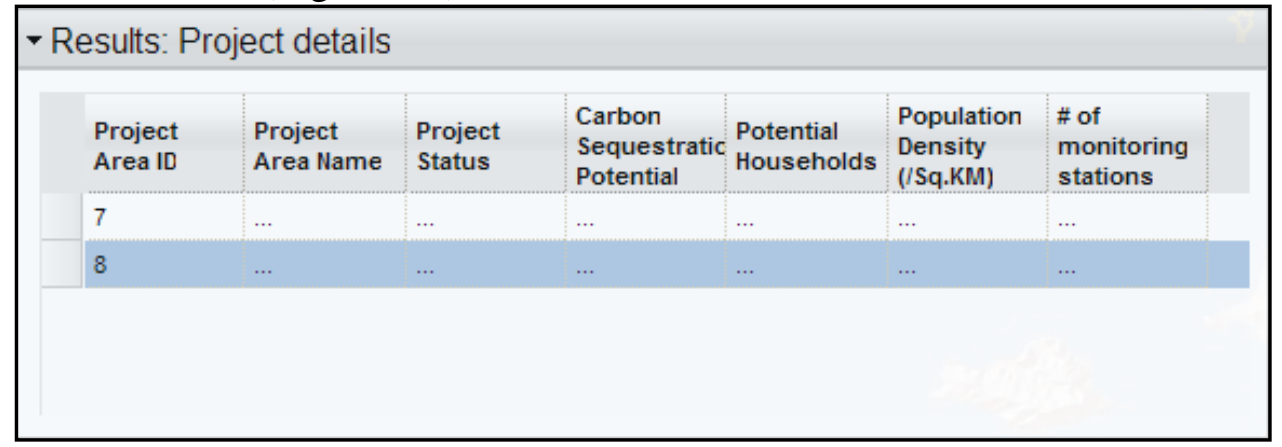

Figure 7.8: Search results

A user enters the name of a project in question and runs the tool. When the tool completes executing, it returns selected project sites and its details on a table form. These results are displayed on the 'Results: Project details' retractable pane located at the bottom left of the map section. A user can then click on one of the project sites to locate and zoom to a particular project site. The general physical characteristics of selected regions are seen on the underlying satellite imagery. 



\section{Chapter 8 - Conclusions and Future Work}

This chapter presents the summary, conclusion, and future work related to the project. It outlines a summary of the user requirements, data requirements, and the implemented solution. The chapter also discusses future works and improvements that can be made to the database system, as well as the web mapping applications.

The main goal of this project was to implement a system to support the monitoring process of carbon sequestration projects and to share resulting spatial information about the Vi Agroforestry Programme in Kenya. The effective execution of carbon sequestration projects requires scientifically grounded methods and tools to assess and quantify biomass contents at given locations, and to keep track of changes over time. These carbon projects are often governed by established procedures that guarantee market credibility of carbon credits produced by an organization, as is the case with the Vi AFP. A system was, therefore, required to meet these requirements and standards for successful implementation of such projects.

The first objective of this project was to develop a spatial system that met the requirements of carbon monitoring of agroforestry in projects. This meant the system had to structurally encompass varied data and project performance indicators required for monitoring carbon, and support project implementation and reporting. A requirement analysis process provided the data requirements and needed information products. Among the information products identified were map needs that the system catered to. The map requirements included standard project region maps, potential sustainable land management (SLM) activity maps, stratified SLM activity maps, potential SLM adoption maps, project status maps, and baseline survey preparation maps. An agile system design approach was used to ensure that all client requirements were met by the system. This development approach involved iterative consultations with the client; system requirements and deliverables evolved over time to meet the outlined requirements.

The project evaluated various data models to determine a best fit to model the monitoring operations of the Vi AFP. The evaluation process adopted a semi objectrelational data model which has the advantages of fast data access coupled with its ability to abstract complex data. This was followed by building a geodatabase to host the client's spatial and non-spatial data thematically divided into the following data sets: carbon monitoring, biophysical data, hydrography, base data, project performance indicators, and time series satellite images.

The second objective of this project was to develop a web mapping application to share the Vi AFP carbon project information to a wider audience over the internet. Having implemented agroforestry projects for over 25 years, the organization has a wealth of information that can be shared with interested partners and donors. Online availability of carbon project status and information enhances transparency and increases project credibility. A requirement analysis was conducted to determine the user's expectations and data restrictions. The analysis determined the purpose of the web mapping application, the target audience, and application tools to be developed to meet the requirements. Selected data with approved restrictions were used to prepare map services required to build web applications. The project authored map services using ESRI’s ArcGIS desktop application - ArcMap and published the services using ArcGIS 
Server technology. The map services were optimized to provide fast, reliable information suitable for use in low internet connection conditions.

The project developed a web mapping application using JavaScript API for the ArcGIS platform. The developed application was a mash-up of project-specific map services and ArcGIS Online map services. It contained interactive maps and a set of tools that allows users to search and query the underlying database. The first tool searches and displays project location in which a user is interested. This tool is intended for project stakeholders and donors who have or are interested in knowing details about on-going projects of the Vi AFP. The second tool queries the database for areas that have the potential of sequestering a given amount of carbon in cubic meters.

In conclusion, the implementation of a Web GIS for monitoring and evaluating carbon sequestration in agroforestry successfully met the client's requirements and therefore, was a success. The prototype system developed by this project will be put into use by the client once the necessary infrastructure is in place.

\subsection{Future Work on the Database}

During the implementation process, several challenges and opportunities were encountered that create areas of research that can improve similar systems.

- Integrating developed system with other organization's systems

- Develop field data collection workflows

This project developed an object relational database that focused specifically on supporting carbon projects within the organization. Two key advantages of semi objectrelational databases are scalability and the flexibility to be integrated with other systems. There are other systems such as finance system, human resource database systems, and donor databases that have the potential to be integrated with systems developed by this project.

The database system implemented for this project took into consideration the workflows of the project monitoring process, which relied heavily on effective field data collection process to provide accurate data with reliable standards. The implemented database schema can be adopted to create field data collection workflows that enforce database structure and standards on the collected data. This will open up other possibilities like remote database synchronization with new data, thus allowing updates from field updates to be made directly to the database.

\subsection{Future Work on the Web Mapping Applications}

Due to time constraints, more desired functionalities could not be added to the web applications. Web applications implemented by this project focused on providing a lightweight application that can effectively run under low internet connectivity. However, a recommendation was made to improve the connection speeds so as to pave the way to more interactive and appealing applications rich in graphics and color. Two main recommendations for future work are to:

- Implement online analysis

- Develop a means to access metadata about data used in the applications 
The success of developing effective online analysis tools is reliant on sufficient internet connectivity of not only the end-user machines but more so of the hosting servers. The Vi AFP can develop applications that give users online analysis to identify areas of interest and model an estimate of the amount of carbon emissions that can be attained over a given period of time. This tool should be able to determine current baseline biomass and use carbon calculation prediction models to estimate the amount of carbon that will be sequestered by a date of the user's choice. Such application functionality is achieved by publishing models and geo-processing tools to create geoprocessing services.

Lastly, the base map services that were created by this project can be publicly shared to allow interested parties to make use of them. Such map services cover an area larger than the Vi AFP project area and would be of interest to project partners and collaborators in the region. Searchable metadata of map services utilized to develop mapping applications can be created and posted online. This metadata should be readily accessible, either from the application tools or in the application web page. Information about availability of carbon project base map services can also be published online.

\subsection{Effective Monitoring of Carbon Sequestration Projects}

Agroforestry carbon sequestration in East Africa is a relatively new concept that is yet to be adopted by many other environmental conservation organizations, agencies, and government institutions among others. The potential impacts of such carbon projects are global and far reaching ranging from reduction of carbon dioxide emissions, climate change mitigation, improved soil structure, increased farm productivity, and improved livelihoods of small scale farmers. However, the realization of these benefits hinges on effective and efficient approaches to project implementation and monitoring of sequestered carbon. In this project, GIS was applied to feasibly create a scientifically grounded framework on which project implementation and monitoring process can rely on. The implemented GIS brought disparate biophysical information together into a system and synthesized to provide and accurate means of calculating soil carbon pools.

Availing project information over the internet not only raised transparency but also credibility of such projects. This formed a powerful advocacy tool to reach out to carbon markets, donors, and other interested stake-holders. The overall effect being the potential availability of more funding sources to support agroforestry carbon sequestration projects and at the same time healthier carbon markets that duly compensates farmers for their carbon emission reduction efforts. 



\section{Works Cited}

Alain, A., \& Serigne, K. T. (2003). Carbon sequestration in tropical agroforestry systems. Agriculture, Ecosystems \& Environment , 99 (1-3), 15-27.

Ambler, S. W. (2005). The Elements of UML 2.0 Style. Cambridge: Cambridge University Press.

Antle, J. M., Capalbo, S. M., Mooney, S., Elliot, E. T., \& Paustin, K. H. (2001). Economic Analysis of Agricultural Soil Carbon Sequestration: An intergrated Assessment Approach. Journal of Agriculture and Resouce Economics .

Arctur, D., \& Zeiler, M. (2004). Designing Geodatabases (1st ed.). Redlands: ESRI Press.

Bentrup, G., \& Leininger, T. (2002). Agroforestry: Mapping the way with GIS. Journal of Soil and Water Conservation (148A).

Bettinger, P., \& Michael, W. G. (2004). Geographic Information Systems: Applications in forestry and natural resources management. New York: McGraw-Hill.

Campagna, M. (2006). GIS for Sustainable Development: GIS for Sustainable Development. Boca Raton: Taylor \& Francis Group.

Ellis, E. A., Bentrup, G., \& Schoeneberger, M. M. (2004). Computer-based tools for decision support in agroforestry: Current state and future needs. Agroforestry Systems , 401-421.

Ellis, E. A., Nair, P. K., Linehan, P. E., Beck, H. W., \& Blanche, C. A. (2000). A GIS based database management application for agroforestry planning and tree selection. Computers and Electronics in Agriculture , 27 (1-3), 41-55.

Ellis, E. A., Nair, P., \& Jeswani, D. S. (2005). Development of a web-based application for agroforestry planning and tree selection. Computers and Electronics in Agriculture , 129-141.

Elmasri, R., \& Navathe, S. B. (2000). Fundamentals of Database Systems. Reading: Addison-Wesley.

Ikerd, J. E. (1993). The need for a system approach to sustainable agriculture. Agriculture, Ecosystems \& Environment, Volume 46 (Issues 1-4), 147-160.

Kingston, R., Carver, S., Evans, A., \& Turton, I. (2000). Web-based public participation geographical information systems: an aid to local environmental decision-making. Computers, Environment and Urban Systems (24), 109-125.

Nair, P. K. (1991). State of the art of agroforestry systems. Forest Ecology and Management, Volume 45 (Issues 1-4), 5-29.

National Research Council of the National Academies. (2002). Down To Earth: Geographic Information for Sustainable Development in Africa. Washington, DC: The National Academies Press.

Peng, Z.-R., \& Tsou, M.-H. (2003). Internet GIS. New Jersey: John Wiley \& Sons, Inc.

Peters, D. (2008). Building a GIS. Redlands: ESRI Press.

Stephens, J. C. (2006). Growing interest in carbon capture and storage (CCS) for climate change. Sustainability: Science, Practice and Policy , 2 (2), 4-5.

Tomlinson, R. (2007). Thinking about GIS: Geographic Information System Planning for Managers (3rd Edition ed.). Redlands: ESRI Press.

United Nations. (1992, July). Agenda 21. 
Warkentin, E. M., Nair, P. K., Ruth, R. S., \& Sparague, K. (1990). A knowledge-based expert system for planning and design of agroforestry systems. Agroforestry Systems , Volume 11 (Number 1), 71-83.

World Bank. (2007). World Development Report 2008: Agriculture for Development. Washington DC: World Bank. 


\section{Appendix A. The Vi AFP Data Model}

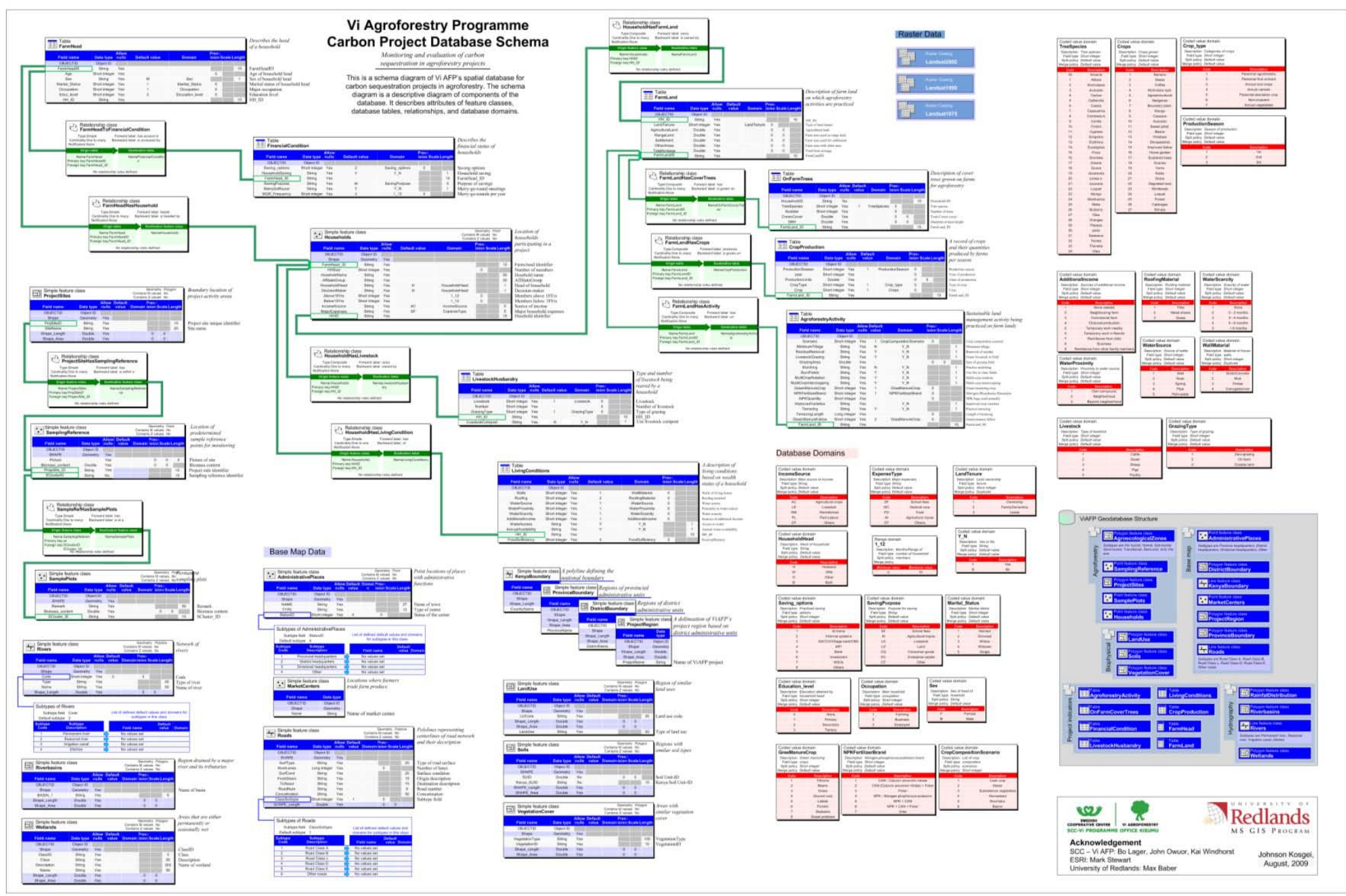


Appendix B. GIS User Needs Analysis Questionnaire

$$
\begin{array}{r}
\text { Vi Agroforestry Programme - Kenya } \\
\text { GIS User Needs Analysis } \\
\text { Questionnaire }
\end{array}
$$

GIS for monitoring and evaluating impacts of sustainable farming practices on carbon sequestration

20 J an 2009

Presented by:

Johnson Kosgei

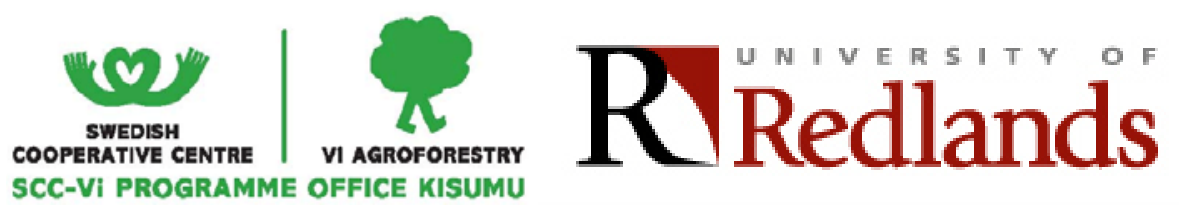




\section{GI S User Needs Analysis Questionnaire}

\section{Introduction}

This is a user needs assessment exercise to identify and collect information that will be useful in designing a GIS system for the organization. The results of this exercise are important and will complement the current efforts of the organization in establishing a GIS to support implementation, monitoring, and evaluating carbon projects. The exercise is carried being out by a student at the Master's of Science in Geographic Information Systems (MSGIS) program at the University of Redlands, California in collaboration with the monitoring and evaluation department of the Vi Agroforestry Program (Vi AFP) - Kenya.

\section{Purpose}

The objective of this questionnaire is to identify specific GIS user groups and usage scenarios of similar GIS functionalities that will help in shaping a robust GIS for Vi AFP. The process will assist in establishing the demand for GIS in the organization in order to design an effective and efficient GIS system to meet those needs. It seeks to:

- Identify the end users of a GIS system,

- Educate users with respect to GIS needs,

- Identify information products,

- Identify data requirements for information products,

- Prioritize data requirements and products,

- Determine GIS functional requirements (hardware/software/future training and expertise). 


\section{What is GI S?}

A geographic information system (GIS) integrates hardware, software, and data for capturing, managing, analyzing, and displaying all forms of geographically referenced information.

GIS allows us to view, understand, question, interpret, and visualize data in many ways that reveal relationships, patterns, and trends in the form of maps, globes, reports, and charts. A GIS helps you answer questions and solve problems by looking at your data in a way that is quickly understood and easily shared.

Some of the information products we can get from a GIS include maps and globes, geographic datasets, processing and workflow models (automated procedures), tables, charts, reports, databases, metadata among others.

Source/further reading: http://www.gis.com/whatisgis/index.html

\section{Analysis}

Please answer the following questions to the best of your ability.

\section{Part I : Personal I nformation}

\section{Name:}

\section{Department: Title:}

How long have you been at the Vi AFP:

What is the level of your knowledge in GIS \& GPS? (Highlight appropriately)

Formally trained in GIS and well conversant with the technology

$\square$ Exposed to GIS and GPS and can collect field data

$\square$ Moderate knowledge on uses and capabilities of GIS and GPS

$\square$ Just heard about the technology 
$\square$ Never heard of it

\section{Part II: Needs assessment}

a) What are your job responsibilities in the organization?

i.

ii.

iii.

iv.

b) What are the tasks that you need to do in order to achieve? i.

ii.

iii.

iv.

c) What information, reports, or data do you have to produce in your work?

i.

ii.

iii.

iv.

i.

ii.

iii.

iv.

d) What information do you need to know to carry out your responsibilities?

e) What information would you expect GIS produce and put to your desk that will provide what you need to know and help you monitor

i. your responsibilities?

ii.

iii.

iv.

\section{Part II I : Follow-up}

As a follow up to this, I will liaise with you to schedule a telephone conversation. The main objective of the call will be to establish workflow within your area of work and to address any issues that might arise from the previous parts. 


\section{Appendix C. Project Use Cases}

\section{Use Case for Mapping a Project Area}

\begin{tabular}{|l|l|l|l|}
\hline Name: & Project site mapping & Priority: & 1 \\
\hline Last Revised: & 21 Jan 2009 & Frequency: & Continuous \\
\hline
\end{tabular}

Description: New project sites have to be mapped to identify households, farm sizes and their locations.

Embedded Use Cases: Famers self assessment

Actors: Farmers, GIS staff, field extension officer, project manager

Trigger: Establishment of a new project site

Stage before: Non-existence of the Vi AFP project activities in the area

Stage after: Start of practicing recommended agroforestry techniques

Script:

1. Project manager makes a mapping request and submits preliminary information about potential project region to GIS team based on reconnaissance visit.

2. The GIS team prepares a standard project region topographical map in preparation for the field work.

3. The project region is categorized into suitable and non-suitable based on base data such as lakes, military zones, and cities.

4. Project sites are further stratified into distinct agro-ecological zones to create a stratified project activity map.

5. GPS locations of households and farms within the project area are collected.

6. Farmers self assessment questionnaires are administered to participating farmers in a project area.

Alternatives: In cases where recent aerial photographs are available, the spatial extent of farms /project sites can be derived whereas additional information will be collected by field extension officers stationed within reach of the site in question.

Business Rules: All project sites should be mapped and documented for at least purposes of reporting and monitoring and evaluation. 


\section{Use Case for Carrying Out a Baseline Biomass Assessment}

\begin{tabular}{|l|l|l|l|}
\hline Name: & Baseline biomass assessment & Priority: & 2 \\
\hline Last Revised: & 21 Jan 2009 & Frequency: & New project onset \\
\hline
\end{tabular}

Description: Before implementing sustainable agroforestry practices on farms in an area, status of existing biomass has to be assessed and recorded as baseline biomass. This process is carried out by monitoring and evaluation team of the Vi AFP

Assumptions: Site reconnaissance has been conducted and a project has been approved.

Embedded Use Cases: Biomass verification.

Actors: Farmers, GIS staff, field extension officer, and monitoring and evaluation team..

Trigger: Establishment and mapping of a new project area.

Stage before: Non-existence of Vi AFP project activities in the area.

Stage after: Start of practicing recommended agroforestry techniques.

\section{Script:}

1. Project manager makes a request to the GIS team to carry out baseline on an identified project area.

2. Permanent sample reference points are generated at an equal interval of $1.5 \mathrm{KM}$ within project areas.

3. The GIS team prepares project adoption topographical maps showing area where farmers actually committed themselves to adopt sustainable land management and agroforestry practices in preparation for the field work.

4. Base maps are prepared to generate logistic information on how to best conduct a baseline assessment.

5. Base maps and permanent sampling reference point data are uploaded into GPS that will be used in the field to guide the baseline assessment.

6. Biomass assessment is carried out at sampling locations by the GIS team with the help of the area field extension officer and the farmers.

7. Sampling plots are measured and located with respect to reference points. At these points the vegetation measurements are made and recorded.

Alternatives: Baseline assessment could be done while carrying out initial site identification and mapping.

Business Rules: A baseline biomass study should be conducted on all sites prior to the start of practicing recommended farming methods. Start of agroforestry projects should take place not later than 3 months after completion of biomass assessment. 


\section{Use Case for Monitoring Carbon at a Project Site}

\begin{tabular}{|l|l|l|l|}
\hline Name: & Carbon monitoring & Priority: & 3 \\
\hline Last Revised: & 2 May 2009 & Frequency: & Annually \\
\hline
\end{tabular}

Description: Periodic carbon monitoring is carried out annually to determine changes in carbon emission reductions at areas where projects are being implemented..

Assumptions: Participating households have implemented sustainable land management and agroforestry practices for at least one year.

Embedded Use Cases: Baseline biomass assessment.

Actors: Farmers, GIS staff, field extension officer, and project manager.

Trigger: At least one year after onset of project implementation and adoption of recommended agroforestry practices.

Stage before: Existing baseline on status of carbon stocks before project implementation.

Stage after: Net changes of carbon emission reductions.

Script:

1. A project manager requests the GIS team to support periodic monitoring of a certain project site.

2. GIS team prepares project adoption topographical maps showing area where farmers actually committed themselves to adopt sustainable land management and agroforestry practices in preparation for the field work.

3. Base maps are prepared to generate logistic information on how to best conduct a baseline assessment.

4. Base maps and sampling plots data are uploaded to GPSes that will be used in the monitoring process.

5. Biomass assessment is carried out at sample plots by the GIS team with the help of the area field extension officer and the farmers.

Exceptions: When sample plots are inaccessible.

Business Rules: This is a participatory process between the farmers implementing the project and Vi AFP staff. It should be carried out according to the Carbon Baseline Survey Manual. 


\section{Use Case for Writing Donor Reports of Project Status}

\begin{tabular}{|l|l|l|l|}
\hline Name: & Writing donor report & Priority: & 4 \\
\hline Last Revised: & 21 Jan 2009 & Frequency: & Annual \\
\hline
\end{tabular}

Description: For every donor funding a certain project area, a donor report is required at the end of every fiscal year.

Assumptions: Funds from a specific donor is enough to support a stand-alone project.

Embedded Use Cases: Carbon monitoring.

Actors: Project manager, GIS team, field extension officer.

Trigger: End of fiscal year.

Stage before: Project implementation and monitoring stages.

Stage after: Project evaluation and approval for more funds and project continuation.

\section{Script:}

1. At the end of every fiscal year the project manager requests GIS team to provide supporting information to compile an annual donor report.

2. The GIS team provides project site maps. It compiles the status of amounts of carbon sequestered over the past year, number of trees planted and surviving, and total number of farmers participating in the project.

3. Project manager compiles report which is reviewed in a meeting before submission.

Exceptions: Terminal donor reports could be written before end of year.

Business Rules: Current status of projects based on carbon monitoring process is reported. All donor reports should be supported by facts and information from the database. 


\section{Appendix D. Information Products Descriptions}

\section{IPD for Project Status Maps}

\begin{tabular}{|l|l|l|l|}
\hline Name: & Project status maps \\
\hline Required by Dept: & Project Management & \multicolumn{2}{|l|}{} \\
\hline Required by Person: & Project Manager & Frequency: & Quarterly \\
\hline Last Revised: & July 20, 2009 & \multicolumn{2}{|l|}{} \\
\hline
\end{tabular}

Synopsis: This is a map of status of ongoing projects used when compiling accountability reports to donors. It shows the amount of sequestered carbon levels and environmental improvement indicators.

Map Requirements:

1. A map of project site showing areas that implement agroforestry projects.

2. Agro-ecological zones required to stratify project areas.

3. Roads, market centers, and household map data.

4. Land cover / land use maps of project sites.

List Requirements:

1. Farms and farmers practicing agroforestry practices.

2. Sustainable land management practices.

3. Agroforestry techniques being implemented.

4. Biomass assessment results for each established sample plots.

Document Requirements:

1. Procedures and assumptions of biomass assessment.

2. Field notes.

Image Requirements:

1. ASTER or Landsat satellite image

Steps required to make the product:

\begin{tabular}{|l|l|}
\hline Step: 1 & Download and preprocess GPS data \\
\hline Description: & $\begin{array}{l}\text { GPS locations of project sites are downloaded. Other features like } \\
\text { roads, town centers, and landmarks mapped by field extension } \\
\text { officers are also downloaded.. }\end{array}$ \\
\hline Data needed: & $\begin{array}{l}\text { 1. GPS point location data } \\
\text { 2. Filed notes }\end{array}$ \\
\hline Function Needed: & $\begin{array}{l}\text { Projection tools, data editing, polyline-to-polygon conversion } \\
\text { tools, data join. }\end{array}$ \\
\hline
\end{tabular}

Step: 2

Create project site overview maps 


\begin{tabular}{|c|c|}
\hline Description: & $\begin{array}{l}\text { An overview map showing the location of the project site in } \\
\text { relation to the country - meant for international audience (donors), } \\
\text { and for internet publishing }\end{array}$ \\
\hline Data needed: & $\begin{array}{l}\text { Project sites, type of project initiatives being practiced, } \\
\text { administrative boundaries, roads, rivers and population } \\
\text { distribution }\end{array}$ \\
\hline Function Needed: & $\begin{array}{l}\text { Display, edit, label, symbolize, plot, create list, scale change, } \\
\text { graphic overplot. }\end{array}$ \\
\hline Step: 3 & $\begin{array}{l}\text { Join sampling plot information tables to the sampling points } \\
\text { shapefile }\end{array}$ \\
\hline Description: & $\begin{array}{l}\text { During a field assessment, biomass indicators are measured and } \\
\text { recorded. Using carbon models, biomass quantities at sampling } \\
\text { plots are calculated. The results of quantities of carbon at sampling } \\
\text { plots are then joined to sampling plots shapefile. }\end{array}$ \\
\hline Data needed: & $\begin{array}{l}\text { Location of sample plots, biomass data for the plots, sample grid } \\
\text { of the area, vegetation cover. }\end{array}$ \\
\hline Function Needed: & Join, edit functions \\
\hline Step: 4 & Prepare maps of projects \\
\hline Description: & $\begin{array}{l}\text { Maps showing ongoing projects, extent of planted areas, } \\
\text { agroforestry techniques being implemented within a project area, } \\
\text { and the amount of biomass levels at a particular time. This is } \\
\text { necessary for compiling reports. }\end{array}$ \\
\hline Data needed: & $\begin{array}{l}\text { Project sites, type of agroforestry initiatives being practiced, } \\
\text { extents of project sites, and biomass content on farms. }\end{array}$ \\
\hline Function Needed: & $\begin{array}{l}\text { Display, edit, label, symbolize, plot, create list, scale change, } \\
\text { graphic overplot. }\end{array}$ \\
\hline
\end{tabular}

\begin{tabular}{|l|l|}
\hline \multicolumn{2}{l|}{ Function utilization table: } \\
\begin{tabular}{|l|l|}
\hline Function: & Number: \\
\hline Import GPS coordinates & 5 \\
\hline Project & 5 \\
\hline Edit table & 10 \\
\hline Join & 10 \\
\hline Attribute query & 20 \\
\hline Cartographic map creation tools & 10 \\
\hline
\end{tabular} \\
\hline
\end{tabular}




\begin{tabular}{|l|l|}
\hline Function frequency table: \\
\hline Function: & Frequency: \\
\hline Import GPS coordinates & 60 \\
\hline Project & 60 \\
\hline Edit table & 120 \\
\hline Join & 120 \\
\hline Attribute query & 240 \\
\hline Cartographic map creation tools & 120 \\
\hline & \\
\hline
\end{tabular}

\begin{tabular}{|l|}
\hline \multicolumn{2}{|l|}{ Logical Linkages: } \\
\begin{tabular}{|l|l|}
\hline Map to Map & $\begin{array}{l}\text { Ability to overlay GPS coordinates, random sample points, } \\
\text { planting site areas and geographic physical features. }\end{array}$ \\
\hline Attribute to Attribute: & $\begin{array}{l}\text { A join between random sample points and collected baseline } \\
\text { assessment data is required. }\end{array}$ \\
\hline
\end{tabular}
\end{tabular}

Error tolerance table:
Types of Errors: Referential, Topological, Relative, and Absolute.
\begin{tabular}{|l|l|}
\hline Type of Error: & Referential \\
\hline Possible occurrences: & $\begin{array}{l}\text { Random sample points not covering the whole project site } \\
\text { due to use erroneous wrong project area in generating them.. }\end{array}$ \\
\hline Result of error: & Inconsistent sampling technique. \\
\hline Impact on benefits: & $\begin{array}{l}\text { Increased amount of spend in the field while locating new } \\
\text { sample plots . }\end{array}$ \\
\hline Error tolerance & $\begin{array}{l}<1 \% \text { Using GPS, an additional sample point can be located } \\
\text { and a plot established while in the field. }\end{array}$ \\
\hline Type of Error: & Relative \\
\hline Possible occurrences: & $\begin{array}{l}\text { Random sample points not fairly distributed / falling on } \\
\text { inaccessible bushes. }\end{array}$ \\
\hline Result of error: & Less sampling plots will be established, than anticipated. \\
\hline Impact on benefits: & Reduced certainty on overall biomass levels of an area. \\
\hline Error tolerance & $<1 \%$ \\
\hline
\end{tabular}

Wait tolerance and response tolerance: The maps should be generated one week from the
date of request. Wait tolerance is at least three days due to other work loads. Response
tolerance is not significant as the wait tolerance is considerably large. 


\section{IPD for VIAFP's Baseline Survey Preparation Maps}

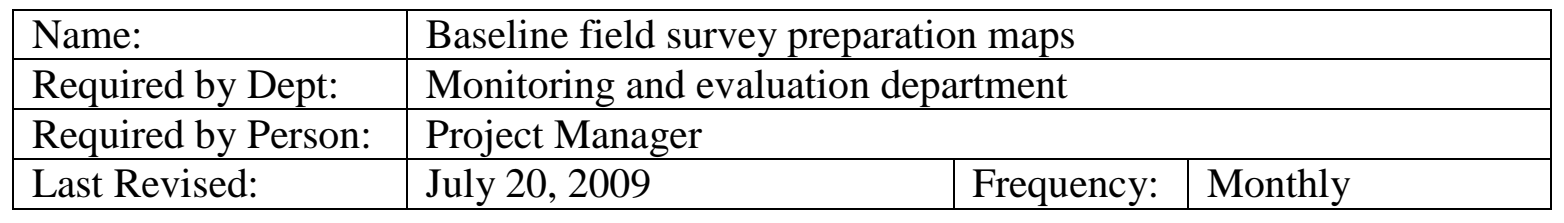

Map Requirements: Location and preliminary boundary of identified sites based on satellite imagery. A randomly generated grid of potential permanent sampling plots. Physical features of the surrounding area - forest boundary, roads, rivers, etc.

\section{List Requirements:}

- Participating farms

- Agroforestry activities being practiced

Document Requirements: Carbon baseline survey manual, farmers self-assessment questionnaires.

Image Requirements:

ASTER or Landsat satellite image of the area

Steps required to make the product:

\begin{tabular}{|l|l|}
\hline Step: 1 & Delineate a project region \\
\hline Description: & $\begin{array}{l}\text { Based on scope, project objectives, and supporting satellite } \\
\text { imagery, project areas are identified. Typically, divisional } \\
\text { administrative boundaries are used to delineate the extent of a } \\
\text { project region. }\end{array}$ \\
\hline Data needed: & $\begin{array}{l}\text { GPS Coordinates of sample points collected at site during } \\
\text { reconnaissance visit, Satellite image of the area, project objectives. }\end{array}$ \\
\hline Function Needed: & Data editing, selection, plotting and labeling tools \\
\hline
\end{tabular}

\begin{tabular}{|l|l|}
\hline Step: 2 & Generate reference sampling points \\
\hline Description: & $\begin{array}{l}\text { Based on preliminary site visit, a sampling density is determined } \\
\text { that will be used to generate grid points on the digitized area. A } \\
\text { systematic random process is used to generate reference points at } \\
\text { equal intervals. }\end{array}$ \\
\hline Data needed: & Polygon shapefile of project region \\
\hline Function Needed: & Random sampling tools \\
\hline
\end{tabular}




\begin{tabular}{||l|l|}
\hline Step: 3 & Prepare map \\
\hline Description: & $\begin{array}{l}\text { Prepare a map showing project areas, roads, rivers, trading centers, } \\
\text { and forest boundaries. The map document should be formatted to } \\
\text { allow field staff to make notes on them during field work. }\end{array}$ \\
\hline Data needed: & Potential sites and sampling grid. \\
\hline Function Needed: & $\begin{array}{l}\text { Display, edit, label, symbolize, plot, create list, scale change, } \\
\text { graphic overplot. }\end{array}$ \\
\hline
\end{tabular}

\begin{tabular}{|c|c|}
\hline Function utilization table: & \\
\hline Function: & Number: \\
\hline Attribute query & 5 \\
\hline Spatial Analyst - random sample points & 5 \\
\hline Custom Python - sort and export list tree nurseries & 5 \\
\hline Custom baseline map & 10 \\
\hline
\end{tabular}

\begin{tabular}{|c|c|}
\hline Function frequency table: & \\
\hline Function: & Frequency: \\
\hline Custom baseline map & 120 \\
\hline Attribute query & 60 \\
\hline Spatial Analyst - random sample points & 60 \\
\hline Custom Python - sort and export list tree nurseries & 60 \\
\hline
\end{tabular}

\begin{tabular}{|l|l|}
\hline \multicolumn{2}{l}{ Logical Linkages: } \\
\begin{tabular}{|l|l|}
\hline Map to Map & $\begin{array}{l}\text { Ability to overlay GPS coordinates, random sample points, } \\
\text { planting site areas and geographic physical features }\end{array}$ \\
\hline Attribute to Attribute: & \\
\hline
\end{tabular}
\end{tabular}


Error tolerance table:

Types of Error: Referential, Topological, Relative, and Absolute.

\begin{tabular}{|l|l|}
\hline Type of Error: & Relative \\
\hline Possible occurrences: & Including vegetated areas in the digitizing process \\
\hline Result of error: & Increased and wrong size of potential planting site areas \\
\hline Impact on benefits: & $\begin{array}{l}\text { Increased amount of resources allocated for project } \\
\text { implementation }\end{array}$ \\
\hline Error tolerance & $2 \%$ \\
\hline
\end{tabular}

Wait tolerance and response tolerance: The maps should be generated one week from the date of request. Wait tolerance is at least three days due to other work loads. Response tolerance is not significant in this case in relation to wait tolerance. 


\section{Appendix E. Web Mapping Application Programming Code}

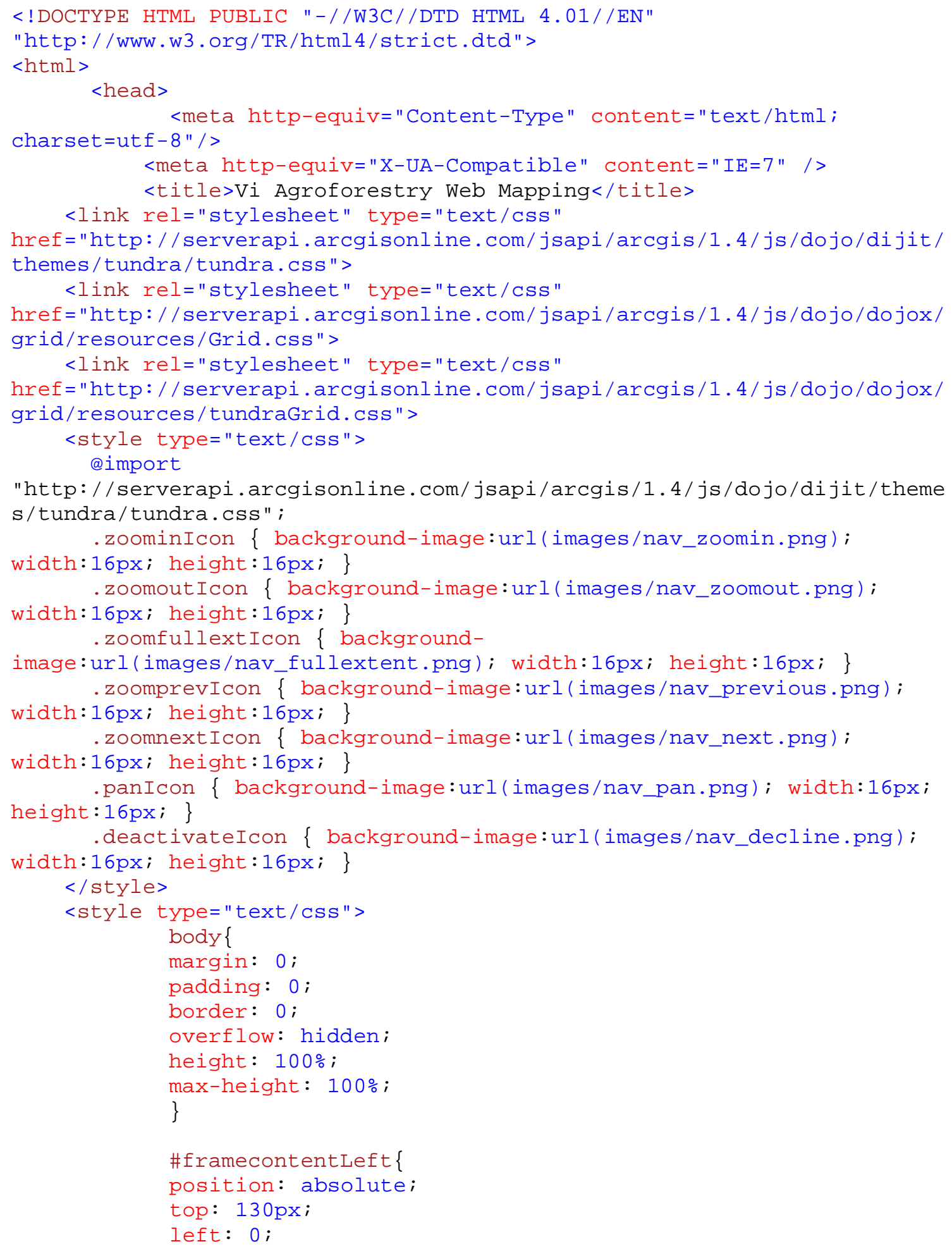




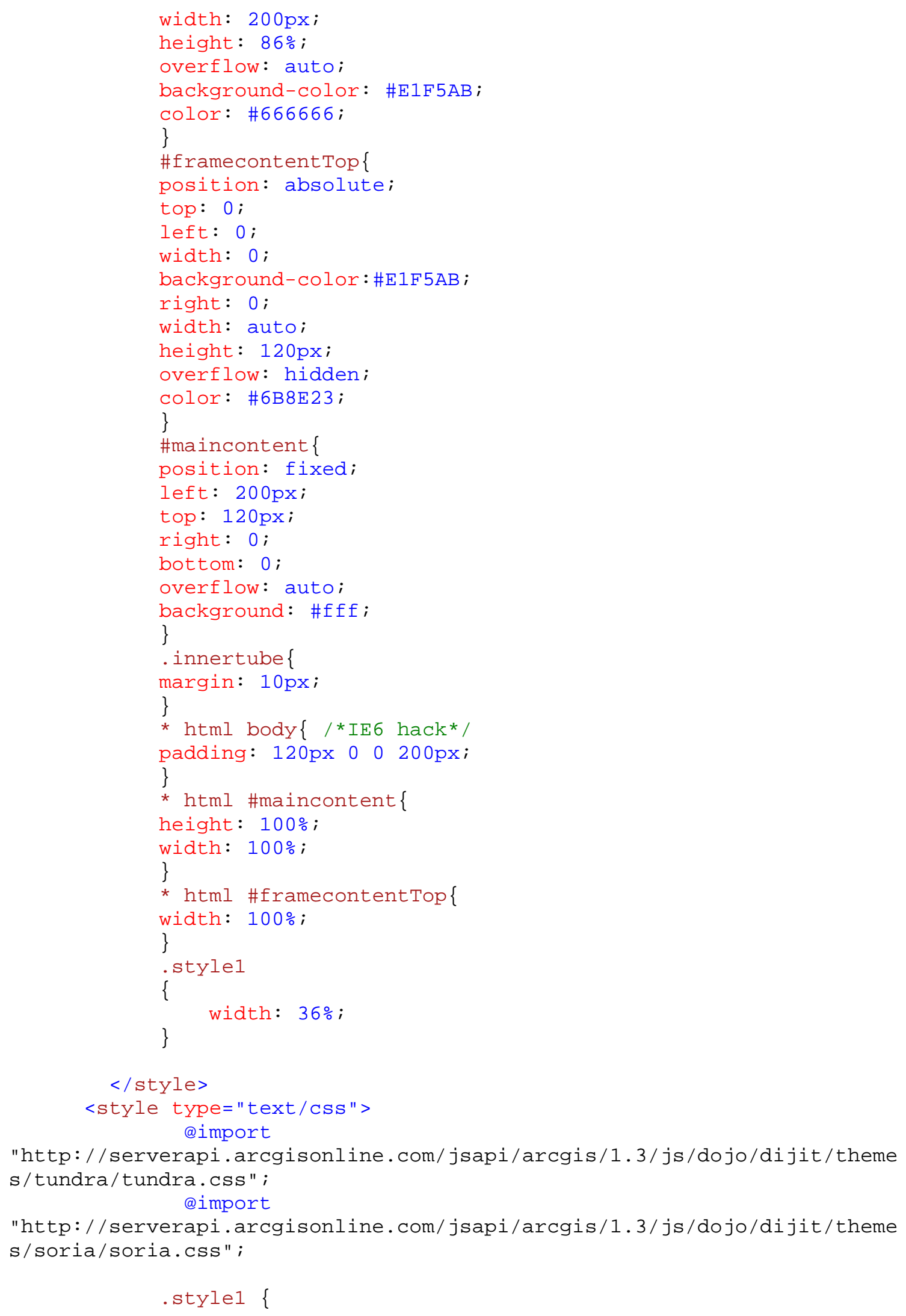




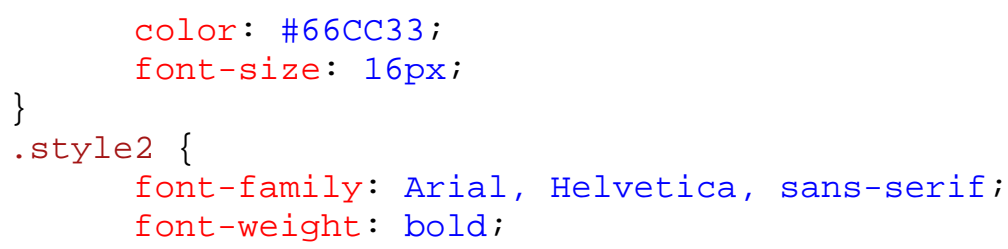




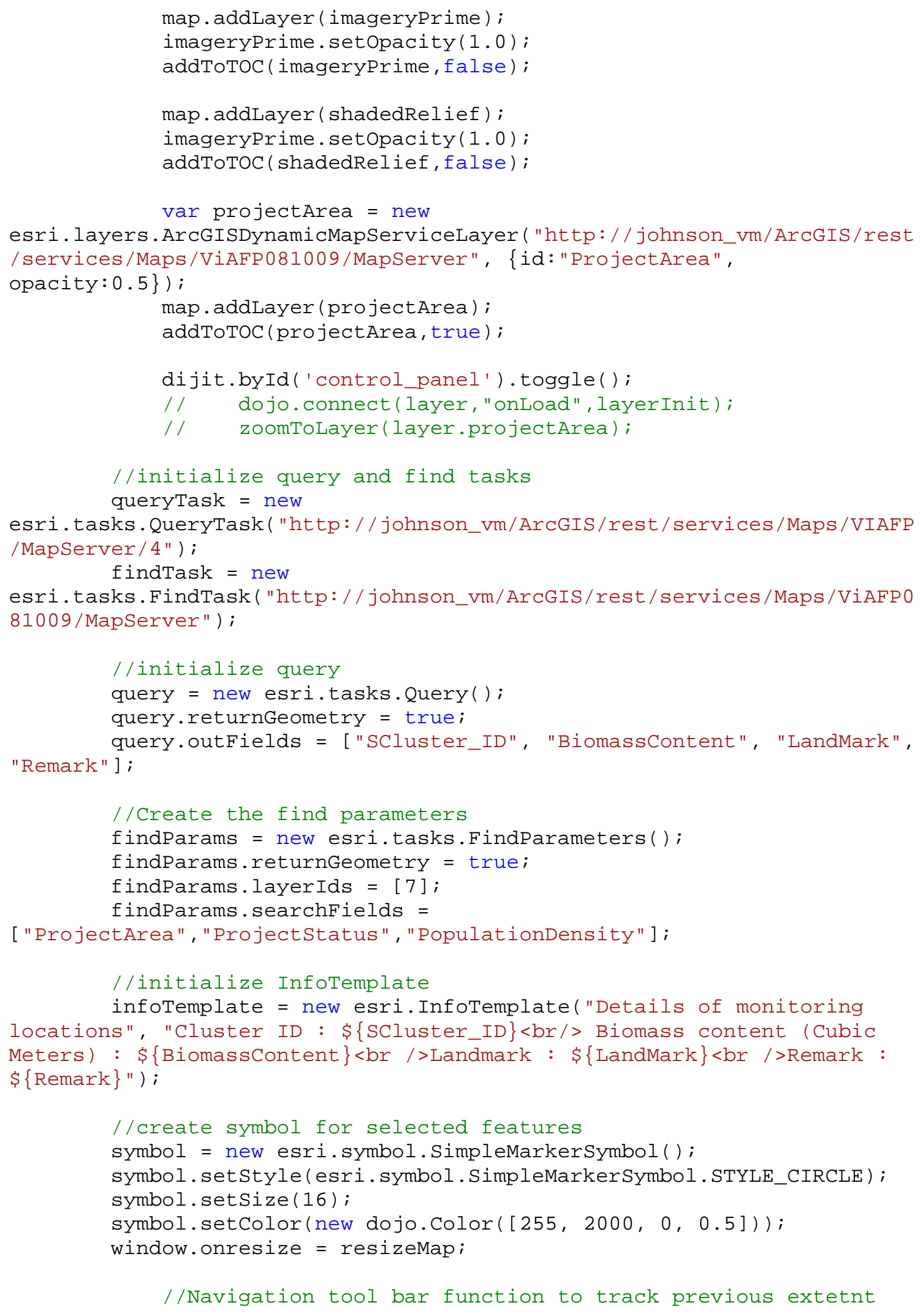




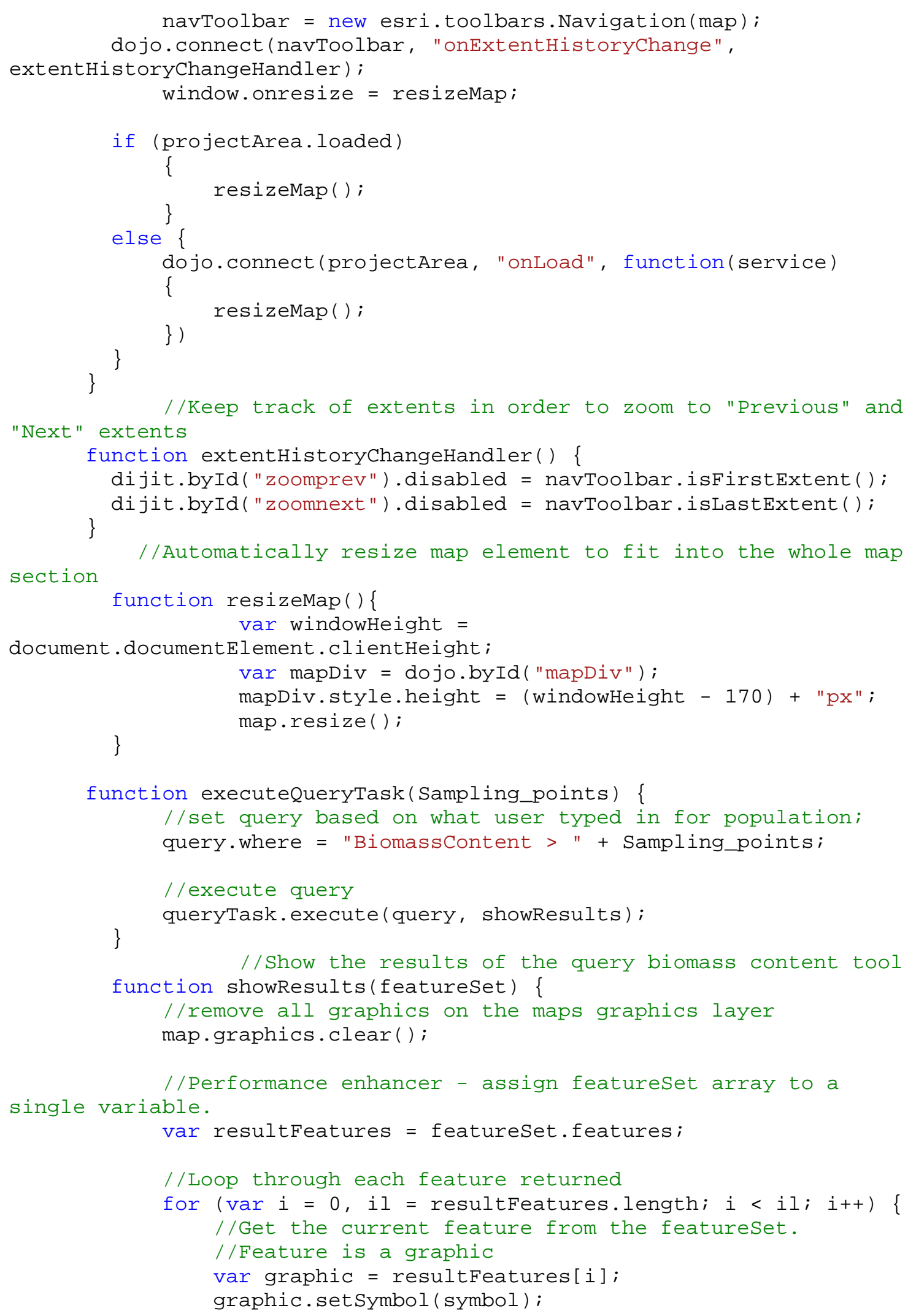




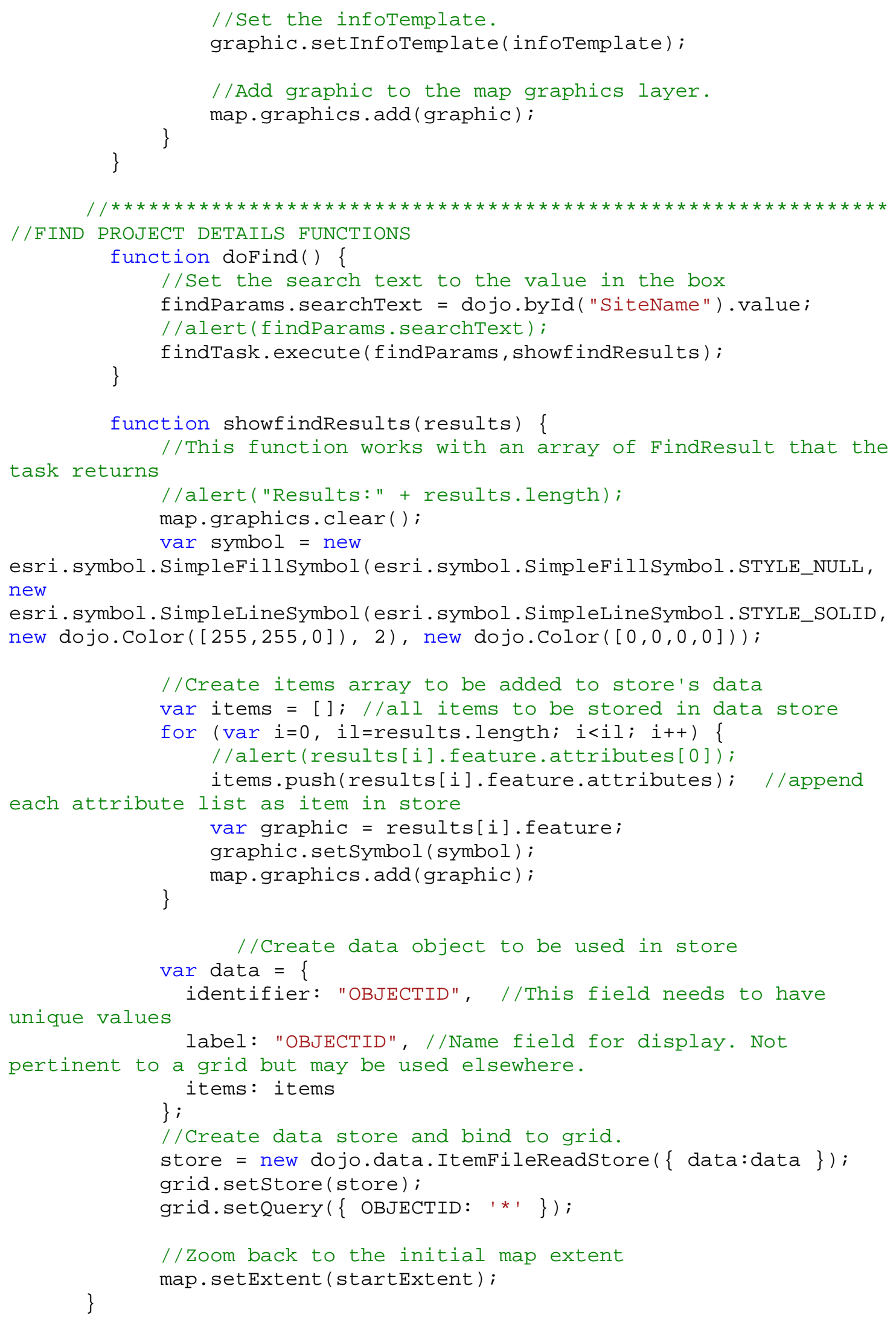




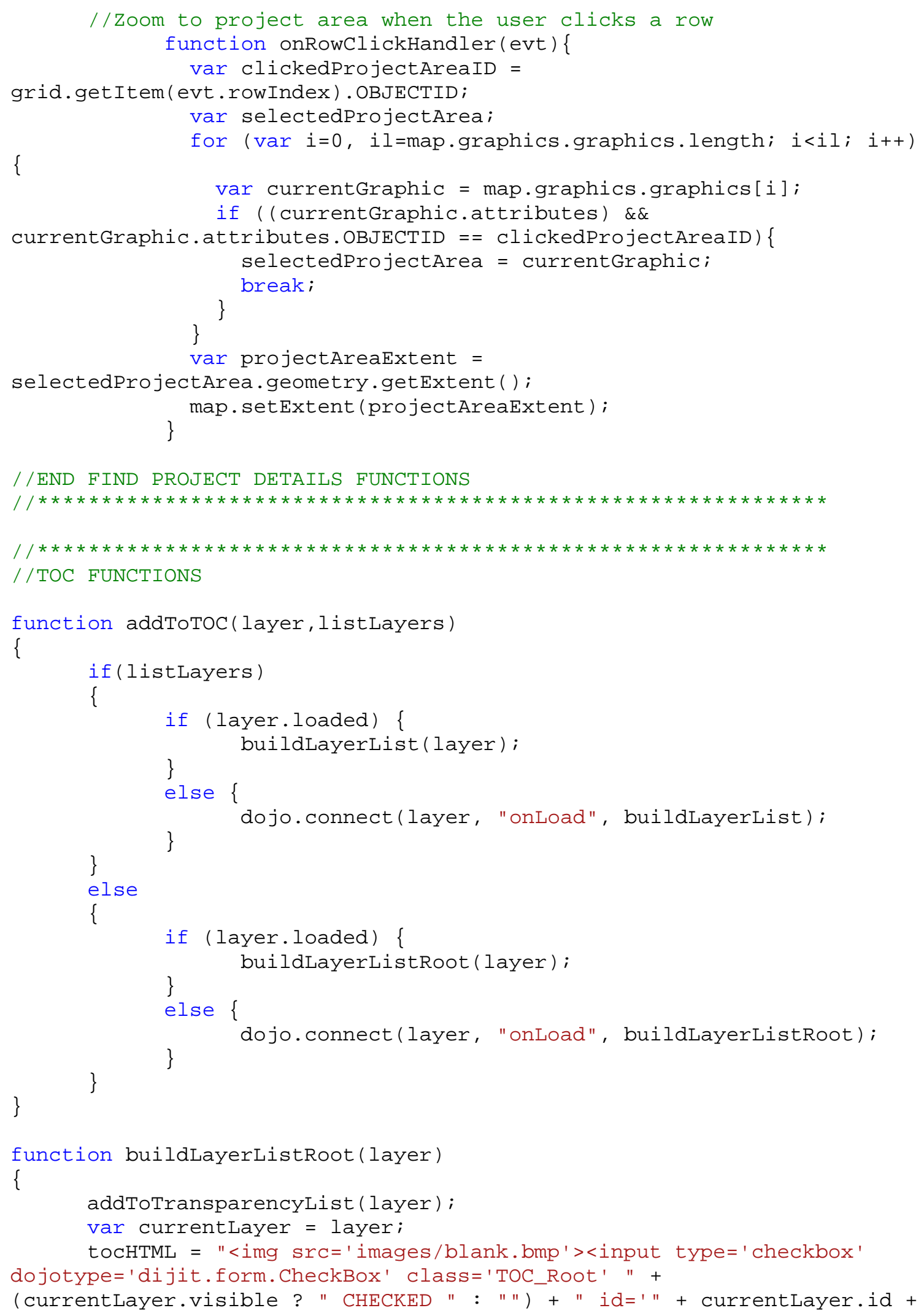




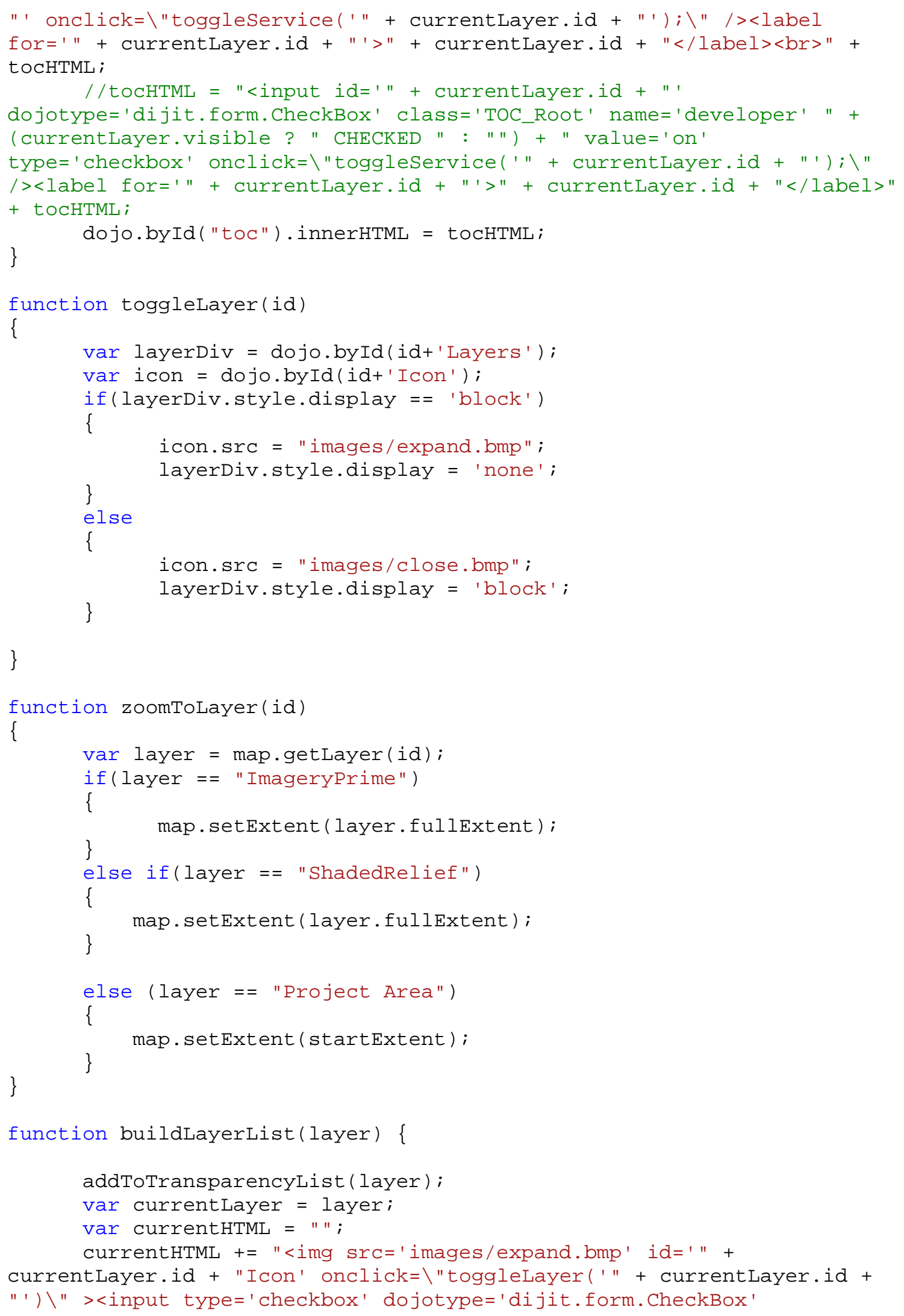




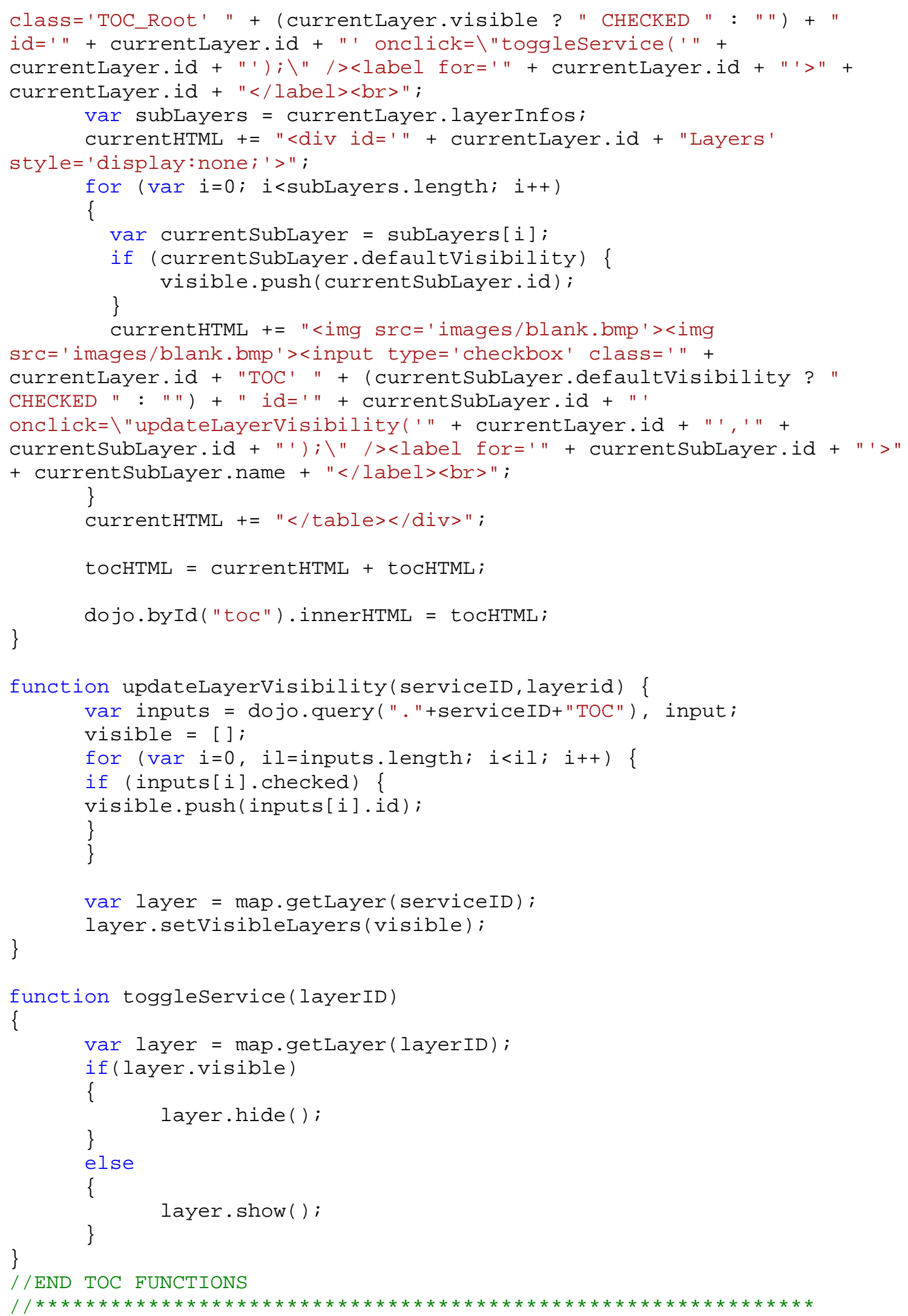




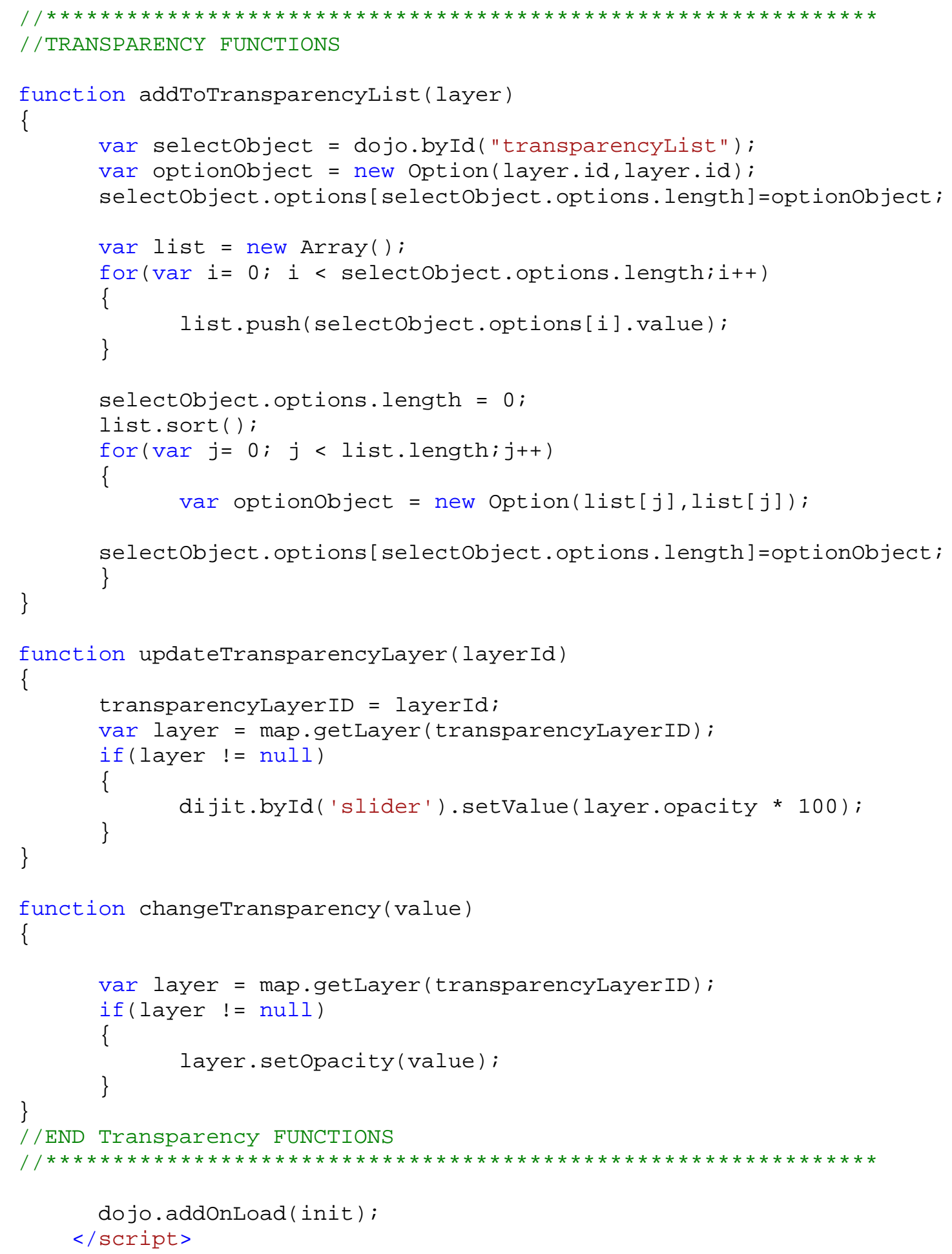




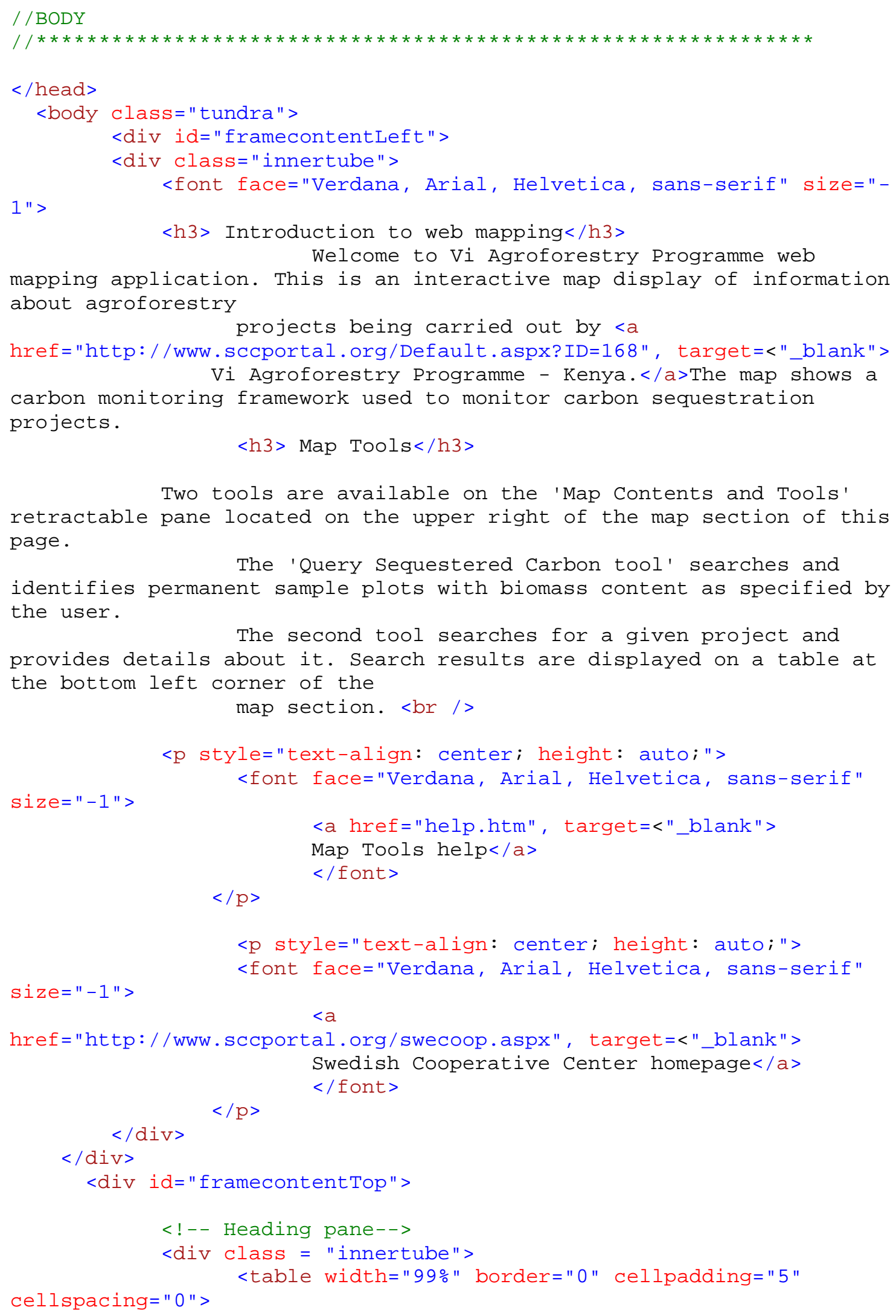




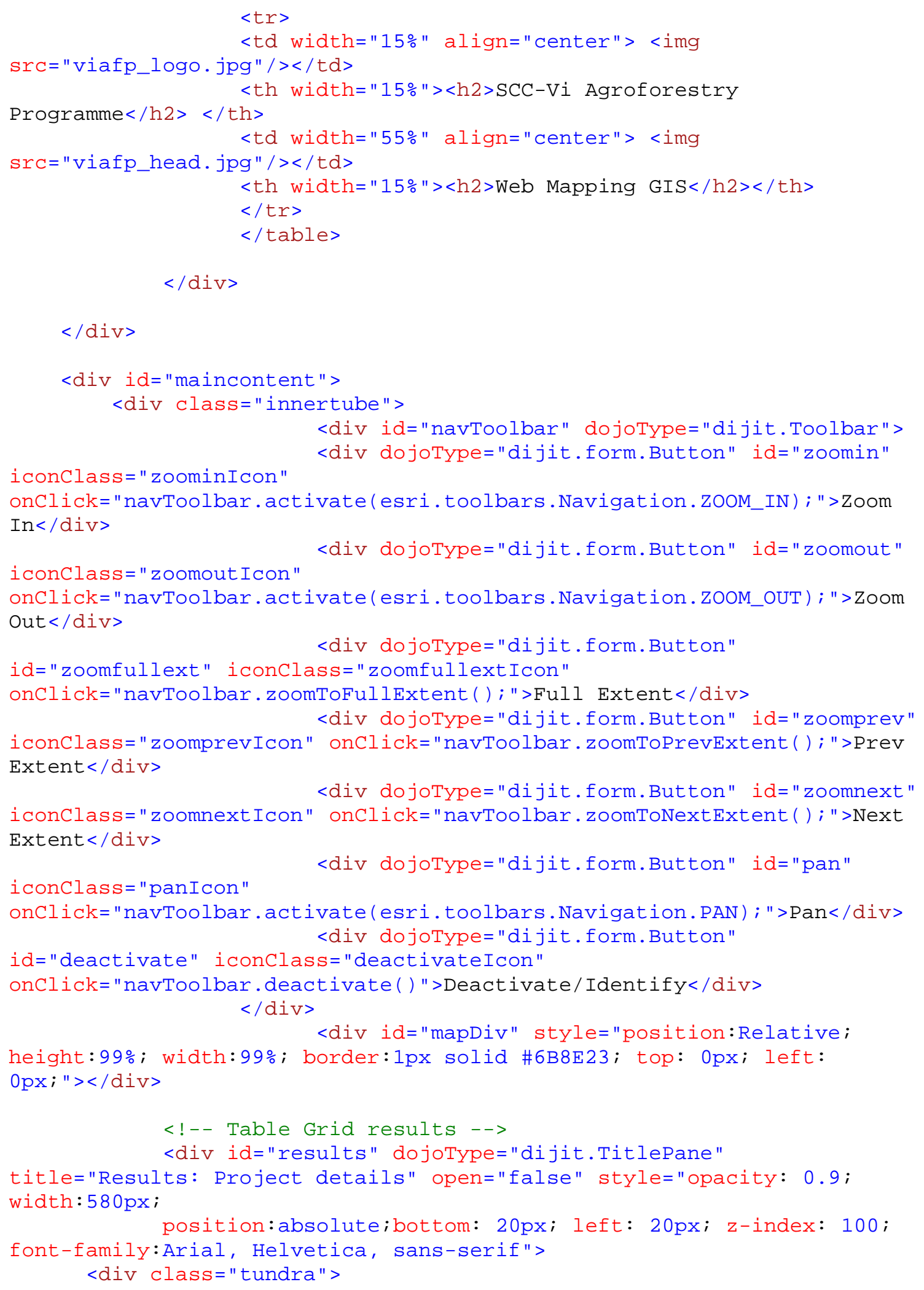


<table dojoType="dojox.grid.DataGrid" jsid="grid"

id="grid" rowsPerPage="3" rowSelector="20px" style="height:150px;

width:560px">

$<$ thead $>$

$<\mathrm{tr}>$

$<$ th field="OBJECTID">Project Area ID $</$ th $>$

$<$ th field="ProjectArea">Project Area Name</th $>$

$<$ th field="ProjectStatus" $>$ Project Status $</$ th $>$

$<$ th field="CarbonPotential">Carbon Sequestration

Potential</th>

<th field="PotentialHouseholds">Potential

Households $</$ th $>$

$(/ \mathrm{Sq} \cdot \mathrm{KM})</ \mathrm{th}>$

<th field="PopulationDensity">Population Density

<th field="Monitoringstns">\# of monitoring

stations $</$ th $>$

$<\mathrm{br}>$

Active Layer:

<select name="transparencyList" id="transparencyList"

onchange="updateTransparencyLayer (this . value)">

<option value="" selected $></ o p t i o n>$

$</$ select $>$

\&nbsp; $<\mathrm{br}>$

$<\mathrm{br}>$

Change Layer Transparency: $<b r\rangle$

name="slider"

<div id="slider" dojoType="dijit.form.Horizontalslider"

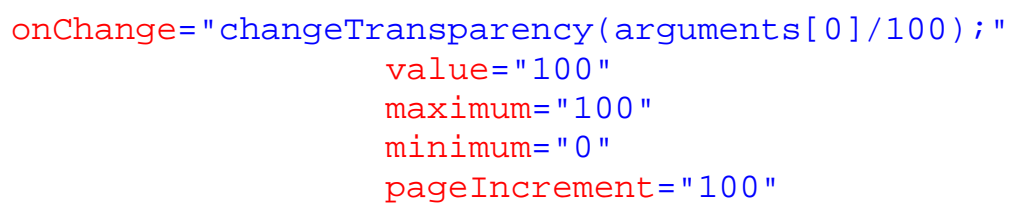




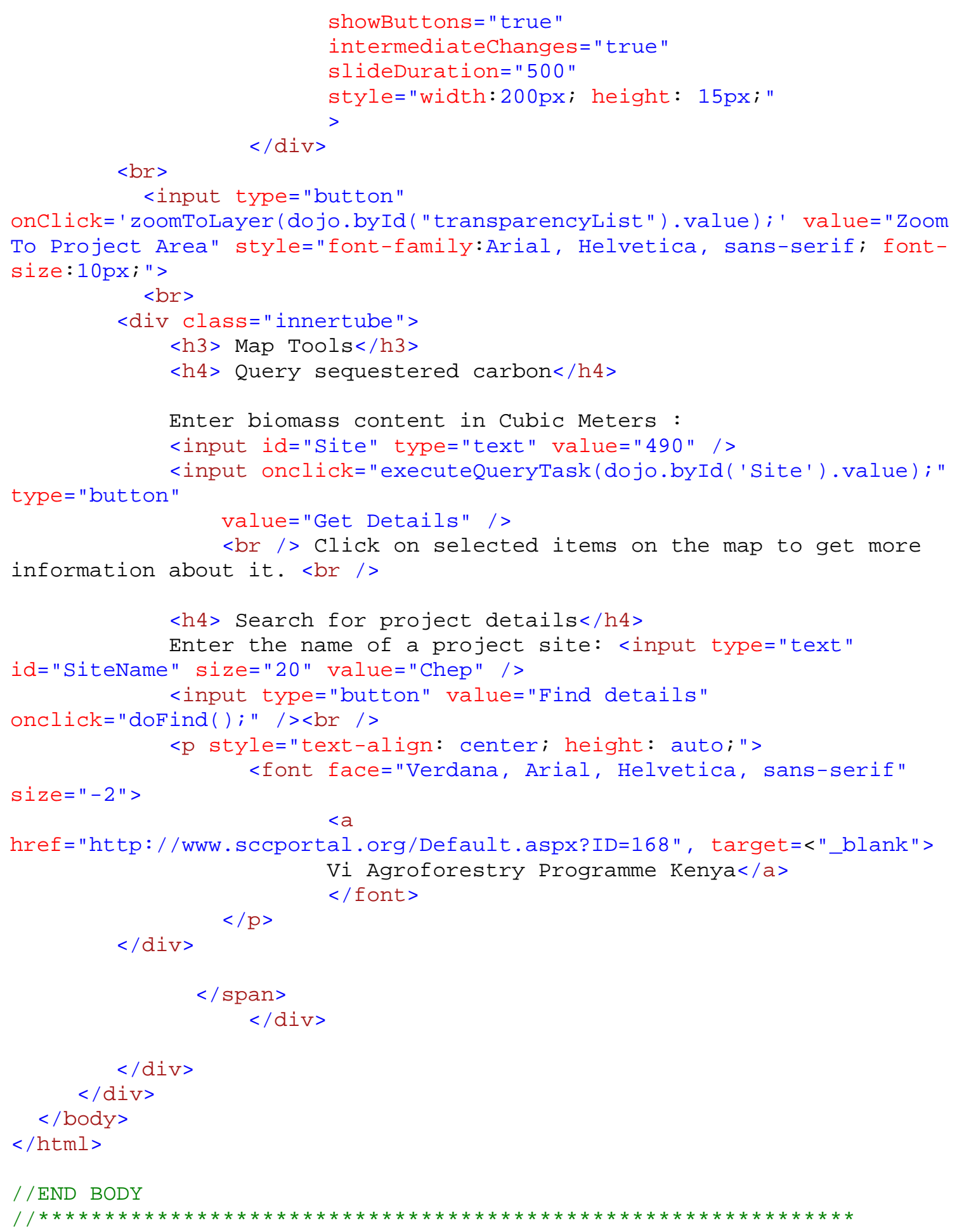




\section{Appendix F. Web Mapping Application Help Page}

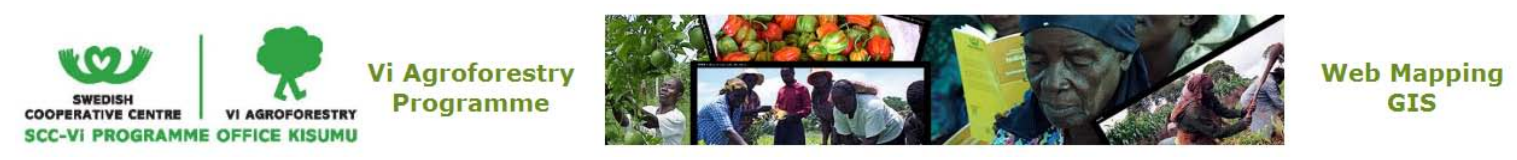

Map Navigation Tools

Navigation tools are used to interact with the map. All buttons in the navigation tool bar have a black bounding box at a time when they are active.

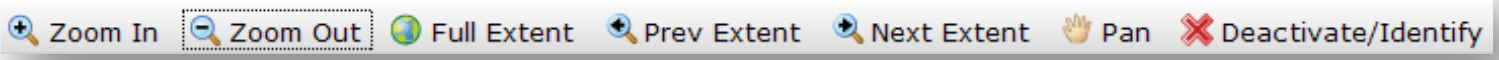

In the navigation bar above, the Zoom Out button is currently active.

- Zoom In and Zoom Out functions are used to zoom in and out of the map respectively. The Full Extent button zooms out to the world extent.

- The Prev Extent takes the map to a previous extent, whereas the Next Extent pans/zooms the map to the next extent.

- The Pan button is used to hold and drag the map while maintaining the zoom extent.

- The Deactivate/Identify button deactivates a currently active button. This will allow you to access the basic functionalities of JavaScrip API for ArcGIS's navigation using the cursor.

Map Contents

This pane gives access to the maps that can be toggled on and off at the check boxes. Selecting a map view on the Active Layer drop box activates a map. Transparency settings can be changed for an active map using the Change Layer Transparency slider bar. The Zoom To Layer button zooms the map to the initial extent of an active layer. Map Tools

\section{Query Sequestered Carbon}

This tool uses the query: query. where = "Biomass_content > "

This tool is queries biomass assessment sample plots. Additional information about selected results is obtained by clicking on them.

Note: The navigation tools must be deactivated in order to click so as obtain additional information. 


\section{Find details}

This tools searches and returns details of a project site. The results are returned in a table. Results can be reordered according to any of the table headings. By selecting a record, the map is zoomed to locate the entry.

\section{Legend}

This is a legend of symbols used in the web application.

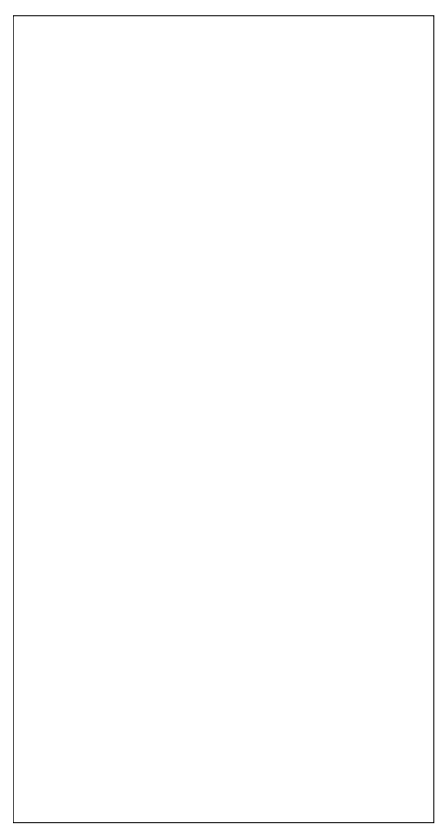

